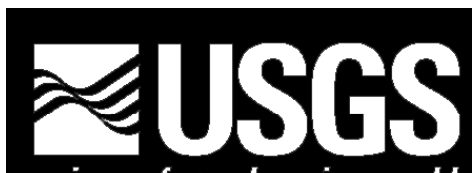

science for a changing world

\title{
Structure and Velocities of the Northeastern Santa Cruz Mountains and the Western Santa Clara Valley, California, from the SCSI-LR Seismic Survey
}

By R.D. Catchings, M.R. Goldman, and G. Gandhok'

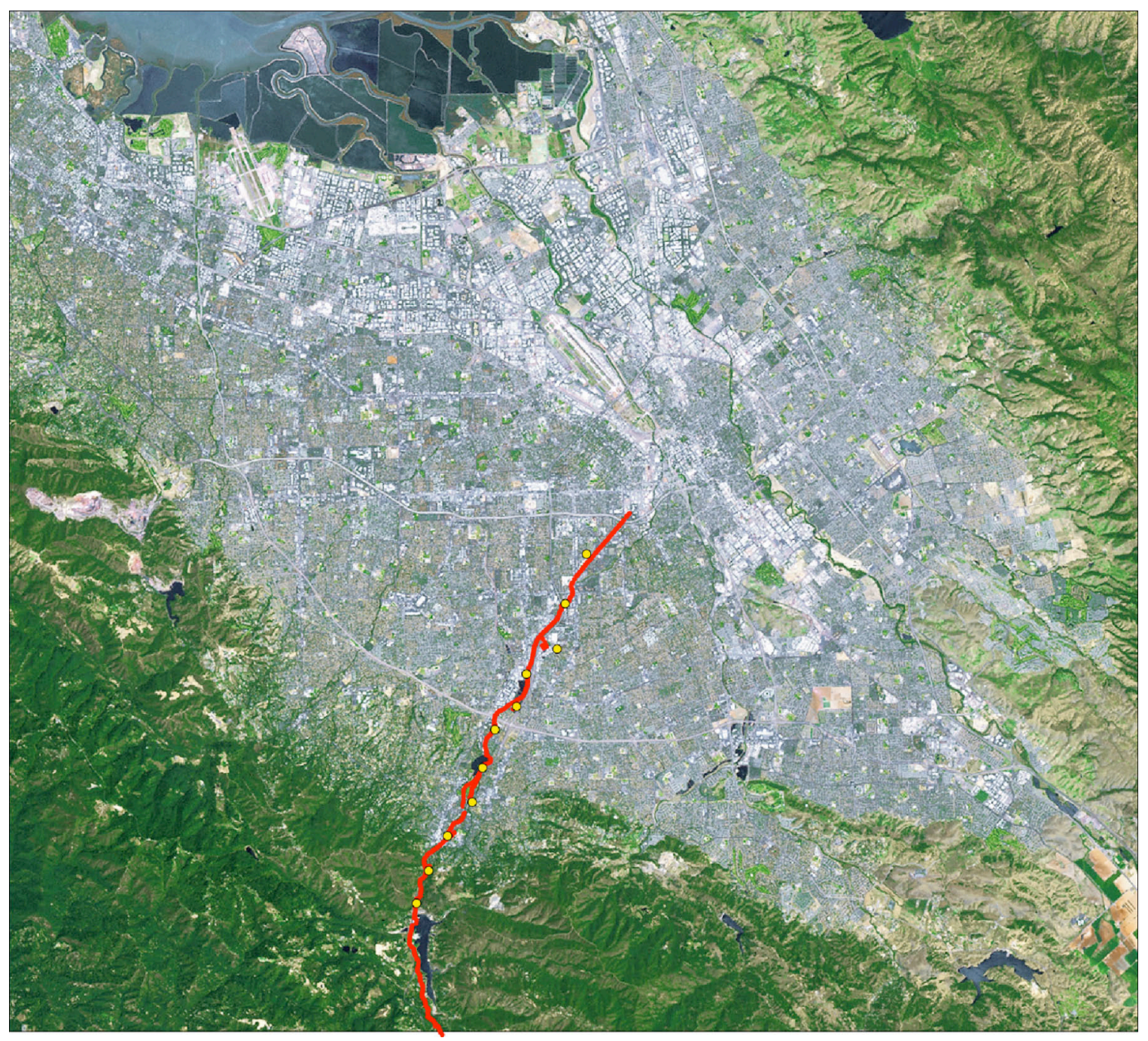

Open-File Report 2006-1014

U.S. Department of the Interior U.S. Geological Survey

${ }^{1}$ U.S. Geological Survey, 345 Middlefield Rd, MS 977, Menlo Park, CA 94025 


\section{U.S. Department of the Interior \\ Gale A. Norton, Secretary \\ U.S. Geological Survey \\ P. Patrick Leahy, Acting Director}

U.S. Geological Survey, Reston, Virginia 2006

Revised and reprinted: 2006

For product and ordering information:

World Wide Web: http://www.usgs.gov/pubprod

Telephone: 1-888-ASK-USGS

For more information on the USGS - the Federal source for science about the Earth, its natural and living resources, natural hazards, and the environment:

World Wide Web: http://www.usgs.gov

Telephone: 1-888-ASK-USGS

Any use of trade, product, or firm names is for descriptive purposes only and does not imply endorsement by the U.S. Government.

Although this report is in the public domain, permission must be secured from the individual copyright owners to reproduce any copyrighted material contained within this report. 


\section{Introduction}

The Santa Clara Valley is located in the southern San Francisco Bay area of California and generally includes the area south of the San Francisco Bay between the Santa Cruz Mountains on the southwest and the Diablo Ranges on the northeast (Fig. 1a). The area has a population of approximately 1.7 million including the city of San Jose, numerous smaller cities, and much of the high-technology manufacturing and research area commonly referred to as the Silicon Valley (2000 U. S. Census; http://quickfacts.census.gov/qfd/states/06/06085.html). Major active strands of the San Andreas Fault system bound the Santa Clara Valley, including the San Andreas fault to the southwest and the Hayward and Calaveras faults to the northeast; related faults likely underlie the alluvium of the valley (CWDR, 1967). This report focuses on subsurface structures of the western Santa Clara Valley and the northeastern Santa Cruz Mountains and their potential effects on earthquake hazards and ground-water resource management in the area. Earthquake hazards and ground-water resources in the Santa Clara Valley are important considerations to California and the Nation because of the valley's preeminence as a major technical and industrial center, proximity to major earthquakes faults, and large population.

To better assess the earthquake hazards of the Santa Clara Valley, the U. S. Geological Survey (USGS) has undertaken a program to evaluate potential earthquake sources and potential effects of strong ground shaking within the valley. As part of that program, and to better assess water resources of the valley, the USGS and the Santa Clara Valley Water District (SCVWD) began conducting collaborative studies to characterize the faults, stratigraphy, and structures beneath the alluvial cover of the Santa Clara Valley in the year 2000. Such geologic features are important to both agencies because they directly influence the availability and management of groundwater resources in the valley, and they affect the severity and distribution of strong shaking from local or regional earthquakes sources. As one component of these joint studies, the U. S. Geological Survey acquired more than $28 \mathrm{~km}$ of combined seismic reflection/refraction data from the Santa Cruz Mountains to the central Santa Clara Valley in December 2000 (Fig. 1a). The seismic investigation included both high-resolution ( $\sim 5-\mathrm{m}$ shot and sensor spacing) and relatively lower-resolution ( $~ 50-\mathrm{m}$ sensor) seismic surveys from the central Santa Cruz Mountains to the central part of the valley (Fig. 1a-c). Collectively, we refer 
to these seismic investigations as the 2000 western Santa Clara Seismic Investigations (SCSI). Results of the lower-resolution study, referred to as SCSI-LR, are presented in this report, and results of the high-resolution seismic study (SCSI-HR) are presented in a separate report by Catchings et al. (2005).

\section{Local Geology, Tectonics, and Hydrogeology}

The Santa Clara Valley is part of the topographic depression that forms the San Francisco Bay between the Santa Cruz Mountains and the Diablo Range (Fig. 1a). Surficial and near-surface sediments within the Santa Clara Valley largely consist of PlioPleistocene to Holocene clastic deposits (clay, silt, sand, and gravel) from the adjacent mountain ranges and marine sediments (CDWR, 1967; Wagner, 1990; Wentworth et al., 1998; McLaughlin et al., 2001). The composition of basement rocks beneath the valley is not known but is assumed to be the same as those in the adjacent mountain ranges (Fig. 1d). These rocks include the Jurassic to Cretaceous Franciscan Complex (marine sediments, largely mélanges, including serpentine, volcanic, and metamorphic rocks), the Coast Ranges Ophiolite (ultramafic to intermediate igneous rocks), and the Great Valley Sequence (McLaughlin et al., 2001). The Jurassic-Cretaceous rocks are, in places, overlain by Eocene to Pliocene marine sediments and intercalated volcanic rocks. At least one recently drilled borehole near the center of the valley encountered serpentinite at about $225 \mathrm{~m}$ depth (Orze et al., 2003), which is likely part of the Coast Ranges Ophiolite.

Within the adjacent mountain ranges, rocks are highly faulted and folded (Fig. 1d) due to tectonism, much of which is associated with the San Andreas fault system (CDWR, 1967; McLaughlin et al., 2001). Similarly faulted and folded rocks underlie the Santa Clara Valley beneath the near-surface Quaternary alluvium, as evidenced by strike-slip and reverse faults and folded strata that have been mapped on uplifted ridges (for example, Santa Teresa Hills and the Sierra Azul) within the valley (McLaughlin et al., 2001). Some of the buried faults are active, as shown by seismic events recorded beneath the valley (Zoback et al., 1995; ANSS Catalog, 2003anss@quake.geo.berkeley.edu). Differential movement on these faults may have produced a series of basement highs and lows, several-kilometer-deep basins near the margins (i.e., Cupertino and Evergreen basins), and a relative basement high near the center of the valley (CWDR, 1967; Stanley et al., 2002). 
Near-surface consolidated and low-permeability Franciscan Complex rocks are regarded as non-water bearing and not a significant contributor to the hydrogeology of the valley. Fresh-water-bearing deposits that form the ground-water reservoir within the Santa Clara Valley are chiefly of Quaternary age, and they include the semi-consolidated, Plio-Pleistocene non-marine Santa Clara Formation (SCFm), associated marine deposits of Pliocene and Pleistocene age, and the overlying Pleistocene-to-Holocene unconsolidated alluvial and bay deposits (CWDR, 1967). Lateral variations in the thickness of the SCFm are poorly known, but the SCFm has been encountered in boreholes at depths ranging from about $30 \mathrm{~m}$ to several hundred meters within the valley. Where exposed in the adjacent Santa Cruz Mountains, the SCFm is locally tightly to mildly folded and faulted and consists of poorly sorted conglomerate, sandstone, siltstone, and clay that is as much as $600 \mathrm{~m}$ thick in outcrop (Dibblee, 1966;

McLaughlin et al., 2001). Where it crops out on the southwest flanks of the valley, the SCFm dips 10 to 30 degrees to the east (CDWR, 1967), but locally, the SCFm dips at 60 degrees to vertical or is overturned where associated with faulting along the southwest Santa Clara Valley margin. The SCFm is assumed to similarly dip beneath the alluvial cover. The unconsolidated alluvial and bay deposits (clay, silt, sand, and gravel) that overlie the SCFm contain the most productive aquifers of the ground-water reservoir (Poland, 1971). Minimum depths to the water table are highly variable within the valley, but generally range from about 10 to $40 \mathrm{~m}$ below ground surface (CWDR, 1967).

\section{SCSI Data Acquisition}

The SCSI survey consisted of two seismic surveys along nearly the same transect, an $\sim 18$-km-long, lower-resolution (50-m sensor; 1-km shot spacing) survey from the San Andreas fault to downtown San Jose (Fig. 1a), and an 10-km-long, high-resolution (5-m shot and sensor spacing) survey between shot points 1 and 10 of the lower-resolution survey (Fig. 1b,c). Each survey was acquired in a manner that yields both seismic refraction and seismic reflection images of the subsurface. This report describes data acquisition, processing, and analysis for the lower-resolution (SCSI-LR) survey.

We used 11 buried explosions (shot points 1-11) ranging in size from about 12 to

$23 \mathrm{~kg}$ to generate seismic sources approximately every kilometer along the central part of the N-60'-E-trending profile (Fig. 1). To record the blasts, we placed 416 "Texan" seismographs, with single-element, Mark Products 1-10B ${ }^{\mathrm{TM}}$, vertical-component, 4.5- 
and 40-Hz geophones, every $50 \mathrm{~m}$ along the profile. The $4.5-\mathrm{Hz}$ and $40-\mathrm{Hz}$ geophones alternated in sequence along the profile, such that there was $100 \mathrm{~m}$ spacing between geophones of the same frequency. The Texan seismographs were programmed to record the 11 blasts during specific time windows between the hours of 12:00 am and 5:00 am, when cultural noises were relatively low. Sixty seconds of data were recorded for each shot at a sampling rate of $1 \mathrm{~ms}$. Seismographs were then retrieved the following day, and the data were downloaded to a computer. The internal timing of the seismographs was checked using Global Positioning System (GPS) clocks before and after deployment, and a linear drift was assumed. Acquisition parameters for the SCSI-LR survey are given in Table 1.

To account for variations in the SCSI profile geometry, each shot point and geophone location was surveyed using an electronic distance meter (EDM) or Global Positioning System (GPS) with theoretical accuracies of a few centimeters (see Appendices 1-3). Seismograph elevations varied by about $250 \mathrm{~m}$ along the profile (Fig. 2a). Lateral variations in the seismograph array (with respect to a line connecting the first and last shot points) were less than about $500 \mathrm{~m}$ within the shot array (Fig. 2b). However, northeast and southwest of the shot array, the seismograph array varied from this line by about $2.5 \mathrm{~km}$. Relative to the seismograph array length $(17.7 \mathrm{~km})$, individual seismographs varied by about $2.8 \%$ and $14 \%$ within and outside of the shot array, respectively. Because the major deviation from an ideally linear profile was not within the shot array (Fig. 2c), the non-linearity of seismographs outside of the shot-point array has a minimal effect on the modeled structure of the Santa Clara Valley. The shot array was about $12.4 \mathrm{~km}$ long (Fig 2c), and shot point elevations varied by about $150 \mathrm{~m}$ (Fig. 2d). Relative to a line connecting the end points of the shot array, individual shots varied laterally from an ideal profile by about $200 \mathrm{~m}$ or $1.6 \%$ of the shot line length. Most of the non-linearity of the seismic profile was required because of the high degree of urbanization in the study area.

For velocity modeling and reflection stacking, we redefined arrays to remove redundant stations as shown in Appendix 2. 
Table 1. Acquisition parameters for the SCSI low-resolution seismic profile. Distance is relative to the first seismograph.

\begin{tabular}{|l|l|l|l|l|}
\hline Parameter & Length & Number & \multicolumn{1}{|c|}{ Type } & Spacing \\
\hline Profile & $17.7 \mathrm{~km}$ & 1 & 2-D & \\
\hline Geophone & $17.7 \mathrm{~km}$ & 416 & $4.5 \& 40 \mathrm{~Hz}$, Vertical & $50 \mathrm{~m}$ \\
\hline Shot Points & $12.4 \mathrm{~km}$ & 11 & Explosion & $1 \mathrm{~km}$ \\
\hline Seismograph & $17.7 \mathrm{~km}$ & 416 & Reftek RT125 (Texan) & $50 \mathrm{~m}$ \\
\hline Record & $60 \mathrm{~s}$ & 4576 & SEGY & \\
\hline Sample Rate & $1 \mathrm{~ms}$ & & & \\
\hline
\end{tabular}

\section{Data Processing}

We minimally processed the shot gathers presented in this report (Fig. 3). After individual shot gathers were assembled, we used trace editing to remove noisy or dead traces, and we bandpass-filtered the data to accommodate the varying frequency ranges of the geophones.

\section{Seismic Data}

Unreduced SCSI-LR shot gathers are shown in figure 3a-k, with low bandpass filtering (2-4-10-20 Hz) applied. A total of $60 \mathrm{~s}$ of data were acquired, but we present only the first $6 \mathrm{~s}$ in figure 3. Although the urban environment was noisy, useful seismic energy from the shots propagated across the seismic profile for most shots. Surface-wave, air-wave, and some shear-wave arrivals are also present on most shot gathers. Nearvertical and wide-angle reflections are also observed on all shot gathers, which allow low-fold reflection images to be developed. The complex topography on the preCenozoic basement structure beneath the Santa Clara Valley is inferred from the nonlinear moveout of refracted arrivals (Fig. 3).

\section{Seismic Velocity Modeling}

To develop P-wave tomographic seismic velocity models of the subsurface along the SCSI seismic profile, we inverted first-arrival refractions from usable seismograms using a modified version of an algorithm by Hole (1992). The velocity inversion method uses 2- or 3-D raytracing (Fig. 4a) to match observed and calculated travel times until a suitable fit is obtained for all arrivals from all shots. A total of about 4500 first-arrival 
picks were available from the data. We used reciprocal shot and receiver travel times to improve accuracy of the first-arrival picks. A maximum error of $10 \mathrm{~ms}$ was allowed between reciprocal $\mathrm{P}$-wave travel time picks. In parameterizing the $\mathrm{P}$-wave model, we used $50-\mathrm{m}$ by $50-\mathrm{m}$ horizontal and vertical grid spacings and a $2-\mathrm{D}$ starting model derived from composite 1-D velocity models, calculated from shot gathers. We used multiple 2-D starting velocity models, but regardless of the starting model used, successive velocity inversions yielded similar final 2-D velocity models, suggesting that velocity structure is fairly well resolved. In general, the model is best resolved where we have the highest density of ray coverage (Fig. 4a). We applied a smoothing routine to the inversion that yielded an approximately 100- to 300-m vertically and horizontally smoothed final model (Fig. 4b). The ray density diagram is colored white (masking) where we have less than 2 ray paths within a given $50 \mathrm{~m}^{2}$ grid. The corresponding $50 \mathrm{~m}^{2}$ areas of the velocity model have similarly limited ray coverage, but to better visualize the velocity model, we present the model without masking.

The minimum depth of velocity imaging is related to the shot $(1 \mathrm{~km})$ and geophone $(50 \mathrm{~m})$ spacing, the model grid spacing $(50 \mathrm{~m})$, and the amount of smoothing used in modeling. Therefore, velocities in the upper $100 \mathrm{~m}$ are a smoothed average of the velocities within those depth ranges. The maximum depth of velocity imaging was limited by the maximum distance that clear first arrivals could be measured on the shot gathers (Fig. 3). Because of the noisy urban environment, clear first arrivals were measurable to varying distances for each shot, but first arrivals were measurable to minimal distances greater than $10 \mathrm{~km}$ from the source for most shots.

Although we used vertical-component geophones and explosive-source shots, shear-wave energy was generated and recorded for some of the shots, particularly those shots within or near bedrock (Fig. 3). We used the same picking parameters and tomographic modeling code to develop an S-wave velocity model of the subsurface along the SCSI seismic profile (Fig. 5b). The secondary shear-wave arrivals were not as clearly measurable to distances as great as those of the first-arrival P-wave, resulting in shallower depths for the S-wave model. The secondary S-wave arrivals were also less reliably picked, and as a result, we have less confidence in the S-wave model than the Pwave model, particularly at depths below $1.5 \mathrm{~km}$. For both the P-wave and S-wave arrivals, we used reciprocity between shot and receiver pairs to increase accuracy. 


\section{Seismic Velocity and Related Images}

\section{P-Wave Velocity Model}

First-arrival refractions were measurable to sufficient distances to develop a Pwave velocity model to maximum depths of about $3 \mathrm{~km}$ (Fig. 4b). Observed velocities are highly variable across the model but are generally highest ( $\sim-$ to $6.5 \mathrm{~km} / \mathrm{s})$ at depth below the Santa Cruz Mountains and also near the base $(\sim 3 \mathrm{~km})$ of the velocity model below the Santa Clara Valley. Velocities are lowest $(<1600 \mathrm{~m} / \mathrm{s})$ at the surface within the Santa Clara Valley, where Quaternary sediments are exposed at the surface. Relatively low velocities $(<3 \mathrm{~km} / \mathrm{s})$ persist to the greatest depths $(\sim 1.5 \mathrm{~km})$ near the central part of the seismic profile (Cupertino Basin), but there are appreciable lateral and vertical variations in velocity. For example, one prominent feature of the model is the velocity anomaly near Los Gatos, where relatively high-velocity $(\sim 4.5 \mathrm{~km} / \mathrm{s})$ rocks overlie lower-velocity $(\sim 4.0 \mathrm{~km} / \mathrm{s})$ rocks. Such reversals in velocity indicate complex structures because on crustal scales, lower-velocity rocks usually overlie higher-velocity rocks. The general upper-crustal $(3 \mathrm{~km})$ pattern along the profile consists of relatively high velocities within the Santa Cruz Mountains and the central Santa Clara Valley (San Jose area) and low velocities beneath the Cupertino Basin.

\section{S-Wave Velocity Model}

S-wave arrivals are observed best near the southwestern part of the seismic profile within harder rocks. Within the alluvium of the Santa Clara Valley, limited generation and/or propagation of S-wave arrivals resulted in poor resolution of the deeper structure on the northeast end of the seismic profile. The S-wave model is most reliably developed for the upper $1.5 \mathrm{~km}$ of the profile, but a poorly resolved model, resulting from uncertainties in picking secondary arrivals, was determined for the upper $3 \mathrm{~km}$ near the center of the seismic profile. Velocities range from $0.5 \mathrm{~km} / \mathrm{s}$ near the surface to about 3.5 $\mathrm{km} / \mathrm{s}$ within the base of the model. Low- and high-velocity features within the S-wave velocity model are similar to those of the P-wave model, including relatively higher nearsurface velocities in the Santa Cruz Mountains and thicker, low-velocity deposits in the Cupertino Basin. The S-wave velocity model also shows a velocity inversion similar to that observed for the P-wave velocity model beneath the Los Gatos area. The lowest Swave velocities $(0.5 \mathrm{~km} / \mathrm{s})$ correspond to near-surface sediments, which appear to be 
thickest within the Cupertino basin. The highest S-wave velocities $(\sim 3.5 \mathrm{~km} / \mathrm{s})$ are observed in the Santa Cruz Mountains and at the base of the model.

\section{Models of Vp/Vs and Poisson's Ratios}

Variations in Poisson's and Vp/Vs ratios can yield information about crustal composition and physical conditions of the crust, such as water saturation and crack density (faulting). We developed a $\mathrm{Vp} / \mathrm{Vs}$ ratio model from the $\mathrm{P}$ - and S-wave velocity models (Fig. 6a). The Vp/Vs ratio model was calculated to the maximum depths of the $\mathrm{S}$-wave velocity model $(\sim 3 \mathrm{~km})$, but the $\mathrm{Vp} / \mathrm{Vs}$ ratios are probably most reliably determined at depths less than $1.5 \mathrm{~km}$. Vp/Vs ratios vary from about 1.5 to about 3.6, with the highest ratios occurring near the surface, particularly in the vicinity of water reservoirs in the Los Gatos area, and near the northeastern part of the seismic profile. The lowest ratios $(\sim 1.5)$ are calculated for depths between 0.5 and $1 \mathrm{~km}$ below Lexington Reservoir and at depths in excess of $1.5 \mathrm{~km}$ near the northeastern part of the seismic profile. Although such low Vp/Vs ratios could be related to faulting (Catchings, 1999), $\mathrm{Vp} / \mathrm{Vs}$ ratios below $1.5 \mathrm{~km}$ on the northeastern part of the profile are not well constrained due to the poor constraints on S-wave velocities in that part of the profile.

A model of Poisson's ratio was developed along the SCSI profile using the P- and S-wave velocities (Fig. 6b). Due to properties of P- and S-wave propagation, Poisson's ratio $(v)$ can be determined using the following relations (Thomsen, 1990; Schon, 1996):

$$
v=(\mathrm{E} / 2 u)-1=(3 \mathrm{~K}-2 u) /(6 \mathrm{~K}+2 u)=\left[(\mathrm{Vp} / \mathrm{Vs})^{2}\right]-2 /\left[2(\mathrm{Vp} / \mathrm{Vs})^{2}\right]-2
$$

Where $u=$ shear modulus, $\mathrm{E}=$ Young's modulus, $\mathrm{K}=$ Bulk modulus, $\mathrm{Vp}=$ compressional or P-wave velocity, and Vs = shear or S-wave velocity.

The modeled Poisson's ratios (PR) show considerable lateral variation along the SCSI-LR profile, with the highest values $(\sim 0.46)$ near the surface and lowest values of about 0.05 . Due to the poor S-wave measurements on the northeastern end of the model below about $1.5 \mathrm{~km}$ depth, very low PR values $(\sim 0.05)$ in that area of the model are probably not reliable. Some other areas of the PR model, however, show relatively low PR values $(\sim 0.26)$, which are consistent with average values $(\sim 0.24-0.29)$ for common plutonic rocks (Christensen, 1996). 


\section{Seismic Reflection Processing}

In acquiring the seismic data, we used a shoot-through geometry, whereby shots were systematically fired through a stationary recording array. The combination of multiple sources and multiple receivers, which were spread over long distances, permitted both reflection and refraction data to be simultaneously acquired.

In seismic-reflection data processing, we followed procedures similar to those outlined by Brouwer and Helbig (1998). Processing steps included geometry installation, independent trace editing, timing corrections, elevation static corrections, automatic gain control (AGC), bandpass filtering, F-K filtering (or surgical muting), velocity analysis (from refractions, semblence, and borehole-velocity measurements), normal-move-out (NMO) correction, stretch muting, common-depth-point (CDP) stacking, post-stack AGC, post-stack bandpass filtering, and post-stack deconvolution. For depth-migrated sections, we used Kirchoff pre-stack depth migration after velocity analysis. Principal parameters used in processing are shown in Table 2.

In trace editing, noisy traces (due to cultural noises) or redundant traces (due to geometry) were removed from the shot gathers before stacking or migrating, leaving approximately 366 channels per shot gather. We surgically muted first-arrival refractions, and we applied bottom muting by surgically removing all arrivals between the surface waves. Elevation statics, migration, and velocity analysis were accomplished using the tomographic velocity model from both the lower- and higher-resolution SCSI profiles. For velocities at depths in excess of those determined by the tomography velocity model, we used parabolic methods, and we inferred velocities based on laboratory-determined velocity-depth (pressure) relations (Carmichael, 1989).

Table 2. Reflection Processing Parameters for the SCSI Profile

\begin{tabular}{|c|c|}
\hline Maximum Fold & 11 \\
\hline CDP Spacing & $25 \mathrm{~m}$ \\
\hline AGC & $2000 \mathrm{~ms}$ \\
Prestack & $300 \mathrm{~ms}$ \\
Poststack & $5-10-80-160 \mathrm{~Hz}$ \\
\hline Bandpass Filter & $5-10-50-100 \mathrm{~Hz}$ \\
Prestack & $700 \mathrm{~ms}, 65 \mathrm{~m}, 0-5000 \mathrm{~m}$ \\
Poststack Low & $200,8000,30$ \\
\hline $\begin{array}{c}\text { Deconvolution (filter length, } \\
\text { prediction dist., application gate) }\end{array}$ & \\
\hline $\begin{array}{c}\text { Migration (frequency, aperture, } \\
\text { angle) }\end{array}$ & \\
\hline
\end{tabular}




\section{Seismic Reflection Images}

A migrated seismic reflection image along the SCSI profile was developed from about meter 2300 to about meter 17000 of the SCSI-LR profile (Fig. 7). The length of the reflection image was largely determined by the position of the shot point array, and to a lesser extent, by the curvature of the recording array on the southwestern part of the seismic profile. In general, the seismic reflection image shows that the Santa Clara Valley is more reflective to greater depths than the Santa Cruz Mountains, but appreciable lateral variations in reflectivity are observed both within the valley and the mountains. The seismic image also shows that the upper few kilometers of the crust is complex, with folded and faulted strata. Because of the complexity of the structure, interpretation of the seismic reflection image is difficult. However, in the discussion section below, we combined the available data (velocities, velocity ratios, reflection, and geologic) to develop an interpretative model.

\section{Combined Velocity and Seismic Reflection Images}

We superimposed the velocity models onto the seismic reflection image so that direct comparisons between $\mathrm{P}$ - and S-wave velocities, their ratios, and the reflection image could be made (Figs. 8a-d). The combined P-wave velocity and reflection image shows appreciable variation in the velocities of the layered rocks (Fig. 8a). Near the southwestern end of the profile (meters 2300 to 5000), near-surface, layered rocks have velocities ranging from about 3000 to $5000 \mathrm{~m} / \mathrm{s}$ in the upper $500 \mathrm{~m}$ depth. However, layered rocks beneath the Cupertino Basin ( meter 9000) have velocities less than 3000 $\mathrm{m} / \mathrm{s}$ in the upper $1.5 \mathrm{~km}$ depth. Higher velocities $(>3500 \mathrm{~m} / \mathrm{s})$ at relatively shallow $(<$ $1000 \mathrm{~m}$ ) depths are also observed near meter 11000. Deeper, less reflective rocks generally have velocities in excess of $3500 \mathrm{~m} / \mathrm{s}$, and a prominent northeast-dipping reflector generally marks the boundary between the higher-velocity rocks and the lowvelocity rocks. As discussed below, the higher-velocity and less-reflective rocks probably correlate with basement rocks.

Similar variations in the S-wave velocity structure are observed (Fig. 8b). Most of the highly reflective rocks have S-wave velocities less than $2000 \mathrm{~m} / \mathrm{s}$ in the upper $1.5 \mathrm{~km}$ beneath the Santa Clara Valley. The high reflectivity and low S-wave velocities are consistent with the presence of sedimentary rocks in that depth range. The rocks 
underlying these probable sediments at depth $(>3 \mathrm{~km})$ beneath the Cupertino Basin are not as reflective and have lower S-wave velocities $(<3000 \mathrm{~m} / \mathrm{s})$ than rocks at similar depths in the adjacent Santa Cruz Mountains and central Santa Clara Valley. Because these rocks are poorly reflective, they are probably not horizontally layered sedimentary rocks (i.e., probably mélange or related Franciscan rocks or massive Coast Ranges Ophiolitic rocks), and as discussed below, the low S-wave velocities are probably related to fractured and faulted rocks beneath the Cupertino Basin. There are similar variations in $\mathrm{Vp} / \mathrm{Vs}$ and Poisson's ratios, whereby high Vp/Vs $(>2.8)$ and Poisson's (0.38) ratios are largely confined to the highly reflective near-surface (probably water saturated) deposits in the Santa Clara Valley (Figs. 8c and 8d, respectively). Low Vp/Vs $(<2.0)$ and Poisson's (0.25) ratios are largely limited to poorly reflective deeper rocks. These Vp/Vs and Poisson's ratios are more consistent with common igneous rocks than sedimentary rocks (Christensen, 1982; 1996).

\section{Geologic Maps and Cross Sections}

The near-surface geology along the SCSI profile includes deposits and rocks ranging in age from Holocene to Jurassic (McLaughlin et al., 2001). As many as seven recognizable fault zones, each with multiple fault strands, are mapped at the surface within the Santa Cruz Mountains between the San Andreas fault and the center of the SCSI profile (Fig. 1d). Each of the fault zones may be several tens of meters wide and includes folded and faulted rocks of varying geologic ages. Published cross sections (McLaughlin et al., 2001) for the Santa Cruz Mountains show a series of near-vertical strike-slip and lower-angle reverse faults (with associated antithetic faults). Many of these faults dip to the southwest at the surface where exposed and are inferred to dip southwestward toward (and presumably join with) the San Andreas fault at depth (McLaughlin et al., 2001). Along the Santa Clara Valley segment of the SCSI profile, rocks are covered by Holocene-to-Pleistocene alluvial deposits (Helley et al., 1994), and the lithology of the subsurface rocks and associated structures are poorly known below the surface. However, the shallow-depth subsurface lithology and structures can be inferred from geophysical data and lithologic logs from a number of nearby boreholes (Stanley et al., 2002). The lithology and structure beneath part of the Santa Clara Valley can also be inferred from rock exposures within the Santa Teresa Hills, approximately $5 \mathrm{~km}$ east-southeast of the SCSI profile. Rocks within the Santa Teresa 
Hills range in age from Quaternary to Jurassic and include geologic materials ranging from sediments to ophiolitic rocks. Similar rocks conceivably underlie the Santa Clara Valley along the SCSI profile. Structures observed in the Santa Teresa Hills may also

provide clues to the subsurface structure beneath part of the SCSI profile, including the dips of some faults and stratigraphic units. McLaughlin et al. (2001) interpret a predominant northeasterly dip for most faults and stratigraphic units in the Santa Teresa Hills. Thus, similar structures may underlie the Santa Clara Valley segment of the SCSI profile.

\section{Comparison with Available Well Data}

Data from two recently drilled wells (McGlincey and Willow wells - see Fig. 1a,c) along and adjacent to the SCSI profile can be compared with the SCSI seismic data. The 240-m-deep McGlincey well was located near meter 12500 (shot point 9) of SCSI profile, and the 254-m-deep Willow well was located at the northeast end of the SCSI profile (Orze et al., 2003). Borehole data from the McGlincey well included P- and Swave velocity measurements and lithologic well logs, which can be compared with SCSI velocity data (Fig. 9). In general, there is close agreement between the borehole sonic velocities and the SCSI refraction velocities. Seismic P-wave velocities in the McGlincey well range from about $1500 \mathrm{~m} / \mathrm{s}$ at $5 \mathrm{~m}$ depth to about $2500 \mathrm{~m} / \mathrm{s}$ at 100 to 200 $\mathrm{m}$ depth (Hansen et al., 2004), with an average P-wave velocity $\sim 2200 \mathrm{~m} / \mathrm{s}$ in the $20 \mathrm{~m}$ to $240 \mathrm{~m}$ depth range. Where the McGlincey well projects to the SCSI profile, SCSI Pwave velocities range from about $2050 \mathrm{~m} / \mathrm{s}$ within $50 \mathrm{~m}$ of the surface to about $2200 \mathrm{~m} / \mathrm{s}$ at $250 \mathrm{~m}$ depth, with an average velocity of about $2100 \mathrm{~m} / \mathrm{s}$. SCSI S-wave velocities in the vicinity of the McGlincey well range from about $500 \mathrm{~m} / \mathrm{s}$ at the surface to about 850 $\mathrm{m} / \mathrm{s}$ at $240 \mathrm{~m}$ depth, with an average S-wave velocity of about $700 \mathrm{~m} / \mathrm{s}$. S-wave velocities measured in the McGlincey well vary from about 500 to $1000 \mathrm{~m} / \mathrm{s}$, with an average S-wave velocity of about $750 \mathrm{~m} / \mathrm{s}$ in the upper $250 \mathrm{~m}$. Thus, both P-wave and Swave velocities from the SCSI profile and those from the McGlincey well are comparable, given the relatively low resolution of the SCSI data. Velocity data are not available for the Willow well, but comparisons can be made based on lithologic logs from both wells.

We also used the lithologic information from oil wells (Stanley et al., 2002) and the McGlincey and Willow wells (Newhouse et al., 2004; Fig. 1c) to constrain probable 
rock types at shallow depths along the SCSI profile. Near the central part of the SCSI profile, Stanley et al. (2002) used lithologic logs from oil wells that were drilled during the late $19^{\text {th }}$ and early $20^{\text {th }}$ centuries to interpret the lithology in the upper $800 \mathrm{~m}$. They interpret Quaternary sediments to overlie Miocene sediments in the upper few hundred meters along the central part of the SCSI profile, with Miocene rocks extending to more than $800 \mathrm{~m}$ below the surface in the deepest oil well. We plotted the interpreted well logs in their approximate locations on the SCSI-LR reflection image (Fig. 7). The well logs indicate that the Quaternary-Miocene boundary correlates with a prominent reflector that extends across most of the western Santa Clara Valley. Because of the relatively low resolution of the SCSI-LR reflection images, reflective layers are averaged over about depth ranges of about $100 \mathrm{~m}$. Thus, SCSI-LR reflection image would generate reflections that are approximately centered on the Quaternary-Miocene boundary where the Quaternary sediments are less than about $100 \mathrm{~m}$ thick.

In all but one of the well logs analyzed, Stanley et al. (2002) interpreted Miocene sediments at the bottom of the wells. In the one excepted well, they interpret Franciscan or Coast Ranges Ophiolitic rocks at about $100 \mathrm{~m}$ depth in the vicinity of Vasona Reservoir. However, we interpret the seismic data as being more consistent with the presence of Miocene sediments at $100 \mathrm{~m}$ depth in the vicinity of Vasona Reservior because apparent Miocene layers appear laterally continuous in that area (Fig. 7).

A hard, relatively low-velocity $(\sim 2200 \mathrm{~m} / \mathrm{s})$ rock, which correlates with the base of the ground-water aquifer (Newhouse et al., 2004), was encountered in the McGlincey well at about $240 \mathrm{~m}$ depth, and this rock correlates with a reflector at the same depth in the SCSI reflection image (Fig. 7). Paleontological data from the McGlincey well indicate that Miocene rocks underlie SCFm rocks (C. Wentworth, Pers. Comm., 1994) at about the depth $(240 \mathrm{~m})$ of our SCSI reflector. The reflector is largely continuous across the Santa Clara Valley northeast of SP 5 ( meter 8000$)$ along the SCSI profile. The correlation between the ground-water aquifer (as revealed in the various wells) and the SCSI reflector suggests that the base of the ground-water aquifer may be traced laterally across most of the western Santa Clara Valley on the SCSI reflection image (Fig. 7, 8b). This reflector and others above and below it appear to be vertically offset by at least tens of meters in several places along the profile, suggesting that the groundwater aquifer system is faulted in places along the profile. 
Only sedimentary rock was observed at the base of the McGlincey well at 240 $\mathrm{m}$, but serpentinite was found at the base of the Willow well at about $245 \mathrm{~m}$ depth. The two wells are separated laterally by about $5 \mathrm{~km}$, and the difference in lithology at the base of the two wells suggests that there is a major lithologic change in shallow subsurface rocks over the 5-km distance. The change in shallow-depth ( upper $250 \mathrm{~m})$ lithology between the McGlincey well and the Willow well (which is located about $0.7 \mathrm{~km} \mathrm{ENE} \mathrm{of}$ the northeast end of the SCSI profile; Fig. 1c) is indicated by an abrupt change in the reflectivity pattern near meter 15000 of the SCSI profile (Fig. 7).

\section{Interpretation and Discussions}

The complex tectonic setting and history of the eastern Santa Cruz Mountains and the western Santa Clara Valley makes interpretation of seismic velocity and reflection images difficult. Multiple fault zones with northeast- and southwest dips and both strikeslip and reverse motions are superimposed upon rocks ranging in composition from sedimentary to ultramafic (Dietz and Ellsworth, 1997; Simpson, 2004; McLaughlin et al., 2001). Because similar tectonism and structural complexity are likely beneath the alluvium of the western Santa Clara Valley, seismic reflection images are difficult to interpret, especially for the deeper (older) structures. By combining the reflection and refraction images with other data, such as seismicity data, geologic mapping, and borehole data, we present non-unique interpretations of the upper $3 \mathrm{~km}$ of the crust that may be important in evaluating water resources and earthquake hazards.

\section{Structure of the Groundwater Aquifer System}

The maximum depth of the ground-water aquifer in the Santa Clara Valley is poorly determined, but it is generally assumed to correlate with the maximum depth of the Pliocene to Holocene semi-consolidated and unconsolidated sediments (CDWR, 1967). Although older consolidated rocks, such as Franciscan rocks, may contain water, they are unlikely to be a major part of the ground-water aquifer system because of their low permeabilities. Therefore, the seismic P-wave velocities, which increase with ground-water saturation or consolidation, can be used to help constrain lateral variations in the ground-water aquifer system across the Santa Clara Valley. Vp/Vs and Poisson's ratios are also sensitive to the presence of water in unconsolidated sediments, and therefore, these measures should also be indicative of lateral variations in the ground- 
water aquifer system. Due to the relatively low resolution of the SCSI-LR profile, however, the velocities and their ratios may be indicative of structures over vertical and lateral ranges of 50 to $300 \mathrm{~m}$.

Because compressional-wave velocities (Vp) greatly increase in unconsolidated sediments which are more than $90 \%$ water saturated (Nur, 1982), saturated unconsolidated sediments generally have minimum P-wave velocities of about $1500 \mathrm{~m} / \mathrm{s}$ (Schon, 1996; Catchings et al., 1999a;b; Gandhok et al., 1999). The shallowest Pwave velocities imaged along the SCSI profile range from about $1500 \mathrm{~m} / \mathrm{s}$ to about 2000 $\mathrm{m} / \mathrm{s}$ in the upper $100 \mathrm{~m}$ (Fig. 4b, 8a). These velocities, which are averaged over at least 50-m intervals, are consistent with velocities expected of the shallow ground-water aquifer along SCSI profile, as the minimum depths to the ground-water aquifer along the SCSI profile is known to range from about 10 to $50 \mathrm{~m}$ (Table 3). Because of the wide $(50 \mathrm{~m})$ spacing of seismographs (low resolution), the velocity images do not provide information about the upper $\sim 25 \mathrm{~m}$, and therefore, the minimum depth of the groundwater aquifer cannot be inferred from the SCSI-LR P-wave velocity data alone. However, minimum depths are inferred from the SCSI-HR velocity data to be about 5 to $40 \mathrm{~m}$ along the SCSI profile (Catchings et al., 2005). The maximum depth of the ground-water aquifer along the SCSI profile, however, can be inferred on the basis of higher-velocity rocks ( 2200 to $2300 \mathrm{~m} / \mathrm{s}$ ), which are typically too consolidated (impermeable) to act as efficient ground-water aquifers. Within the McGlincey well, consolidated sedimentary rocks $(\sim 2200 \mathrm{~m} / \mathrm{s})$ form the base of the ground-water aquifer at about $240 \mathrm{~m}$ depth (Hansen et al., 2004). If similar rocks extend across the western Santa Clara Valley at the base of the ground-water aquifer, lateral variations in the depth to ground water may be inferred on the basis of the rocks (faulted or fractured), degree of saturation, and compositional variations. In particular, for similar sequences of rocks, those rocks that have experienced significant faulting would have lower P-wave velocities than rocks that have not been faulted. Another problem with using the P-wave velocities to infer lateral variation in the ground-water aquifer system is the probable lateral variation in ground-water saturation. Because the SCSI-LR profile was situated along and between recharge ponds, reservoirs, and the Los Gatos Creek, some of the velocity measures are likely averages of velocities within a few hundred meters of major sources of ground-water recharge. For example, within the Santa Clara Valley, areas along the SCSI-LR profile near major recharge ponds, reservoirs, or Los Gatos Creek 
appear to have relatively high velocities at relatively shallow depths, suggesting relatively saturated sediments at relatively shallow depths (Fig. 4b). Conversely, those areas that are more distant from recharge ponds, reservoirs, or Los Gatos Creek have relatively low velocities at shallow depths. In places, both the ground-water aquifer system and the underlying Miocene sediments are probably variable in saturation and the degree of faulting, resulting in laterally variable velocities.

Shear-wave velocities (Vs) are much less sensitive to water saturation. Thus, unconsolidated saturated sediments tend to have higher $\mathrm{Vp} / \mathrm{Vs}$ ratios than consolidated saturated sediments, and both have higher $\mathrm{Vp} / \mathrm{Vs}$ ratios than unsaturated sediments. For example, Gibbs et al. (2000) show Vp/Vs ratios that range from about 3 to about 5 for most unconsolidated and saturated sediment sites surveyed in southern California, but they show most consolidated sediments to have $\mathrm{Vp} / \mathrm{Vs}$ ratios of about 2.5 or less. Consolidated and saturated sediments would have significantly lower Vp/Vs ratios, such as those ( 2.2) for 100\% saturated Massilon sandstone (Nur, 1982), than unconsolidated and saturated sediments.

Because both Vp and Vs data are available from the SCSI profile, Vp/Vs ratios can be used to infer lateral variation and depth of water-saturated sediments, which may be indicative of the degree of water recharge into the subsurface along the SCSI profile (Fig. 6a, 8a). However, high Vp/Vs ratios can also be caused by features other than fluid saturation, such as the presence of highly faulted strata or serpentinite, both of which have been found within the Santa Clara Valley and the eastern Santa Cruz Mountains. At the McGlincey well (shot point 9), a Vp/Vs ratio of 2.7 correlates with the base of the ground-water aquifer (Fig. 6a, 8a). If one assumes that the sedimentary rocks underlying the shallow subsurface are not highly faulted, then the $2.7 \mathrm{Vp} / \mathrm{Vs}$ contour may infer lateral variations in the ground-water aquifer. The thickest deposits with $\mathrm{Vp} / \mathrm{Vs}$ ratios of 2.7 or higher occur between shot point 1 and 3, near shot point 5, and northeast of shot point 10 . Between shot points 5 and 10, it is unlikely that there are significant deposits of serpentinite at shallow depths; thus, the $2.7 \mathrm{Vp} / \mathrm{Vs}$ ratio contour is probably indicative of lateral variations in the base of the ground-water aquifer in that area. However, because of the possible presence of serpentinite in various other areas along the profile, the 2.7 $\mathrm{Vp} / \mathrm{Vs}$ ratio contour may not correlate with the base of the ground-water aquifers in those areas along the SCSI profile. 
Poisson's ratio is also sensitive to high levels of groundwater saturation. For crustal materials, Poisson's ratio typically varies between about 0.15 and 0.5 (Schon, 1996), where a Poisson's ratio of 0.5 is indicative of fluids. In the shallow crust, high values $(>\sim 0.43)$ of Poisson's ratio probably correlate with saturated sediments or unusual rock types. In the vicinity of the McGlincey well, the base of the ground-water aquifer $(\sim 240 \mathrm{~m})$ correlates with a Poisson's ratio of about 0.43 , but faulting and the presence of serpentinite may also affect the Poisson's ratios. As with the $\mathrm{Vp} / \mathrm{Vs}$ ratios, however, the lateral variations in Poisson's ratio (0.43, as measured at the base of the McGlincey well) likely outline the ground-water aquifer between shot points 5 and 10, where near surface deposits are probably sedimentary.

On the basis of the $\mathrm{Vp}, \mathrm{Vp} / \mathrm{Vs}$, and Poisson's ratios found at the base of unconsolidated deposits in the McGlincey well and lateral variations in these values along the SCSI profile, we suggest that the thickest (up to $300 \mathrm{~m}$ ) ground-water aquifer is located between shot points 9 and 10. If, however, there are not significant serpentinite deposits or faulting near shot point 3 , the velocity data are also consistent with the presence of a thick aquifer in that area.

\section{Near-Surface $(<250 \mathrm{~m})$ Structure}

Near-surface strata along the SCSI profile are dominated by a series of faults and folds in the Santa Cruz Mountains (Fig. 1d) (McLaughlin et al., 2001). The SCSI seismic reflection images show folds that persist into the subsurface to several hundred meters depth or more. Between meters 3000 and 7000 of the SCSI profile, the shallow ( $\sim 50$ to $250 \mathrm{~m}$ ) strata appear folded, with dips as high as 45 degrees, and associated faults may dip both northeastward and southwestward as much as 80 degrees (Fig. 7).

Within the Santa Clara Valley, the folds are largely covered at the surface by unfolded or mildly folded alluvium, but the deeper (older) strata below about $200 \mathrm{~m}$ depth appear similarly faulted and folded as those in the Santa Cruz Mountains. The SCSI reflection image suggests that some subsurface strata in the Santa Clara Valley have dips greater than 30 degrees. The similarity in faulting and folding between the deeper valley structure and the near-surface mountain strata suggests that both areas have experienced similar tectonism. However, either the tectonism may have slowed in the valley, or deposition of near-surface Pliocene to Holocene sediments in the valley is sufficiently high that ongoing tectonism remains covered. 
Strata above about $200 \mathrm{~m}$ depth in the Santa Clara Valley are gently folded (Fig. 7), with wavelengths of about $2 \mathrm{~km}$ or more and both southwest and northeast dips ( 3 to 10 degrees). From about meter 7000 to about meter 9000, the shallow-depth strata largely dip (3 to 6 degrees) northeastward, but from about meter 9000 to meter 10000 , the shallow-depth strata dip ( $\sim 6$ degrees) southwestward along the limb of an apparent fold that apexes at about meter 10200. From meter 10200 to about meter 11500 , the shallowdepth strata also dip ( $\sim 6$ degrees) northeastward. Between meters 11500 and 13000, the shallow-depth strata are largely horizontal to about meter 13000, where they dip ( 3-7 degrees) southwestward to the end of the SCSI profile. Some of the near-surface strata beneath the alluvium appear to be faulted, but because the SCSI reflection image does not image the near surface (upper few tens of meters) strata, it is not possible to determine the minimum depth of faulting from these data. However, the seismic image shows evidence of faulting near the base of the ground-water aquifer. Such faults may affect ground-water recharge and flow across the valley.

\section{Basin Depth and Structures}

Basement rocks beneath the Santa Clara Valley are presumed to be the same as those in the eastern Santa Cruz Mountains, the Santa Teresa Hills, and the New Almaden areas, which consist of Franciscan Complex rocks and parts of the Coast Ranges Ophiolitic sequence, strata of the Great Valley sequence, and early Tertiary (Eocene) to mid-Tertiary (Miocene) rocks (McLaughlin et al., 2001). The Franciscan Complex is composed of a variety of penetratively sheared rocks including Cretaceous and Jurassic basaltic volcanic rocks, cherts, and sandstone, Cretaceous melange (blueshist, amphibolite, chert, basaltic volcanics, conglomerate and metadiorite), limestone, volcanics, and tuff. Within the Santa Clara Valley, the basement rocks are overlain by Miocene to Holocene sediments (Stanley et al., 2002). Basement rocks and the overlying sediments are likely to have significantly different velocities, which can be used to infer basement depth along the SCSI profile.

Shot point 1 was located within basement rocks consisting of Franciscan melange rocks (McLaughlin et al., 2001). At the surface, these rocks have a P-wave velocity of about $3000 \mathrm{~m} / \mathrm{s}$ (Fig. $\mathbf{4 b}$ ), but at depths of $2 \mathrm{~km}$ or less, these rocks would experience lithostatic pressures of about $50 \mathrm{KPa}$, resulting in P-wave velocity increases due to compaction (Carmichael, 1989). Laboratory measurements on pressurized Franciscan 
rocks show that compressional velocities $(\sim 4.35$ to about $6.0 \mathrm{~km} / \mathrm{s})$ vary widely in the upper few kilometers (Stewart and Peselnick, 1977). When pressurized to about 0.5 kbar, the Franciscan rocks used in Stewart and Peselnick's (1977) investigation increased in velocity an average of about $0.4 \mathrm{~km} / \mathrm{s}$. Assuming similar Franciscan basement rocks beneath the valley as at the surface at shot point 1 , and assuming an increase in velocity of about 0.4 to $0.5 \mathrm{~km} / \mathrm{s}$ due to lithostatic pressure, such Franciscan mélange rocks beneath the Cupertino Basin would have velocities of about 3400 to 3500 $\mathrm{m} / \mathrm{s}$. The $3500 \mathrm{~m} / \mathrm{s}$ velocity contour is located at about $1600 \mathrm{~m}$ depth in our velocity image, suggesting basement is about 1600 to $1800 \mathrm{~m}$ deep along the SCSI profile between shot points 5 and 6 and between shot points 9 and 10 (Fig. 4b), if basement beneath the Cupertino Basin is composed of such Franciscan rocks.

A similar analysis of the velocities of the Miocene sediments within the Santa Clara Valley can be made. On the basis of numerous P-wave measurements in deep boreholes, Press (1966) showed the range of velocities typical of sandstones and shales of various ages and varying depths of burial (Fig. 10). Miocene sandstones and shales typically have $\mathrm{P}$-wave velocities that range from about $2200 \mathrm{~m} / \mathrm{s}$ at about $300 \mathrm{~m}$ depth to about $2900 \mathrm{~m} / \mathrm{s}$ at $2 \mathrm{~km}$ depth (Press, 1966). In contrast, the SCSI P-wave velocity image shows that velocities beneath the central Cupertino Basin are approximately 4500 $\mathrm{m} / \mathrm{s}$ at $2 \mathrm{~km}$ depth. Comparison of the borehole sonic velocities and the SCSI refraction velocities suggest that sandstone and shale sediments of any age between Miocene and Jurassic are probably no deeper than about 1600 to $1800 \mathrm{~m}$ in the Cupertino Basin (Figs. 10a). Brocher et al. (1997) made a similar analysis of sonic velocities as a function of depth from boreholes in the San Francisco Bay area. They show that the average velocity for sedimentary rocks at about $1800 \mathrm{~m}$ depth is less than $3500 \mathrm{~m} / \mathrm{s}$, but at depths in excess of $1800 \mathrm{~m}$, the SCSI refraction data show that velocities are more than $4500 \mathrm{~m} / \mathrm{s}$ (Fig. 10b). Both comparisons of the SCSI refraction velocities with sonic velocities suggest that the deepest sediments along the SCSI profile are probably not more than about 1800 $\mathrm{m}$.

We also interpret a maximum depth to basement of 1600 to $1800 \mathrm{~m}$ along the SCSI profile from the SCSI reflection image (Fig. 7). The reflectivity pattern, which is indicative of layered sedimentary rocks, abruptly changes to a pattern of en echelon northeast-dipping reflectors at depths of approximately 1600 to $1800 \mathrm{~m}$ depth near the central Cupertino Basin (meter 9000). These en echelon reflectors are part of a high- 
amplitude series of reflectors that extend to the near surface southwest of Lexington Dam, where geologic mapping shows a northeast-dipping thrust fault separates Franciscan rocks from Coast Ranges Ophiolitic rocks (McLaughlin et al., 2001). Because of its upward projection toward the thrust fault and because of the high basement velocities (up to $6.5 \mathrm{~km} / \mathrm{s}$ at $3.5 \mathrm{~km}$ depth) in the northeastern Santa Cruz Mountains, we interpret the high-amplitude, northeast-dipping reflector as a contact between the Coast Ranges Ophiolite and Franciscan Complex rocks. As the Franciscan and Coast Ranges Ophiolite are considered basement rocks, the en echelon reflectors at about $1800 \mathrm{~m}$ depth beneath the Cupertino Basin, which may have resulted from tectonic wedging of Coast Ranges Ophiolitic rocks into Franciscan Complex rocks (R. McLaughlin, Pers. Comm., 2004), are also likely to be basement rocks.

Our velocity- and reflectivity-based estimates to the top of basement (or maximum depth of Miocene sediments) are consistent with at least one other estimate of the minimum thickness of Miocene sediments beneath the western Santa Clara Valley. Based on chemical analysis of oil from a well along the seismic profile, Stanley et al. (2002) suggest that the oil producing rocks (top of the oil-generative window) could be buried as shallowly as 1600 to $1800 \mathrm{~m}$ below the surface, although their preferred depth range is between 2100 and $2500 \mathrm{~m}$ (p. 36). Thus, the chemical analyses do not require present-day sediments below 1600 to $1800 \mathrm{~m}$ depth in the western Santa Clara Valley.

On the basis of gravity modeling, the depth to basement beneath the Cupertino Basin in the vicinity of the SCSI-LR profile has been estimated at about 3.5 to $4 \mathrm{~km}$ depth (R. Jachens, Pers. Comm., 2001; Stanley et al., 2002). However, the velocity and reflectivity data from out study suggest that sediments of the Cupertino Basin are less than about $1800 \mathrm{~m}$ thick in the vicinity of the SCSI-LR profile.

\section{Faulting Relationships:}

Numerous faults are mapped at the surface in the eastern Santa Cruz Mountains (McLaughlin et al., 2001), and beneath the alluvium cover of the western Santa Clara Valley, faults are also inferred from previous geophysical and borehole investigations (CDWR, 1967). Most of the prominent reverse faults in the eastern Santa Cruz Mountains are interpreted to dip southwestward toward the San Andreas fault, with some antithetic, northeast-dipping normal faults that merge with the southwest-dipping faults at depth (McLaughlin et al., 2001). In contrast, many of the mapped faults and 
stratigraphic units near the edge of the Santa Clara Valley and within the Santa Teresa Hills ( $\sim 5 \mathrm{~km}$ south of the seismic profile) dip steeply to the northeast (McLaughlin et al., 2001).

Because of the relatively low resolution of the SCSI-LR profile and the complexity of the subsurface structure, fault structures to depths of several hundred meters along the SCSI-LR profile are best determined from the SCSI-HR profile images (Catchings et al., 2005) and from known surface faults (Fig. 7). Although the SCSI-LR and SCSI-HR profiles are not everywhere coincident, when SCSI-HR interpreted faults are superimposed on the SCSI-LR reflection image, apparent stratigraphic offsets on the SCSI-LR reflection image coincide with most of the interpreted faults to depths of about $600 \mathrm{~m}$ (Fig. 7). Below about $600 \mathrm{~m}$, the fault structures are not well resolved on the SCSI-LR reflection image, but there appear to be near-vertical offsets of stratigraphic layers that extend to several kilometers depth (Fig. 11). On the basis of offset layers and the dips of faults at shallow depths, we suggest that many of the near-surface faults merge at depths of one to three kilometers into several discrete, largely southwest-dipping fault zones.

Surface and near-surface (trenching) geologic mapping (McLaughlin et al., 2001) shows that most of the faults along the SCSI profile dip at high angles ( $\sim 75$ to 80 degrees), and our seismic images also indicate that the high-angle (75 to 80 degrees) faults extend to at least $600 \mathrm{~m}$ depth (Fig. 7). Focal mechanisms for the best-recorded earthquakes within a few kilometers of the SCSI-LR profile also show that most of the faults between about 1 to $20 \mathrm{~km}$ depth are relatively high-angle, reverse faults (Figs. 7 and 11). Thus, it is likely that many of the fault zones within the western Santa Clara Valley merge with the San Andreas fault zone at depths of 3 to $15 \mathrm{~km}$. However, seismic events centered northeast of the Cupertino Basin indicate that there may also be one or more fault zones that either merge with the San Andreas fault at depths of 15 to $30 \mathrm{~km}$, or they are separate fault zones that do not merge with the San Andreas at all (Fig. 12).

\section{Summary}

The seismic images from this study show the larger-scale features of the upper few kilometers of the crust. The seismic images provide structural constraints, including (1) the thickness of the sedimentary rocks within the Santa Clara Valley, (2) depth to and 
lateral variations in basement rocks, (3) distribution and structure of subsurface faults, and (4) probable lateral variations in the ground-water aquifer system.

We suggest that Miocene sandstone and shales are thickest (1600 to $1800 \mathrm{~m}$ ) beneath the central Cupertino Basin, but thin rapidly toward the center of the basin and near its southwestern edge. In places in the northeastern Santa Cruz Mountains surface mapping shows that the Miocene rocks are underlain by Franciscan Complex rocks (McLaughlin et al, 2001), and the same structural relationship may exist beneath the Santa Clara Valley. However, serpentinite observed at relatively shallow depths ( 245 $\mathrm{m})$ in the Willow well (Orze et al., 2003), near the northeast end of the SCSI-LR profile, suggests that at least parts of the Santa Clara Valley are underlain by rocks of the Coast Ranges Ophiolite. This observation is somewhat consistent with our seismic reflection image, whereby a high-amplitude northeast-dipping reflector extends from surface exposures of the Coast Ranges Ophiolite in the Santa Cruz Mountains to the base of the Cupertino Basin, and back toward the shallow subsurface in the vicinity of the Willow well (Fig. 11). On the basis of the reflection image, we suggest that Miocene sediments of the western Santa Clara Valley may be underlain by a wedge of Coast Ranges Ophiolitic rocks that has been thrust beneath the valley. These rocks have relatively high velocities $(\sim 6.5 \mathrm{~km} / \mathrm{s})$ within the Santa Cruz Mountains. Similar high-velocity ( $\sim 6.4$ to $6.5 \mathrm{~km} / \mathrm{s})$ rocks have been observed to the north of the SCSI-LR profile, beneath the San Francisco Bay, (Catchings et al, 2004) and below the eastern side of the Santa Clara Valley (Catchings et al., unpublished data). Such high-velocity rocks are consistent with ultramafic rocks that compose parts of the Coast Ranges Ophiolite (Carmichael, 1989), but such high velocities are not consistent with most Franciscan rocks at that depth (Stewart and Peselnick, 1977).

Offset reflectors and folded Pre-Pliocene strata suggest multiple faults beneath the alluvium of the Santa Clara Valley. Offset strata imaged on the SCSI-LR reflection image show that some of the faults offset the base of the ground-water aquifer system. Such shallow-depth faulting implies at least post-Pliocene movement on faults beneath the Santa Clara Valley, and SCSI-HR images show that many of these fault extend to the near surface or to within about $10 \mathrm{~m}$ of the surface (Catchings et al., 2005). Furthermore, earthquakes recorded over the past 30 years show that similar faults are presently active at depths of 1 to $30 \mathrm{~km}$. These stratigraphic relationships and earthquakes recorded beneath the valley clearly indicate the presence of potentially 
hazardous earthquake faults beneath the Santa Clara Valley. These faults represent a potential hazard both from the standpoint of local sources beneath a large population base and increased ground amplification due to regional sources, such as the San Andreas fault. The maximum magnitudes of earthquakes that can be generated from the imaged faults are unknown but are related to the lengths of the faults. The seismicity pattern and mapped faults near the base of the mountains suggest that the valley faults may extend 70 $\mathrm{km}$ or more. Where they extend to the shallow depths, these faults probably cause lateral variations in the ground-water aquifer by acting as barriers to lateral flow across the valley.

Lateral variations in P-wave velocities, $\mathrm{Vp} / \mathrm{Vs}$ and Poisson's ratios, and reflection images, correlated with borehole data, indicate that the maximum depth of the groundwater aquifer is variable across the Santa Clara Valley, varying from less than $50 \mathrm{~m}$ to about $300 \mathrm{~m}$. Quaternary deposits that form the ground-water aquifer system appears to thicken eastward of Vasona Dam, with the thickest deposits in the area northeast of the city of Campbell (shot point 11). The thinnest Quaternary deposits are located southwestward of Vasona Reservoir, with the possible exception of isolated basins, such as that beneath the city of Los Gatos. Most lateral variations in the depth of the groundwater aquifer system correlate with apparent fault offsets in subsurface reflectors, suggesting that the ground-water aquifer is faulted in multiple locations across the western part of the valley. The SCSI reflection images suggest that the Quaternary rocks are faulted at various locations along the length of the SCSI-LR profile, including the central part of the valley between Campbell and San Jose. A short seismic profile acquired farther to the northeast of the end of the SCSI-LR profile suggests similar faulting extends beneath the eastern downtown area of San Jose (Catchings et al., 2000), but our 2000 SCSI-LR seismic profile did not extend far enough to the northeast to address that area.

The dimensions and velocities of the low-velocity Cupertino Basin are important parameters needed to understand potential ground shaking resulting from movement on regional and/or local faults. The velocity and reflection images suggest that the Cupertino Basin is about 1600 to $1800 \mathrm{~m}$ deep, which is about one-half the depth previously suggested from potential fields studies (R. Jachens, Pers. Comm., 2001; Stanley et al., 2002). Although other factors, such as basin shape, velocities, location of the sources, type of fault, etc., are important contributors, the shallower depth of the Cupertino Basin 
may also indicate less hazard from amplification of seismic waves in the valley than previously believed. However, the seismic images also suggest multiple faults beneath the valley, some of which are active, as indicated by earthquakes recorded over the past few decades (Fig. 12) and by near-surface traces of the faults imaged on the seismic reflection images (Fig. 11). Slip on any one of the major faults may trap fault-zone guided waves into the general fault system, and produce amplified seismic waves within the each of the fault zones. However, the principal hazard for the Santa Clara Valley may be the high-amplitude seismic energy generated by the reverse faults that underlie the valley. 


\section{Acknowledgements:}

This work was jointly funded by the U.S. Geological Survey's (USGS) Earthquake Hazards Program and the Santa Clara Valley Water District (SCVWD). We than IRIS-PASSCAL for providing the Texan seismographs, and we especially thank Bob Greschke and Pete Ulbricht, who provided technical support during the seismic investgation. We thank numerous individuals and organizations, including the SCVWD, the City of Los Gatos, City of Campbell, Open Space District, Los Gatos High School, Del Mar High School, and the San Jose Water Company, who provided permits and access to their properties. We thank Alonzo Aballo, Joe Catchings, Coye Criley, Coyn Criley, Courtney Criley, Ed Criley, Samuel V. Gudino, Samuel R. Gudino, Silvia Gudino, Ron Kaderabek, Grey Jensen, Shawn Hanson, Lora Kiger, David Reneau, Jose Rodriguez, Paul Singh, Jeffrey Thacker, and John VanSchaack, who assisted in data acquisition. We thank Lora Kiger for helping with many of the logistical challenges of this investigation, and we also thank Lora Kiger and John Hamilton for providing precision survey data. We thank Carl Wentworth, David Schwartz, and Jack Boatwright, who provided administrative assistance. We thank Bob Mclaughlin for scouting and recommending the Santa Cruz Mountains segment of the SCSI profile northeast of Lexington Reservoir. Thanks to Tom Brocher, Bob McLaughlin, and Peter Martin, who provided reviews of this manuscript.

\section{References}

Advanced National Seismic System (ANSS) Catalog (2004). anss@quake.geo.berkeley.edu

Bortugno, E.J., McJunkin, R.D., and Wagner, D.L. (1991). Map showing recency of faulting, San Francisco-San Jose quadrangle, 1:250,000: Department of Conservation, Division of Mines and Geology Regional Geologic Map Series, Map $5 \mathrm{~A}$, Sheet 5

Brocher, T. M., A. L. Ruebel, and E. E. Brabb (1997). Compilation of 59 sonic and density logs from 51 oil test wells in the San Francisco Bay area, California. U.S. Geological Survey Open-File Report 97-987 75 pp.

Brouwer, J., and K. Helbig (1998). Shallow high-resolution reflection seismics. In: Helbig, K., Treitel, S. (Eds.), Handbook of Geophysical Exploration: Seismic Exploration, Vol. 19, Elsevier, New York, New York, 391 pp.

California Department of Water Resources (CDWR) (1967). Evaluation of Ground Water Resources, South Bay, Appendix A: Geology: Bulletin 118-1, 153 p.

California Department of Water Resources (CDWR ) (1975). Evaluation of groundwater resources, south San Francisco Bay, Volume III, northern Santa Clara County area: Bulletin No. 118-1, various pagination

Catchings, R. D. (1999). Regional Vp, Vs, Vp/Vs, and Poisson's ratios across earthquake source zones from Memphis, Tennessee to St. Louis, Missouri. Bull. Seism. Soc. Am, 89, 1591-1605 
Catchings, R. D., G. Gandhok, M. R. Goldman, E. Horta, M. J. Rymer, P. Martin, and A. Christensen (1999a). Subsurface, high-resolution, seismic images from Cherry Valley, San Bernardino County, California: Implications for Water Resources and Earthquake Hazards, US Geological Survey Open-File Report 99-26, 57 pp.

Catchings, R. D., M. R. Goldman, G. Gandhok, E. Horta, M. J. Rymer, P. Martin, and A. Christensen (1999b). Structure, velocities, and faulting relationships beneath San Gorgonio Pass, California: Implications for water resources and earthquake hazards, US Geological Survey Open-File Report 99-568, 53 pp.

Catchings, R.D., and Goldman, M.R., Gandhok, G., Rymer, M.J., and Underwood D.H. (2000). Seismic imaging evidence for faulting across the northwestern projection of the Silver Creek Fault, San Jose, California: U.S. Geological Survey Open-File Report 00-125, 29 p.

Catchings, R. D., M. R. Goldman, C. E. Steedman, and G. Gandhok (2004). Velocity models, first-arrival travel times, and geometries of the 1991 and 1993 USGS landbased controlled-source seismic investigations in the San Francisco Bay area, California: In-line shots, U.S. Geological Survey Open-File Report 2004-1423, 32 pp.

Catchings, R. D., G. Gandhok, M. R. Goldman, C. E. Steedman, and R. Hanson (2005). Near-surface structure and velocities of the northeastern Santa Cruz Mountains and the western Santa Clara Valley, California from seismic imaging, U.S. Geological Survey Open-File Report, in press.

Carmichael, R. S. (1989) Practical Handbook of Physical Properties of Rocks and Minerals, CRC Press, Boca Raton, Ann Arbor, Boston

Christiansen, N.I. (1982). Seismic Velocities in R.S. Carmichael ed., Handbook of Physical Properties of Rocks, v. II, CRC Press, Boca Raton.

Christiansen, N. I. (1996). Poisson's ratio and crustal seismology, J. Geophys. Res., 101, p. $3139-3156$

Dibblee, T.R., Jr. (1966). Geology of the Palo Alto quadrangle, Santa Clara and San Mateo Counties, California: California Division of Mines and Geology Map Sheet 8, scale $1: 62,500$.

Dietz, Lynn D., and William L. Ellsworth (1997). Aftershocks of the Loma Prieta Earthquake and their tectonic implications, in The Loma Prieta, California Earthquake of October 17, 1989: Earthquake Occurrence. Aftershocks and Postseismic Effects, U.S. Geological Survey Profess. Paper 1550-D, p. D5-D47

Gandhok, G., R. D. Catchings, M. R. Goldman, E. Horta, M. J. Rymer, P. Martin, and A. Christensen (1999). High-Resolution Seismic Reflection/Refraction Imaging from Interstate 10 to Cherry Valley Boulevard, Cherry Valley, Riverside County, California: Implications for Water Resources and Earthquake Hazards, U.S. Geological Survey Open-File Report 99-320, 52 pp.

Gibbs, J. F., J. C. Tinsley, D. M. Boore, and W. B. Joyner (2000). Borehole velocity measurements and geological conditions at thirteen sites in the Los Angeles, California region, U.S. Geological Survey Open-File Report 00-470, 118 pp.)

Hanson, R.T., Newhouse M.W., Wentworth, C.M., Williams, C.F., Noce, T.E., Bennett, M.J. (2002b). Santa Clara Valley Water District multi-aquifer monitoring-well site, Coyote Creek Outdoor Classroom, San Jose, California: U.S. Geological Survey Open-File Report OFR 02- 369, 4 p. 
Helley, E.J., R.W. Graymer, G.A. Phelps, P.K.Showalter, and C.M. Wentworth (1994). Quaternary geology of the Santa Clara Valley, Santa Clara, Alemeda, and San Mateo counties, California: A digital database. U.S. Geological Survey Open-File Report 94231.

Hole, J. A. (1992). Nonlinear high-resolution three-dimensional seismic traveltime tomography. J. Geophys. Res. 97, 6553-6562.

Lin, Wunan, and Wang, C.-Y., 1980, P-wave velocity in rocks at high pressure and temperature and the constitution of the central California crust: Royal Astronomical Society Geophysical Journal, v. 61, no. 2, p. 379-400.

McLaughlin, R. J., J. C. Clark, E.E. Brabb, E.J. Helley, and C.J. Colon (2001). Geologic maps and structure sections of the southwestern Santa Clara Valley and southern Santa Cruz Mountains, Santa Clara and Santa Cruz Counties, California, U.S. Geol. Surv. Misc. Field Studies Map MF-2373

Newhouse, M.W., R.T. Hanson, C.M. Wentworth, Rhett R. Everett, C.F. Williams, J.C.Tinsley, T.E. Noce, B.A. Carkin (2004). Geologic, Water-Chemistry, and Hydrologic Data from Multiple-Well Monitoring Sites and Selected Water-Supply Wells in the Santa Clara Valley, California, 1999-2003, U.S. Geological Survey Scientific Investigations Report, 2004-5250

Nur, A. (1982). Notes on wave propagation in porous rocks, Stanford Rock Physics Progress Report, January 1982, vol. 13, 121 pp. Stanford University, Stanford, CA,

Orze, C. J., M. J. LaForce, C. M. Wentworth, R. T. Hanson, D. K. Bird, and R. G. Coleman (2003). Chromium geochemistry of serpentinous sediment in the Willow Core, Santa Clara County, California, U.S. Geological Survey Open-File Report 03-251, 24 pp.

Press, F. (1966). Seismic Velocities, In Handbook of Physical Constants, S.P. Clark SP, ed., pp. 195-218, Geol. Soc. Am. Mem. 97, Geol. Soc. Am., New York.

Poland, J.F. (1971). Land subsidence in the Santa Clara Valley, Alameda, San Mateo, and Santa Clara Counties, California: U.S. Geological Survey Open-File Report, Map Scale $1: 125,000$

Schmidt, D.A. (2002).The kinematics of faults in the San Francisco Bay area inferred from geodetic and seismic data: unpublished $\mathrm{PhD}$ dissertation, University of California at Berkeley, $200 \mathrm{p}$.

Schon, J. H. (1996). Physical Properties of Rocks. Fundamentals and principals of petrophysics, in Handbook of Geophysical Exploration V. 18 (K. Helbig and S. Treitel, eds.), Pergamon Press, Elsevier Science, Inc. New York, New York, 583 pp.

Simpson, R. (2004). http://ehzweb-menlo.wr.usgs.gov/DD_Eq_Plots/Eqs_scvbt/)

Stanley, R.G., Jachens, R.C., Lillis, P.G., McLaughlin, R.J., Kvenvolden, K.A., Hostettler, F.D., McDougall, K.A., and Magoon, L.B. (2002). Subsurface and Petroleum Geology of the Southwestern Santa Clara Valley ("Silicon Valley”), California: U.S. Geological Survey Professional Paper 1663, 55 p.

Stewart, R.M., and Peselnick, Louis, 1977, velocity of compressional waves in dry Franciscan rocks to $8 \mathrm{kbar}$ and $300^{\circ} \mathrm{C}$ : Journal of Geophysical Research, v. 82, no. 14, p. 2027-2039.

Thomsen, Leon (1990). Poisson was not a geophysicist, The Leading Edge of Exploration, December 1990, p. 27-29 
Wagner, D.L., K.J. Bortugno, and R.D. McJunkin (1990). Geologic map of the San Francisco-San Jose quadrangle: California Department of Conservation, Division of Mines and Geology, Regional Geologic Map Series, Map No. 5A, 5 sheets.

Wentworth C.M. (1997). General distribution of geologic materials in the San Francisco Bay region, California: a digital map database: U.S. Geological Survey Open File Report 97744.

United States Census Bureau (2003). http://quickfacts.census.gov/qfd/states/06/06085.html

Zoback, M.L., J. A. Olson, and R. C. Jachens (1995). Seismicity and basement structure beneath the south San Francisco Bay, California, in Sangines, E.M., Anderson, D.W., and Busing, A.V., eds., Recent geologic studies in the San Francisco Bay area: Scoeity of Economic Paleontologists and Mineralogists, Pacific Section Special Publication 76, p. 31-46. 


\section{Figures}

Fig. 1 (a) Location map of the southern San Francisco Bay area and the Santa Clara Seismic Imaging (SCSI) profile. Shot points and seismograph locations for the SCSI profile are shown in the inset. Major faults (from Bortugno et al., 1991), roadways, and selected cities are also shown. Inferred faults that cross the SCSI profile in the Santa Clara Valley are shown only at their inferred crossing. The Cupertino (CB) and Evergreen (EB) Basins (from Stanley et al., 2002) are outlined as dashed lines. (b) Shot points (Shot point \#) of the southwestern half of the SCSI low-resolution (SCSI-LR) seismic profile. The brown asterisks show the locations of individual seismographs of the southwestern part of the SCSI-LR profile. The green asterisks show the locations of shot points along the southwestern part of the SCSI high-resolution (SCSI-HR) seismic profile. Where the profile overlap, the SCSI-HR (green) shot points are shown on top. The base map is from the USGS 7.5 minute Los Gatos quadrangle. (c) The locations of the northeastern parts of the SCSI-LR and SCSI-HR seismic profiles, plotted as in figure 1b. The base map is from the USGS 7.5 minute Los Gatos quadrangle. Recently drilled USGS/SCVWD water wells (McGlincey, Willow, and STPK) are shown by the red dots, with distances to the wells shown. (d) Geologic map (from McLaughlin et al., 2001) of the northeastern Santa Cruz Mountains with the southwestern part of the SCSI profiles plotted as in figure $1 \mathrm{~b}$. Note the numerous faults mapped along the seismic profile. See McLaughlin et al. (2001) for map legend.

Fig. 2. Geometry of the SCSI-LR profile. Variation in seismograph array (a) elevation and (b) linearity. Variation in shot-point array (c) elevation and (d) linearity. Note that most of the non-linearity occurs outside of the shot-point array. (e) Fold as a function of common depth point (CDP) along the SCSI profile.

Fig. 3. (a-k) Shotgathers for SCSI-LR shot points 1-11, respectively. Several prominent reflectors are highlighted on the southwestern end of the seismic profile. Some of these reflectors project to the surface at a fault contact between rocks of the Coast Ranges Ophiolite and Franciscan rocks.

Fig. 4. (a) Ray density diagram showing raypaths for P-waves and redundancy for shot and receiver pairs along the SCSI profile. (b) P-wave velocity model for the upper $3 \mathrm{~km}$ along the SCSI profile. Distance is relative to the southwestern most geophone, located near the San Andreas fault. Depth is relative to the lowest elevation along the SCSI profile. The shallow depth white contour denotes the $2200 \mathrm{~m} / \mathrm{s}$ velocity contour, which correlates with the base of the ground-water aquifer system in the McGlincey water well, located approximately at meter 12500 of the velocity model. The other white velocity contour denotes the $3000 \mathrm{~m} / \mathrm{s}$ velocity contour, which correlates with Franciscan basement rocks at the surface at shot point 1 (meter 3500). The red contour denotes the $3500 \mathrm{~m} / \mathrm{s}$ contour, which is the probably the maximum velocity for similar basement rocks at $2 \mathrm{~km}$ depth.

Fig. 5. (a) Ray density model showing raypaths for S-waves and redundancy for shot and receiver pairs along the SCSI profile. (b) S-wave velocity model for the upper $5 \mathrm{~km}$ along the SCSI profile. Depth and distance are the same as those in figure $4 \mathrm{~b}$. Velocities below about $1500 \mathrm{~m}$ depth are poorly constrained due to uncertain picks on the shot gathers. 
Fig. $6 \mathrm{Vp} / \mathrm{Vs}$ ratio model along the SCSI profile. Depth and distance are the same as those in figure $4 \mathrm{~b}$. The $2.7 \mathrm{Vp} / \mathrm{Vs}$ ratio contour, which correlates with the base of the ground-water aquifer in the McGlincey well ( meter 12500) is shown in white. Due to the presence of serpentinite and faults along the profile, high values of $\mathrm{Vp} / \mathrm{Vs}$ ratios in various places are not necessarily related to the ground-water aquifer along all of the SCSI profile. (b) Poisson's ratio model along the SCSI profile. Depth and distance are the same as those in figure $4 \mathrm{~b}$. The 0.43 Poisson's ratio contour, which correlates with the base of the ground-water aquifer in the McGlincey well ( $\sim$ meter 12500$)$ is shown in white. Low values of Poisson's ratio below $1.5 \mathrm{~km}$ depth are not well constrained.

Fig 7. (a) Migrated seismic reflection image of the upper $1000 \mathrm{~m}$ along the SCSI profile. Red vertical arrows above the reflection image denote the locations of mapped faults (McLaughlin et al., 2001) along the SCSI-LR profile. Blue arrows indicate interpreted faults. (b) Migrated reflection image from figure 7a, with the locations of faults as interpreted on the SCSI-HR reflection images (Catchings et al., 2005). Focal mechanisms for earthquakes within about $3 \mathrm{~km}$ of the SCSI profile are shown below the reflection image. Most focal mechanisms indicate northeast striking, high-angle ( 75 to 90 degrees) faults. (c) Migrated reflection image from figure 7a, with interpretative strata, derived from surface mapping and wells along the profile. Yellow indicates Quaternary sediments, blue indicates Miocene strata, and green indicates Franciscan rocks.

Fig. 8. (a) Seismic reflection image from figure 7 with the unmasked P-wave velocity model from figure $4 \mathrm{~b}$ superimposed. (b) Seismic reflection image from figure 7 with the unmasked S-wave velocity model from figure 5b superimposed. (c) Seismic reflection image from figure 7 with the $\mathrm{Vp} / \mathrm{Vs}$ model from figure 6a superimposed. (d) Seismic reflection image from figure 7 with the Poisson's ratio model from figure $6 \mathrm{~b}$ superimposed. Wells located along or near the seismic profile are shown in yellow. See Stanley et al. (2002) for well descriptions.

Fig. 9. Comparison of P- and S-wave sonic velocities from the McGlincey well (see fig. 1) with SCSI refraction velocities. The SCSI velocities, which are averaged over 50-100 $\mathrm{m}$ intervals are comparable to the sonic logs over similar depth ranges.

Fig. 10. (a) Average P-wave velocities of sandstone and shale as a function of age (from Press, 1966) and comparison with velocities determined along the SCSI-LR profile beneath the Cupertino Basin (meter 9000). Tertiary sandstone and shale are known to underlie the near-surface Quaternary deposits in the western Santa Clara Valley (Stanley et al, 2002). This comparison suggests that sandstones and shales are probably confined to the upper $1600 \mathrm{~m}$ beneath the Santa Clara Valley. (b) Comparison of velocity-depth relationships from sonic velocities obtained from boreholes in the San Francisco Bay area (from Brocher et al., 1998) and SCSI refraction velocities. Sonic velocities are derived from boreholes drilled in various sedimentary basins in the San Francisco Bay area, and refraction velocities are from a vertical profile at meter 9000 of the SCSI velocity model (fig. 4b). The SCSI and average sonic velocities differ significantly at about 1600 to $1800 \mathrm{~m}$ depth, suggesting that sediments of the Cupertino Basin are probably not deeper than 1600 to $1800 \mathrm{~m}$. 
Fig. 11 Seismic reflection image from figure 7 , with probable rock types and interpretative faults outlined at shallow depths. Interpretative rock types are based on known stratigraphy at the surface, borehole data, and continuity of reflectors. Interpretative faults are based on fault mapped at the surface, SCSI-HR reflection images (Catchings et al., 2005), and offset reflectors on the SCSI-LR image. Focal mechanism for well-recorded earthquakes within $3 \mathrm{~km}$ of and along the seismic profile are shown below the SCSI-LR reflection image.

Fig 12 Interpreted seismic image figure 11 with earthquakes that have been recorded over the past 3 decades within $3 \mathrm{~km}$ of the SCSI profile. Although locations are not precise, there are at least two separate zones of seismicity along the SCSI profile. Seismicity below each of these zones extend to depths greater than $25 \mathrm{~km}$, but only earthquakes in the upper $14 \mathrm{~km}$ are shown here. 


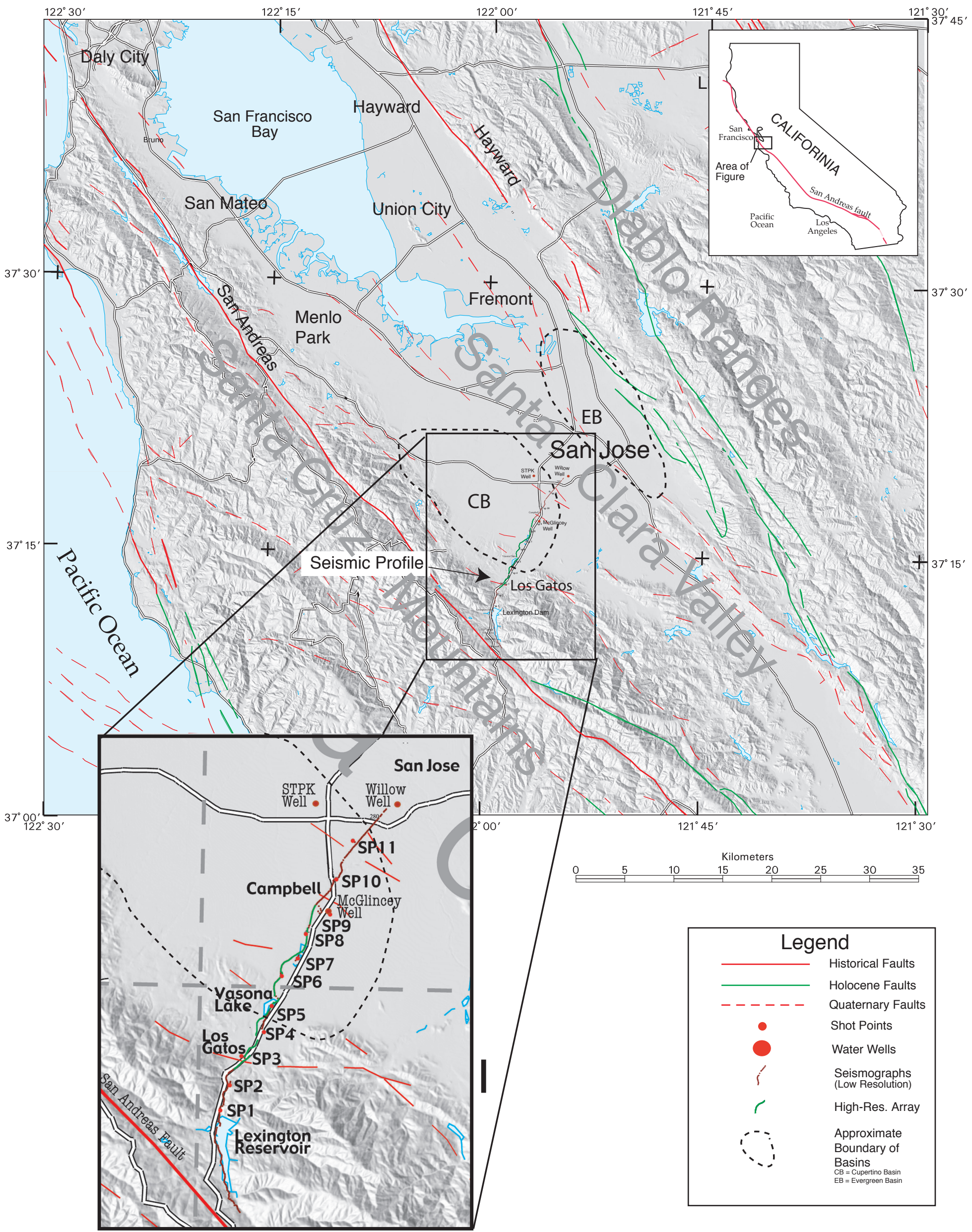

Fig. 1a 


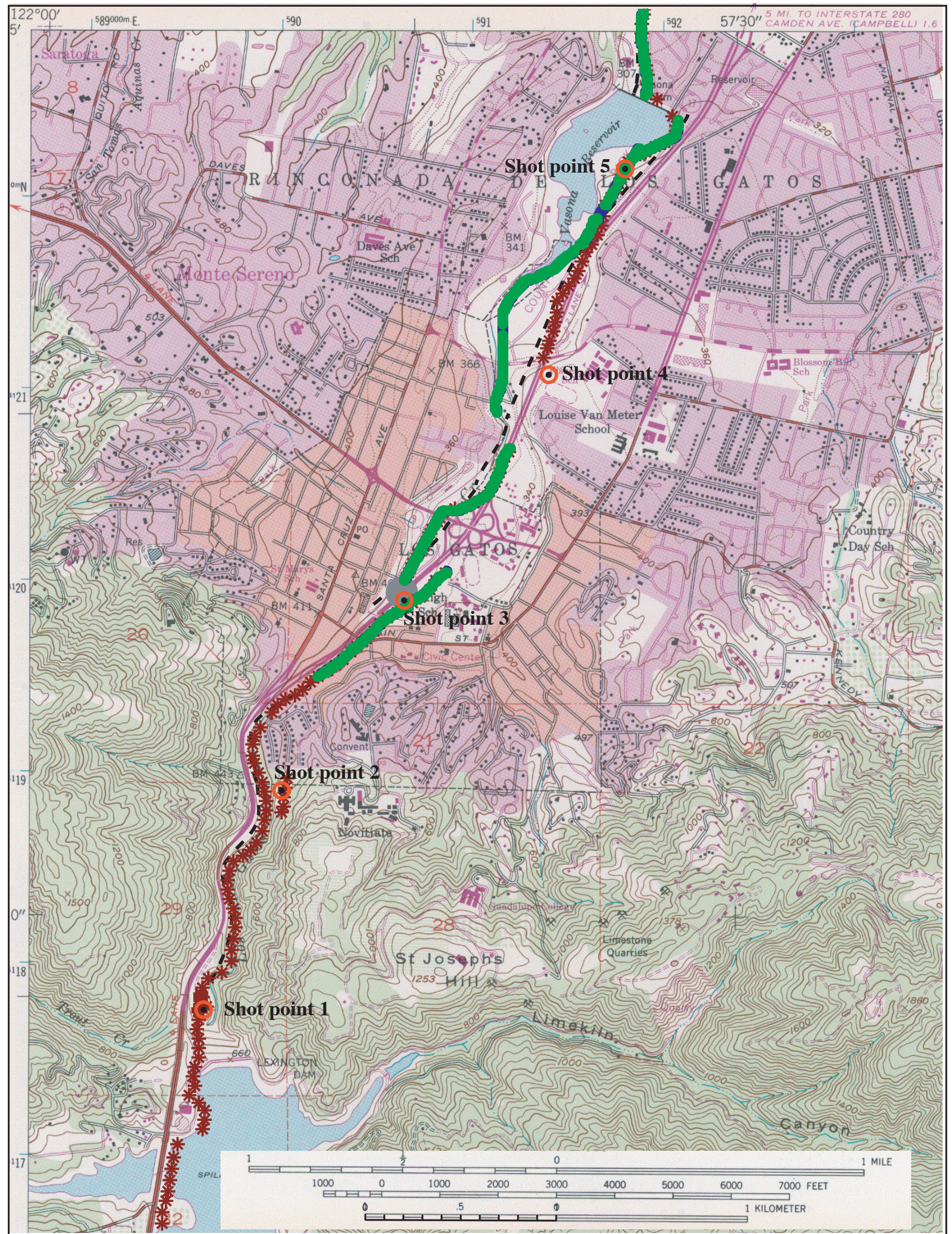




- SCSI-HR Profile
* SCSI-LR Seismograph
○ SCSI-LR Shot Point

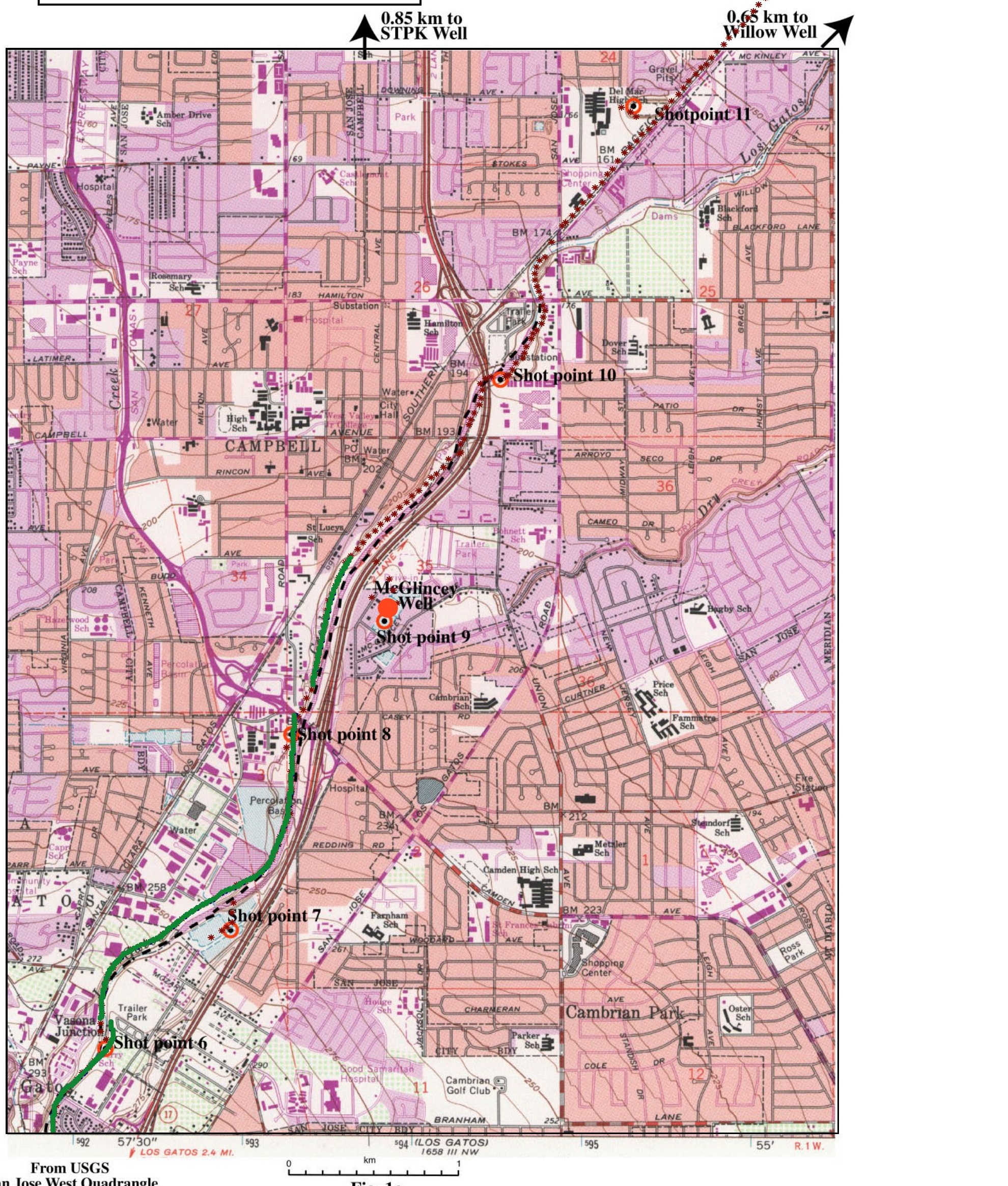




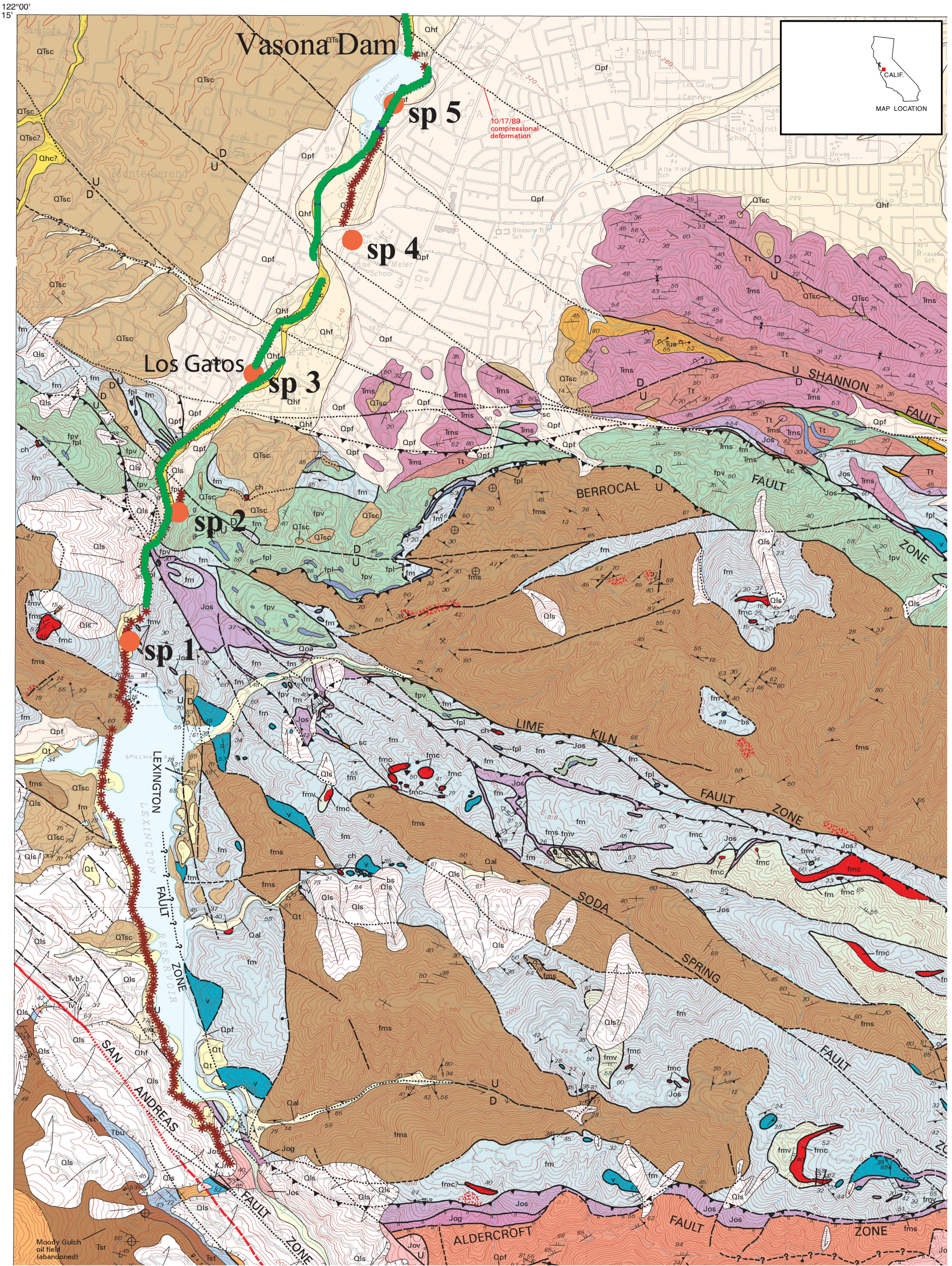

- SCSI-HR and/or LR Profiles

* SCSI-Seismographs

SCSI-LR Shot Points

Fig. 1d 


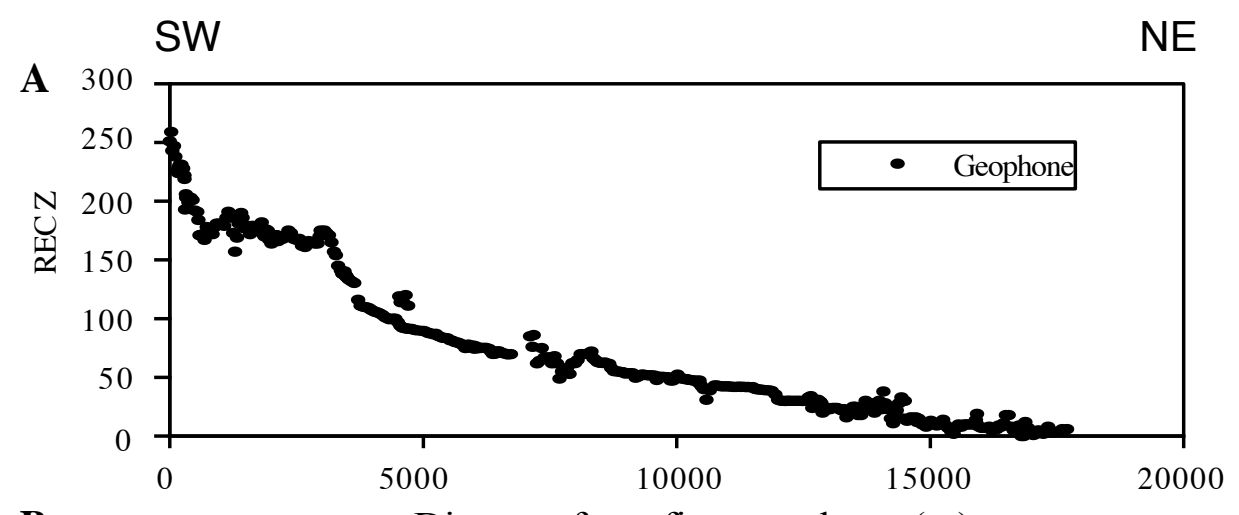

B Distance from first geophone (m)

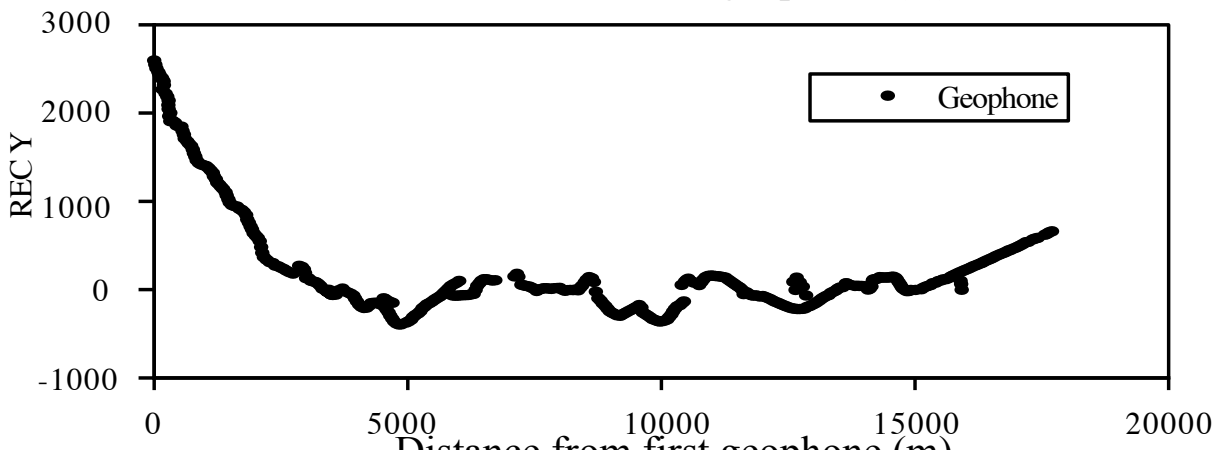

C

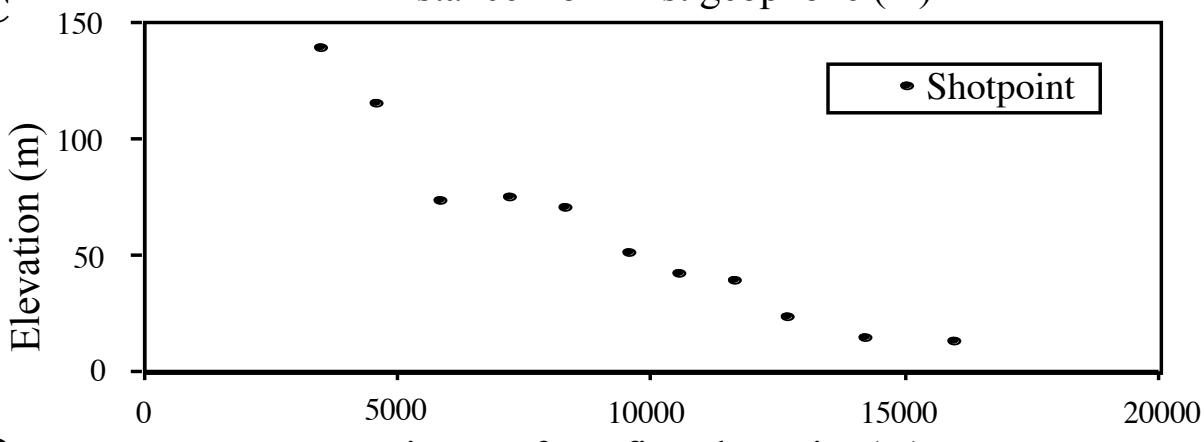

D

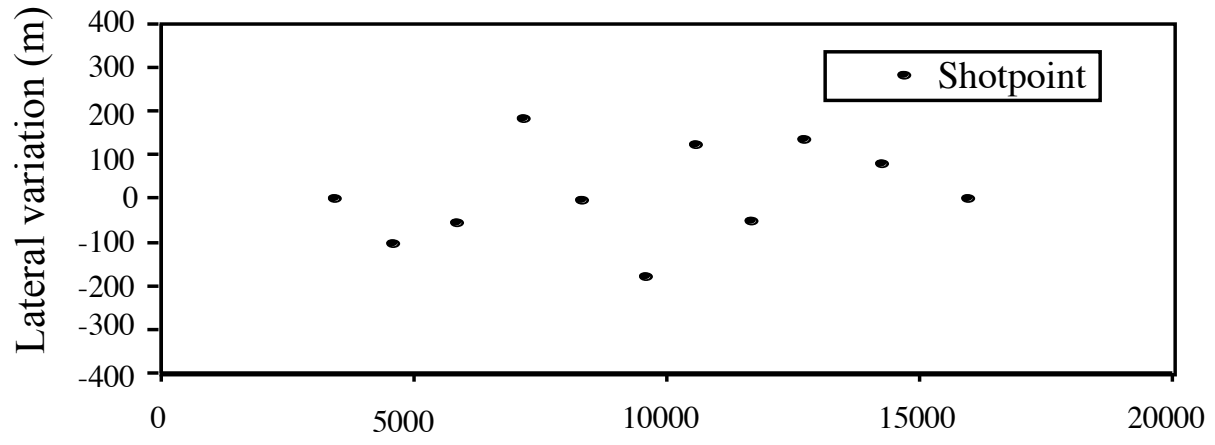

$\mathbf{E}$

Distance from first shotpoint (m)

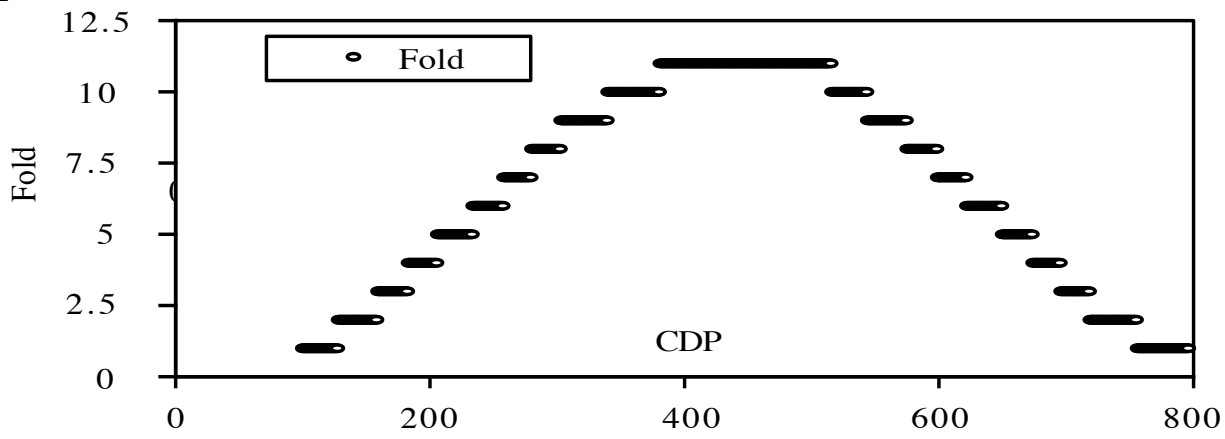

Fig. 2 


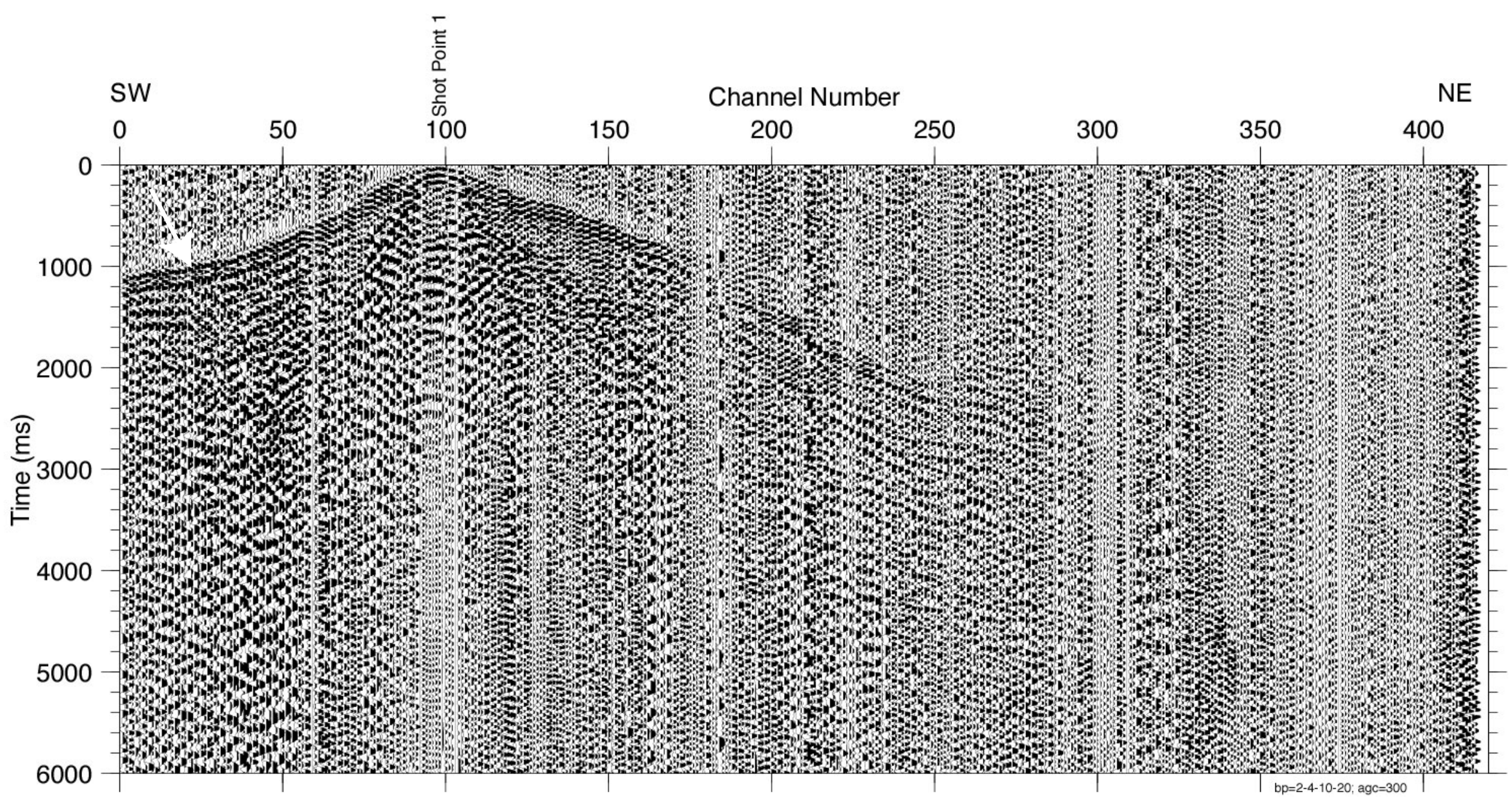

Fig 3a 


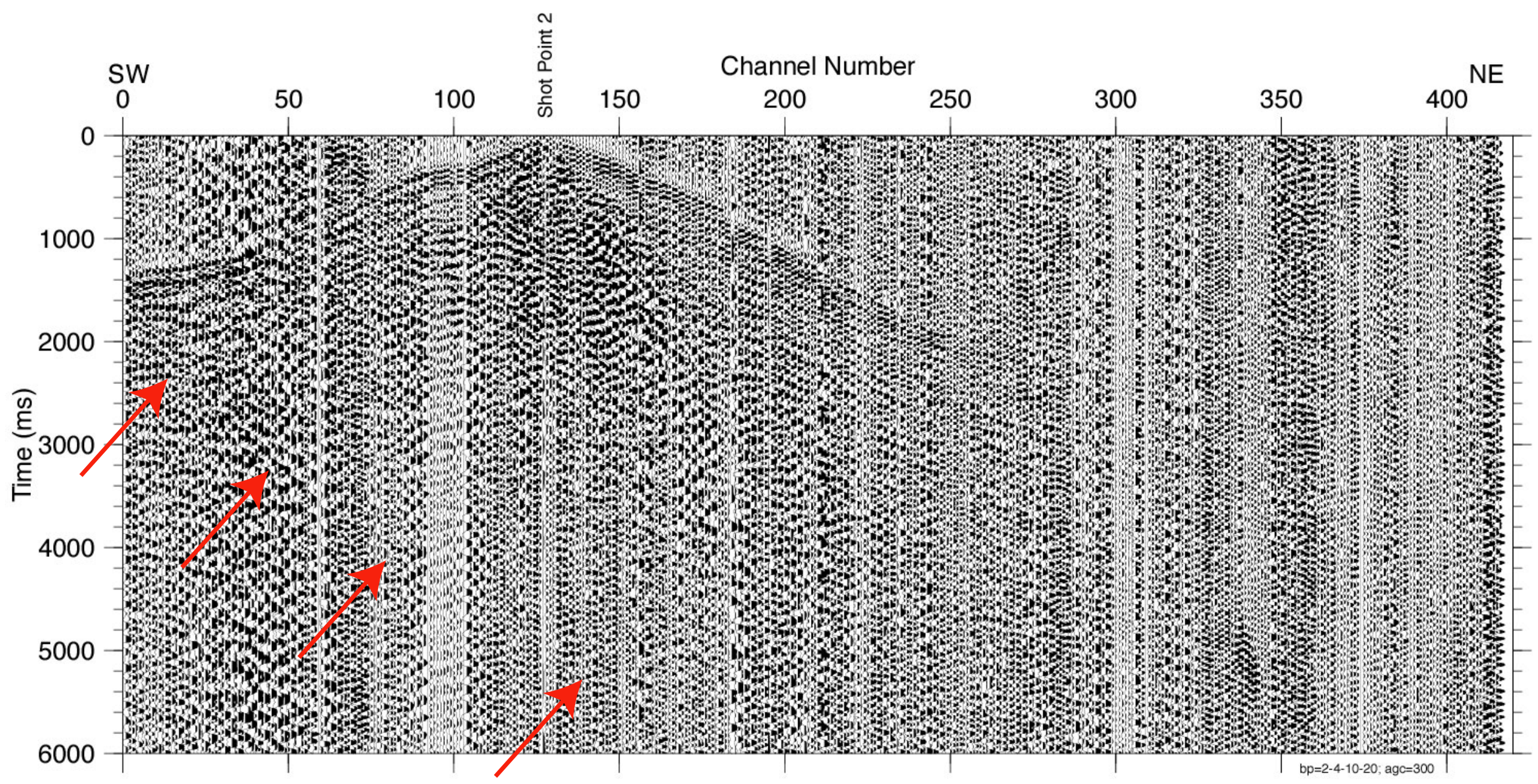

Fig. 3b 


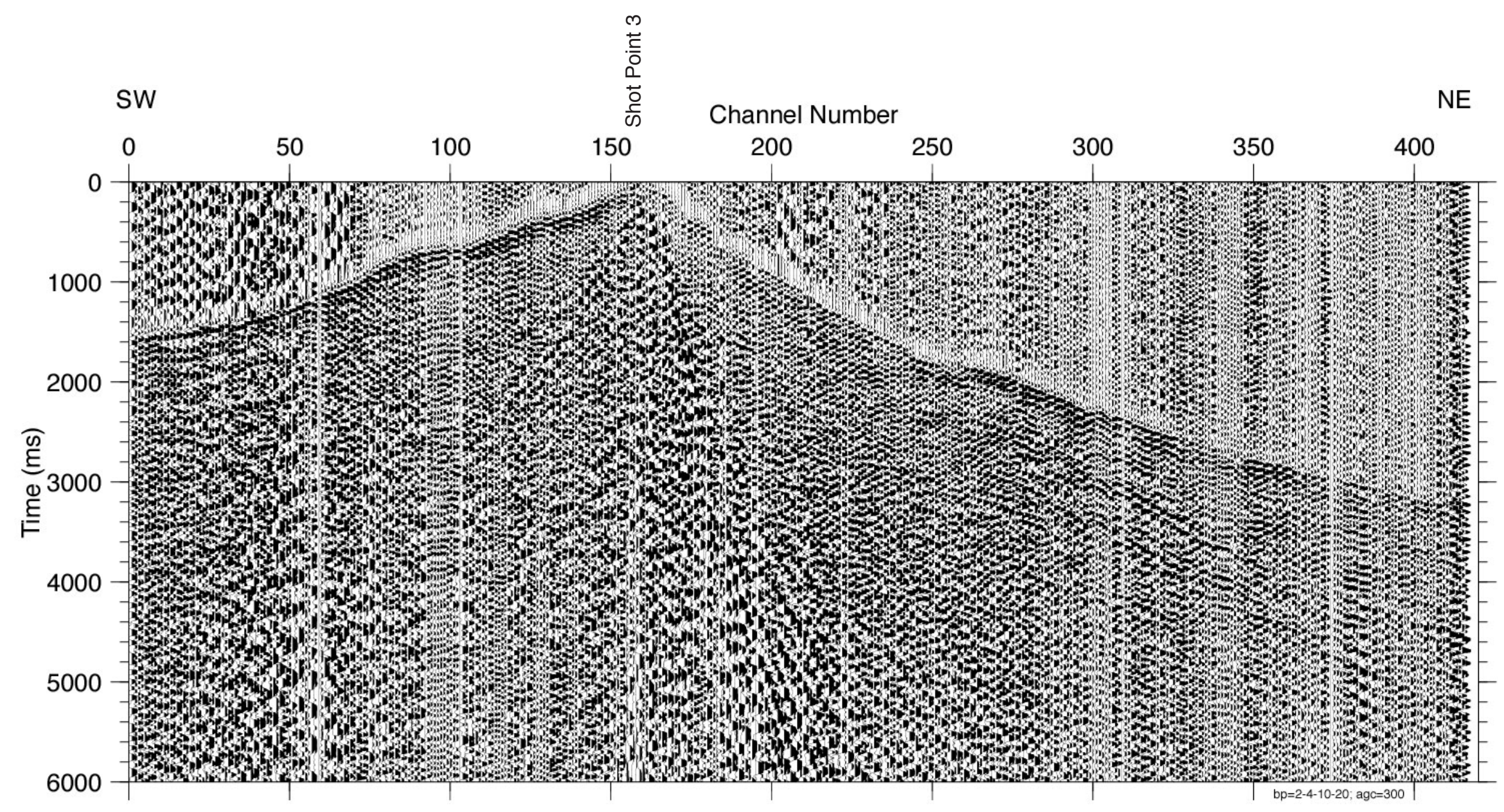

Fig. 3c 


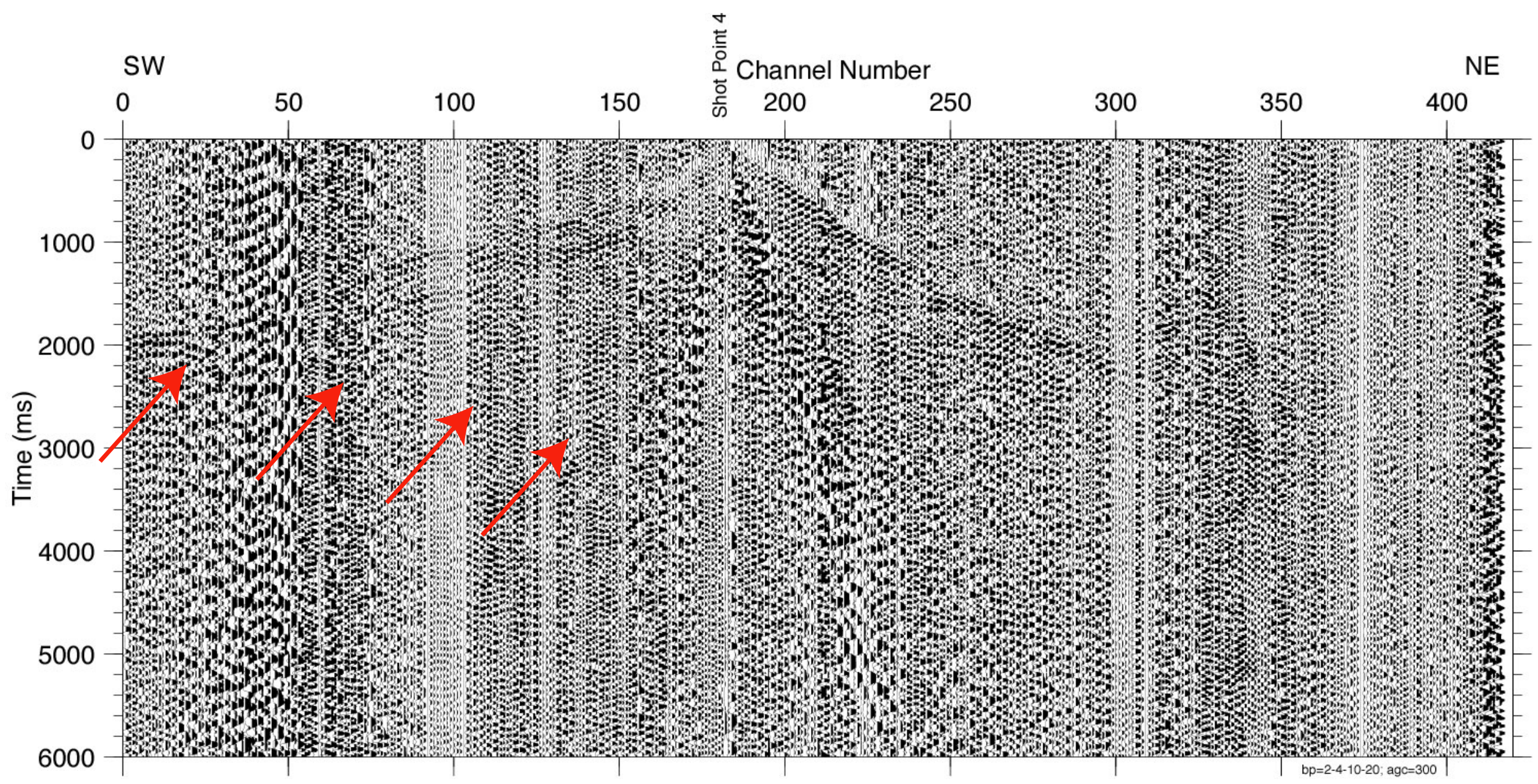

Fig. 3d 


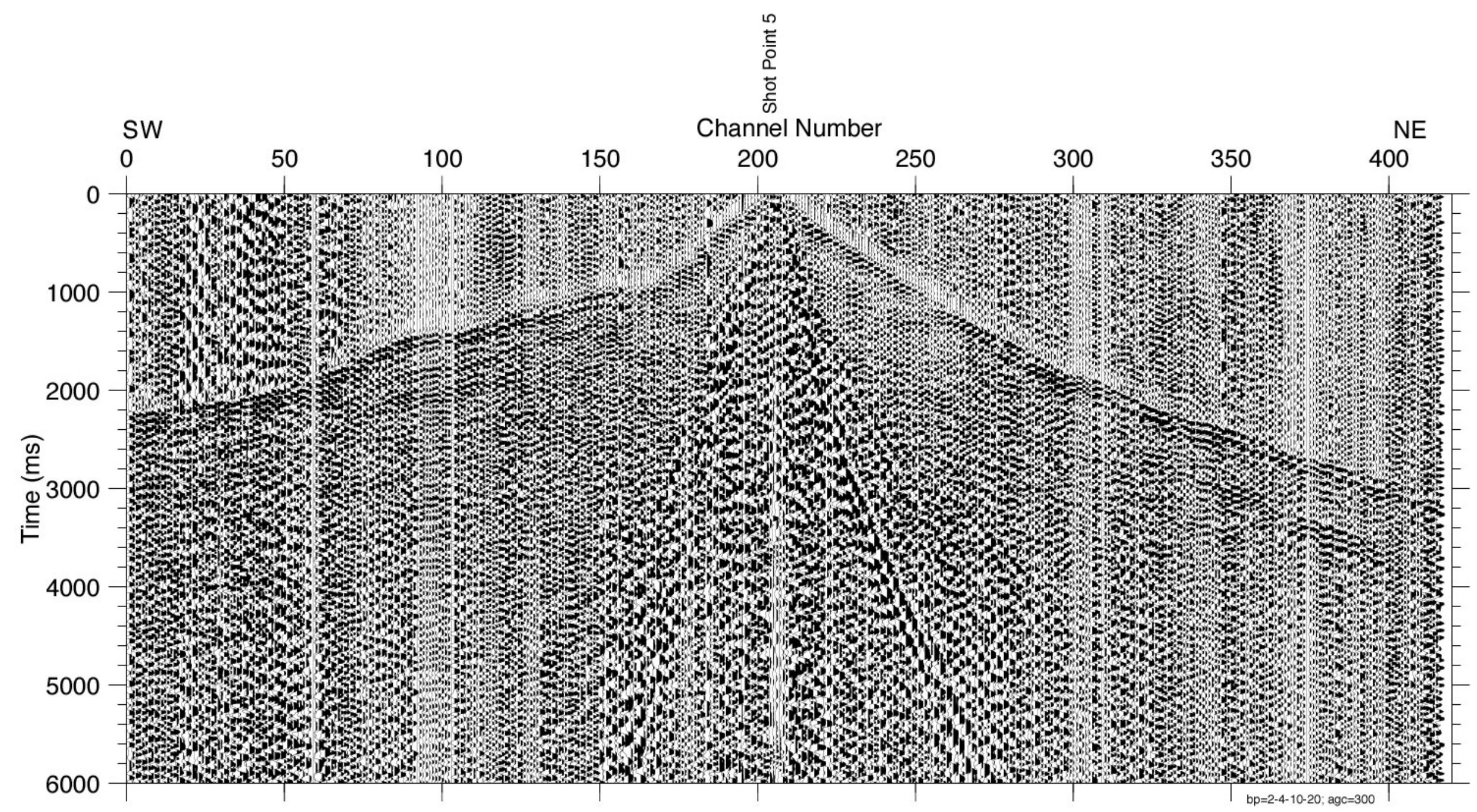

Fig. 3e 


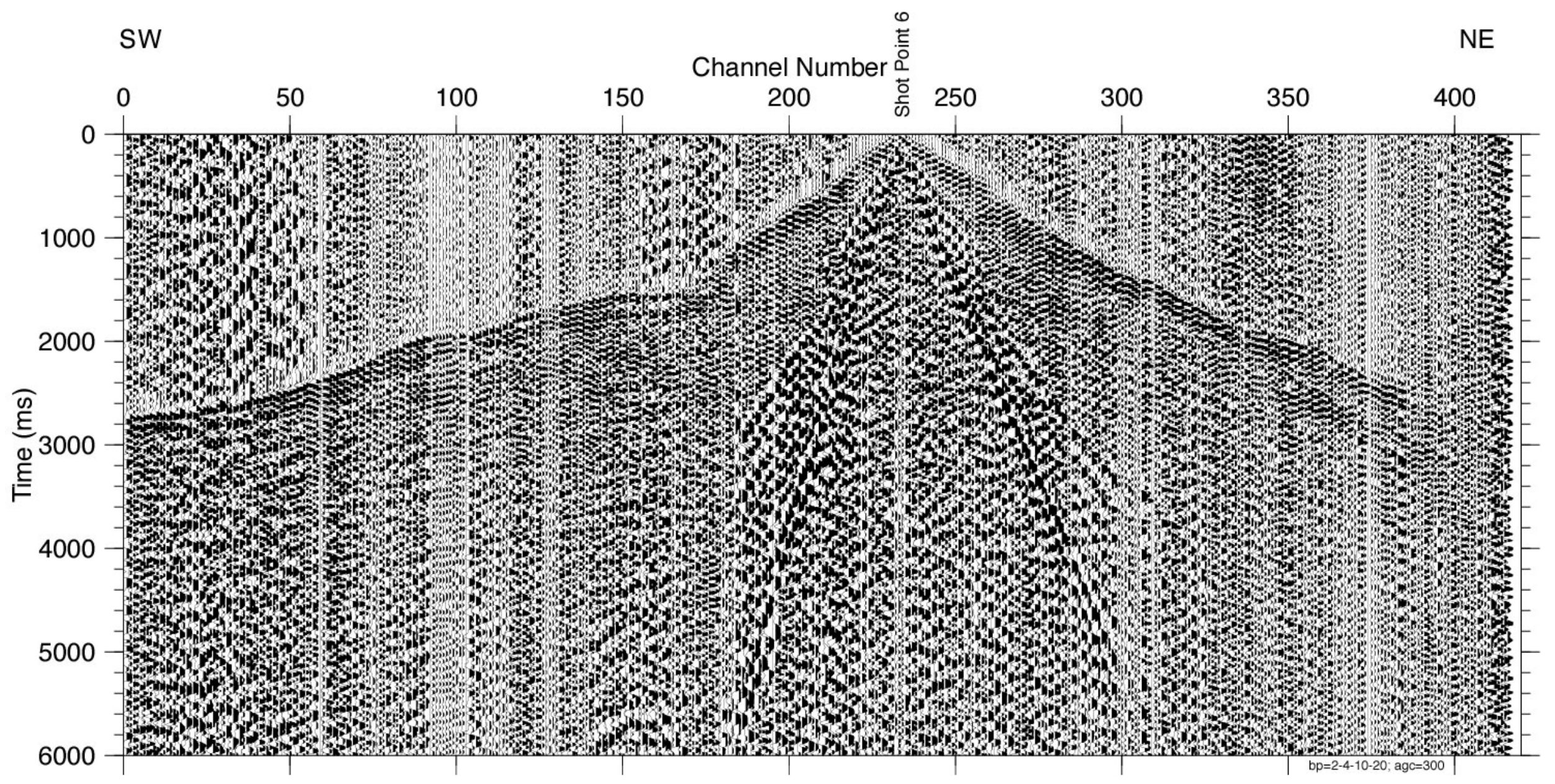

Fig. 3f 


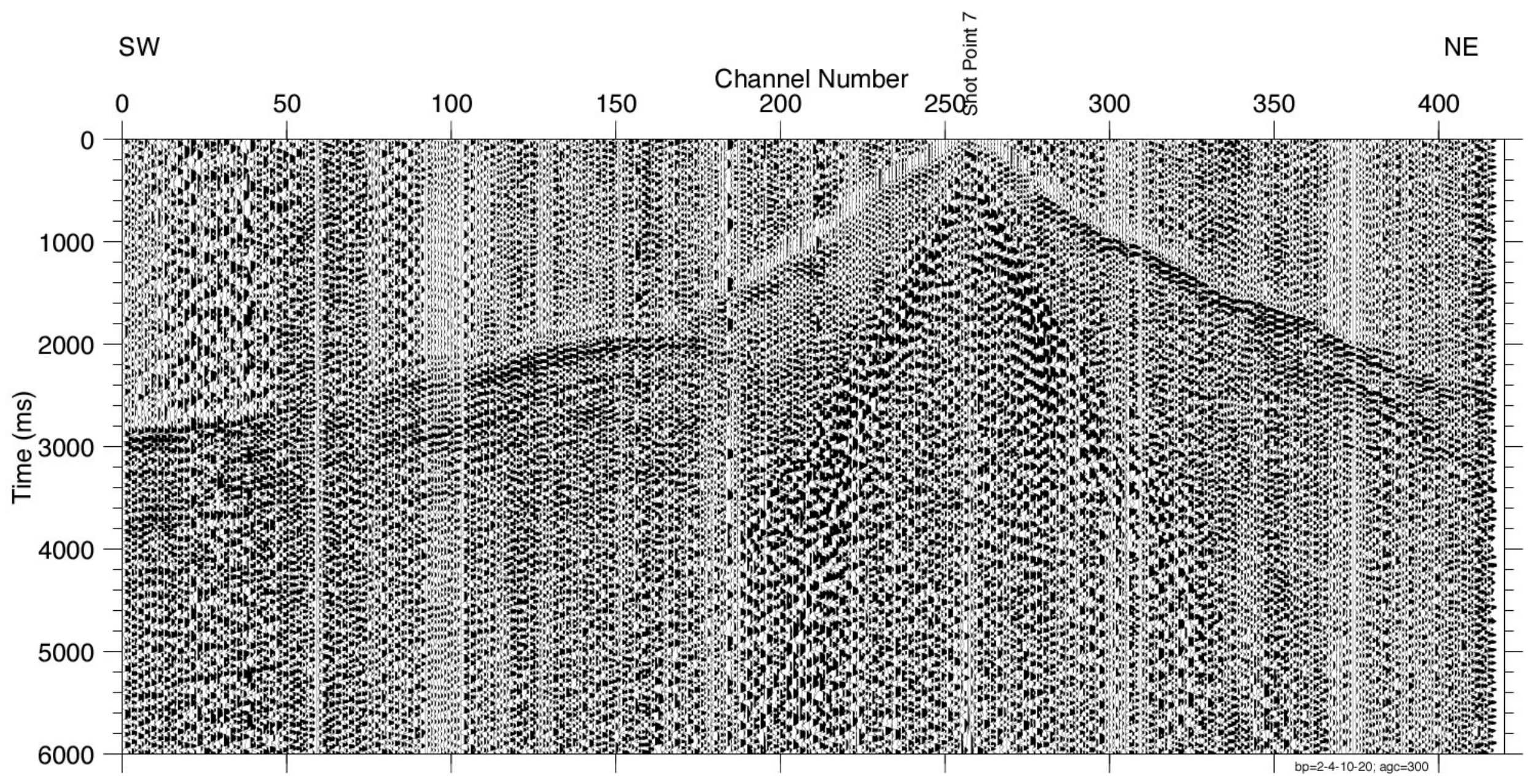

Fig. 3g 


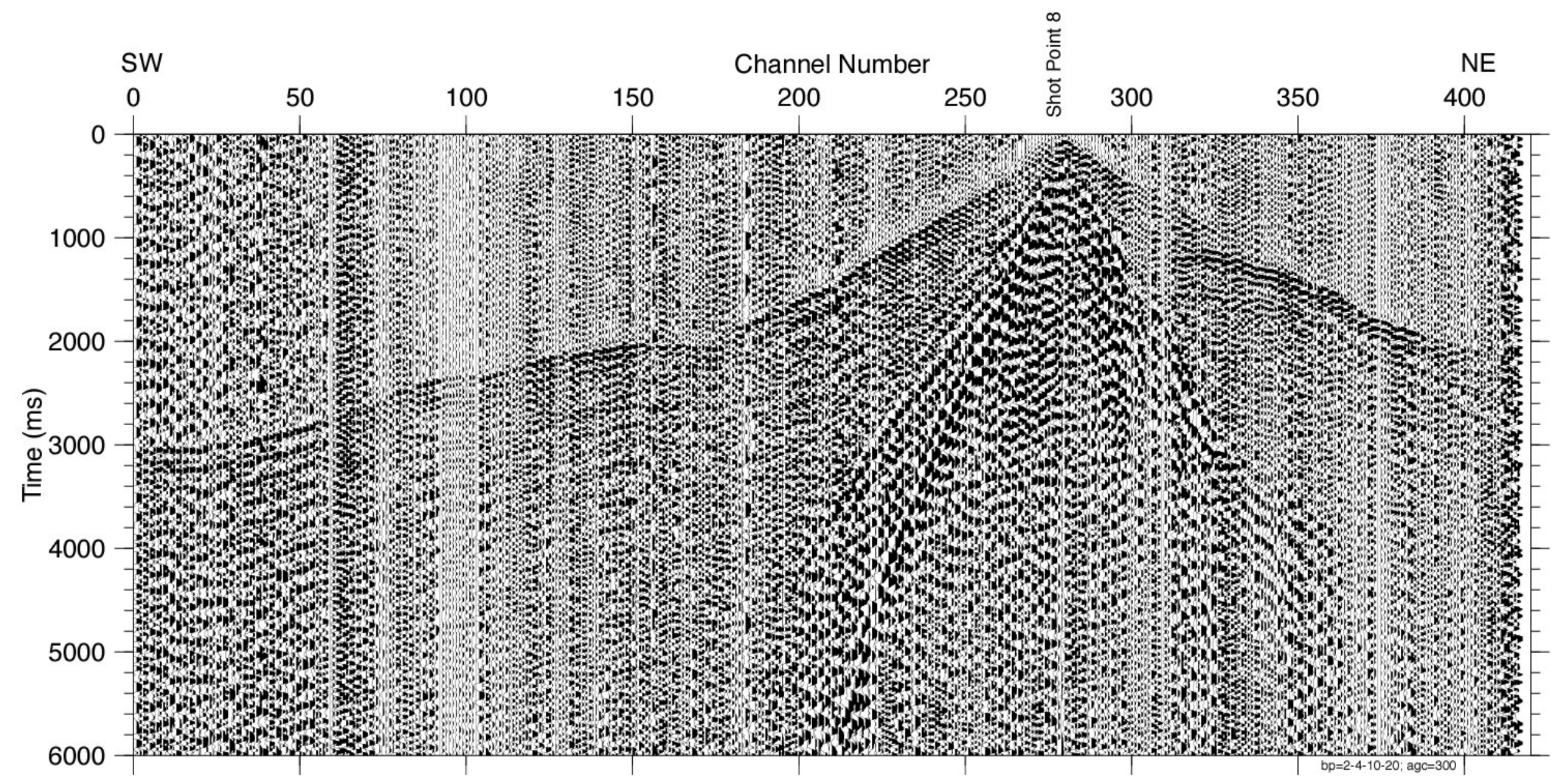

Fig. 3h 


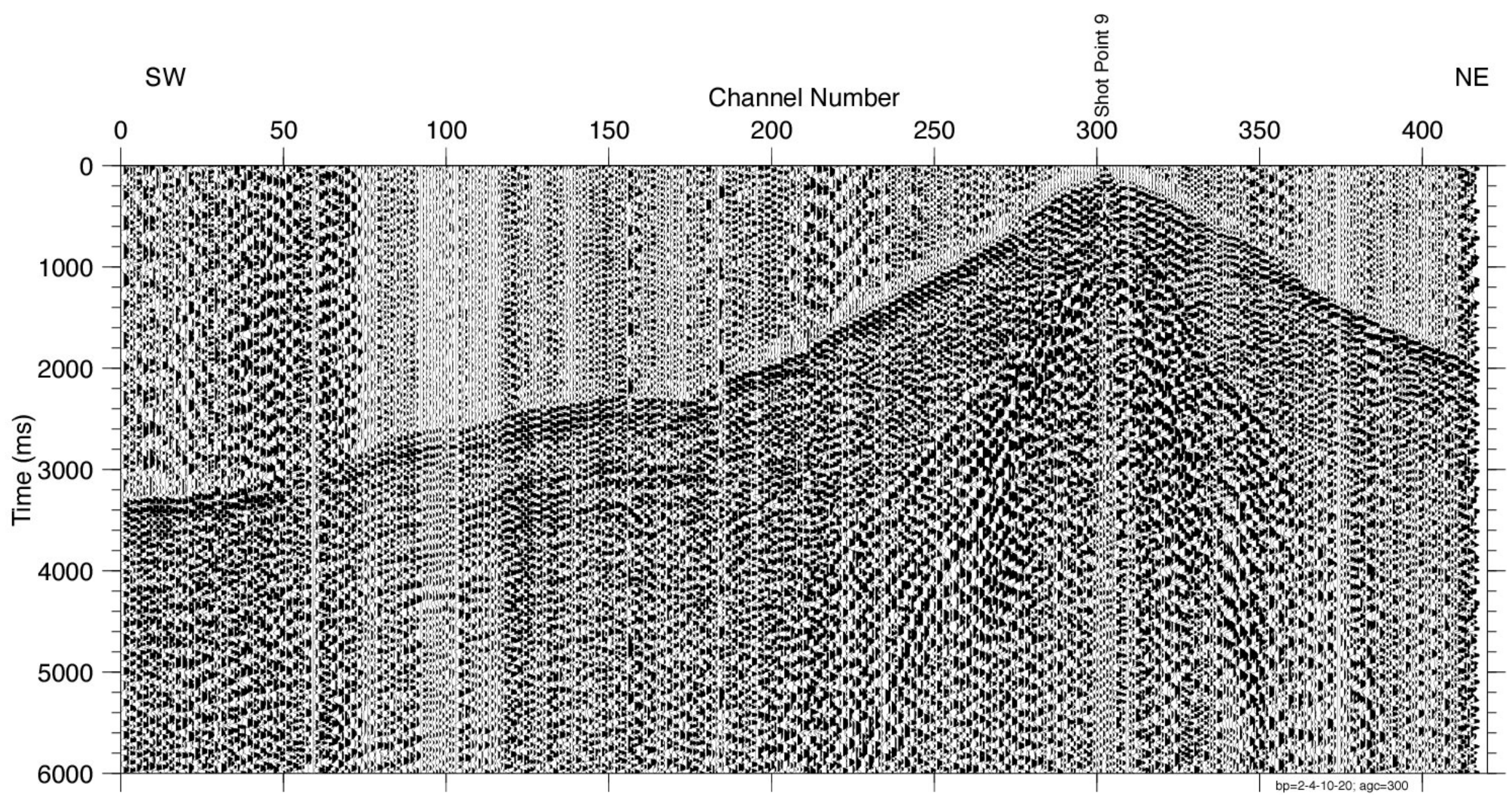

Fig. 3i 


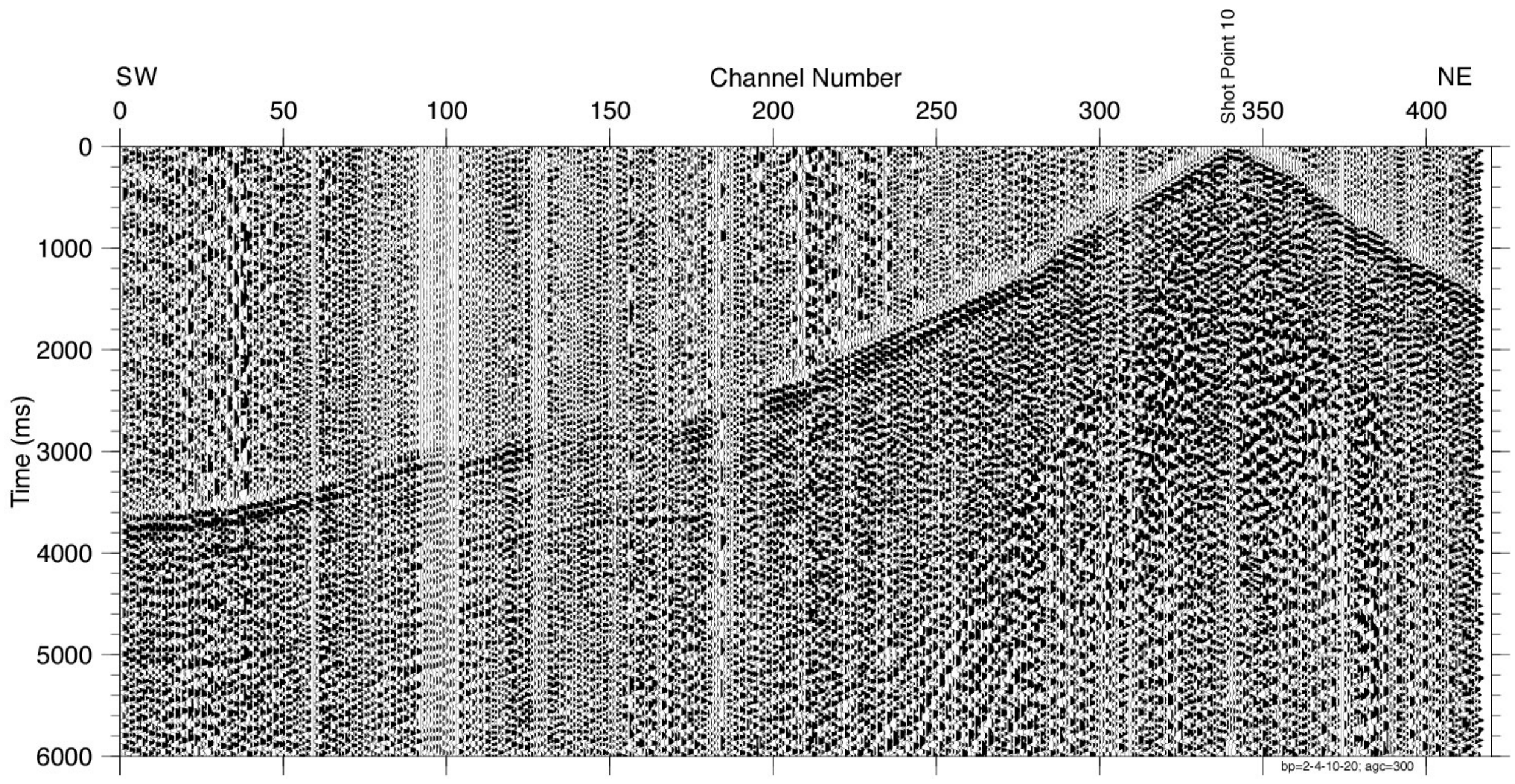

Fig. 3j 


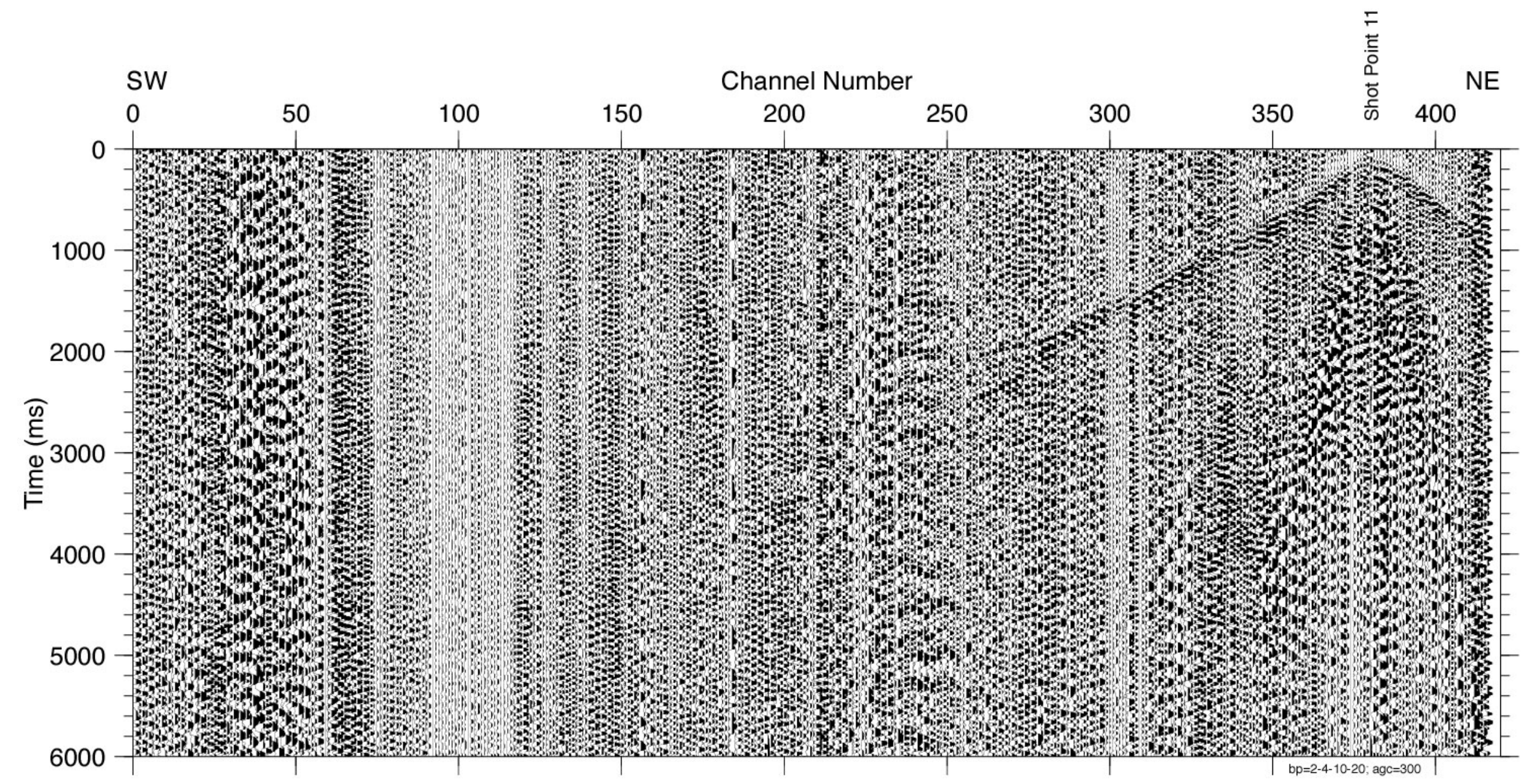

Fig. 3k 

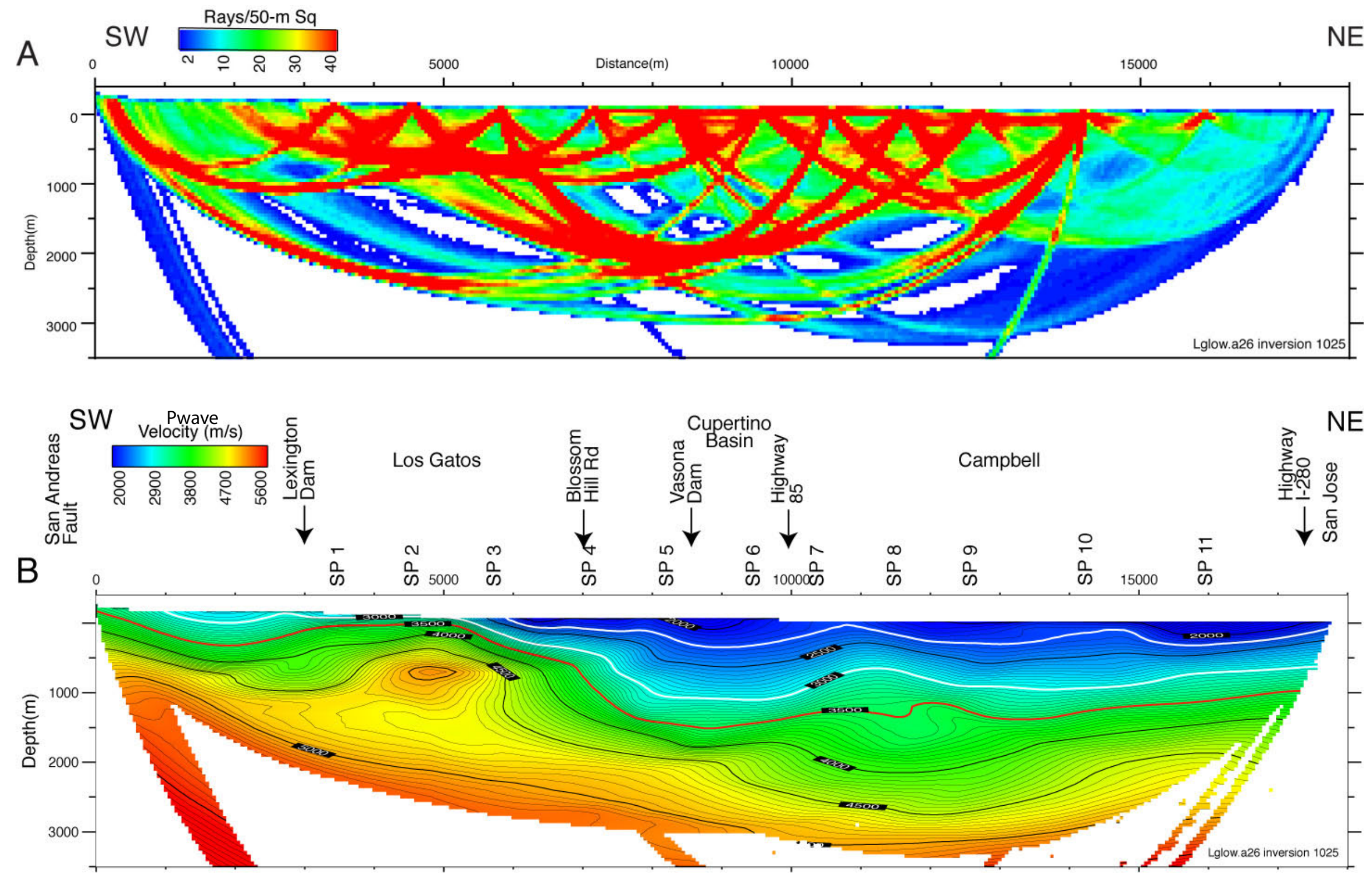

Fig. 4 

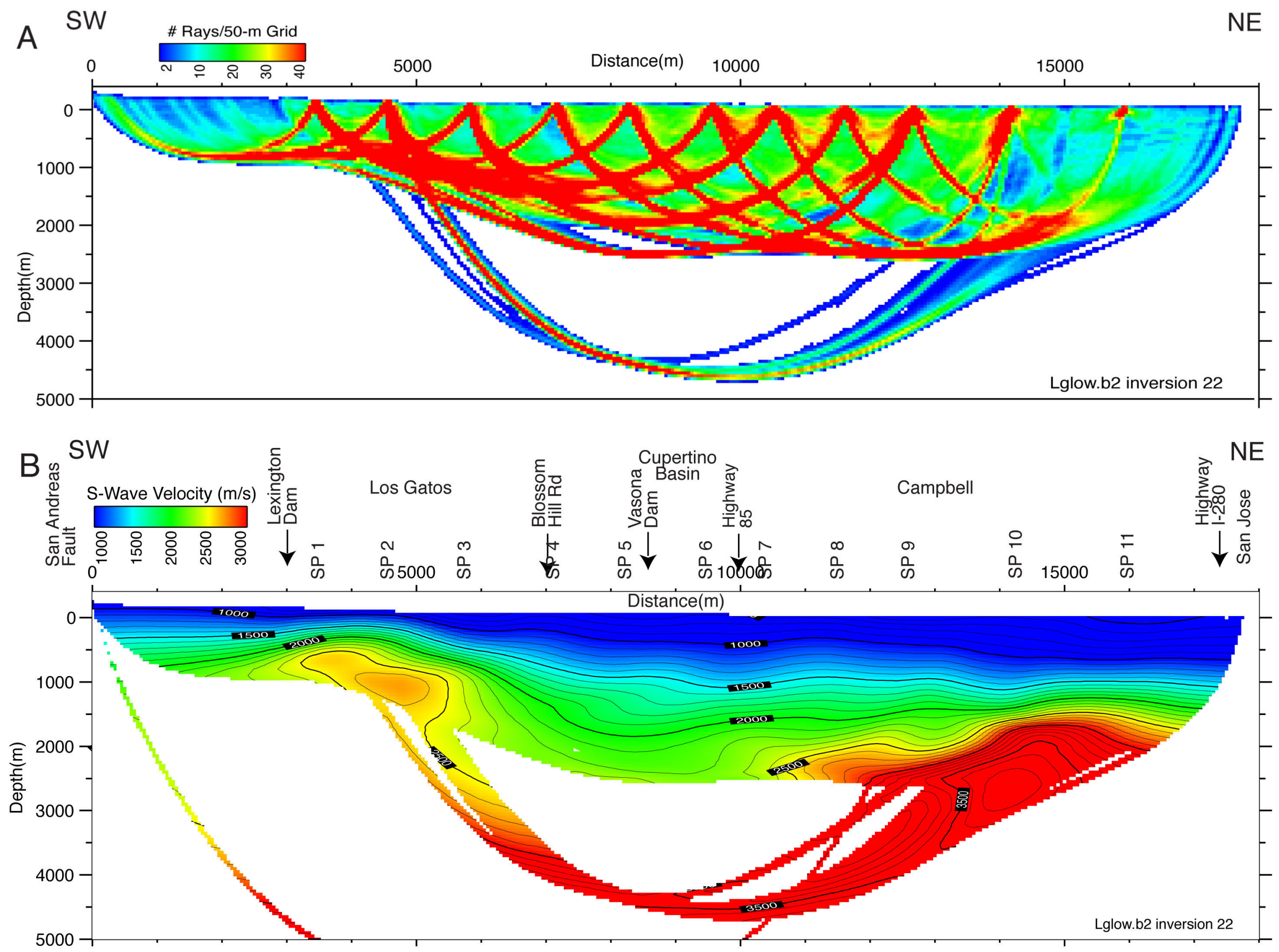

Fig. 5 

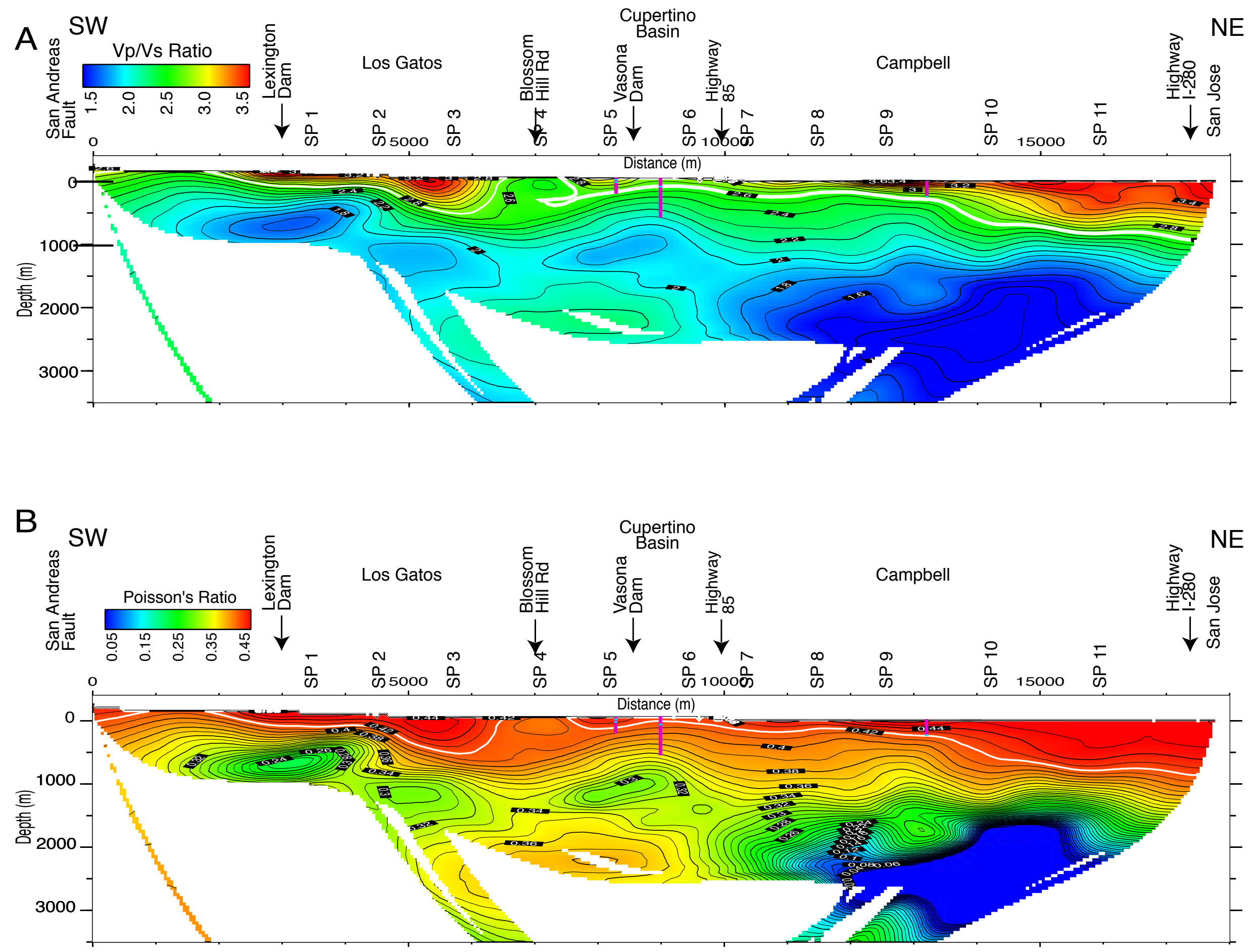

Fig. 6 


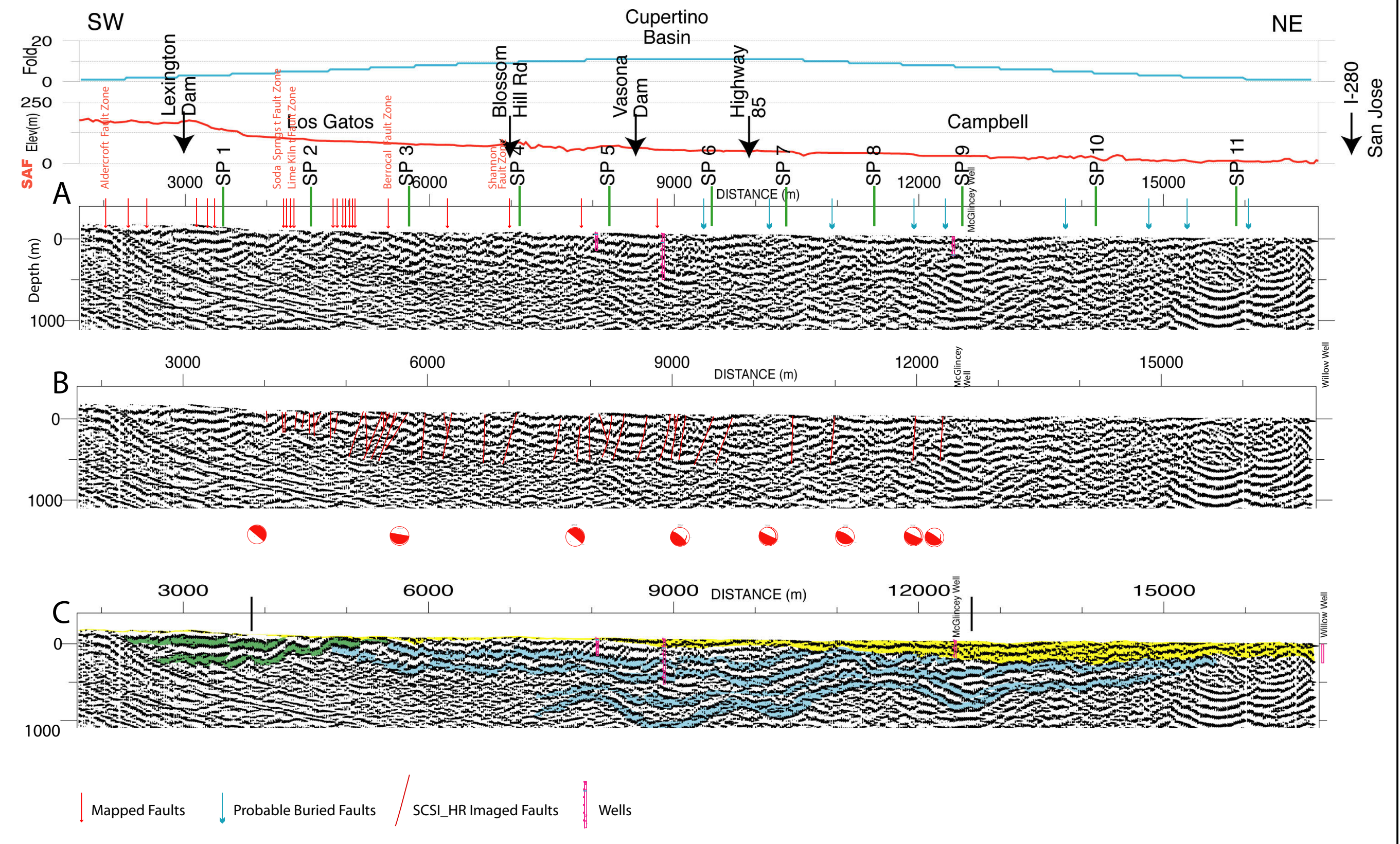

Fig. 7 

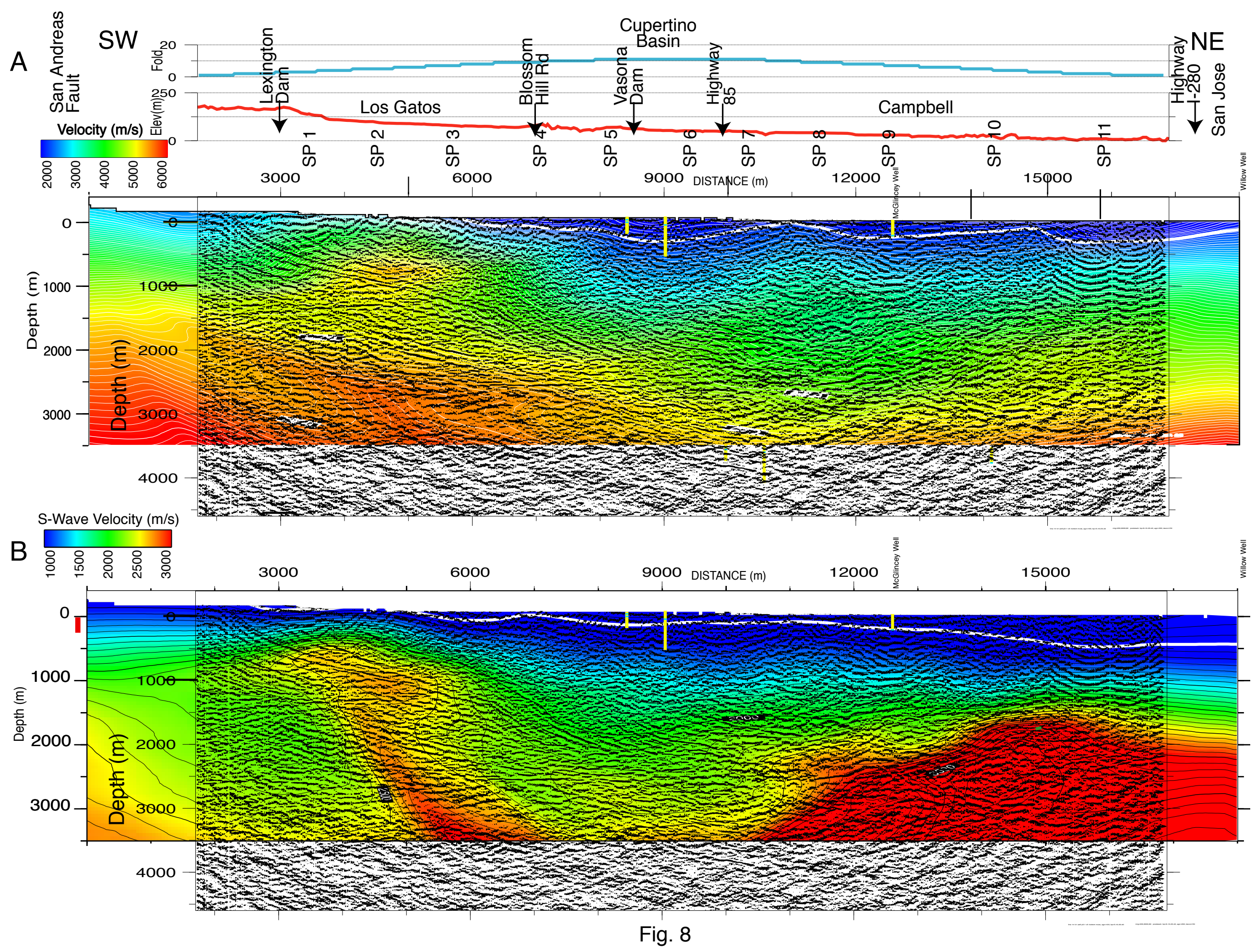

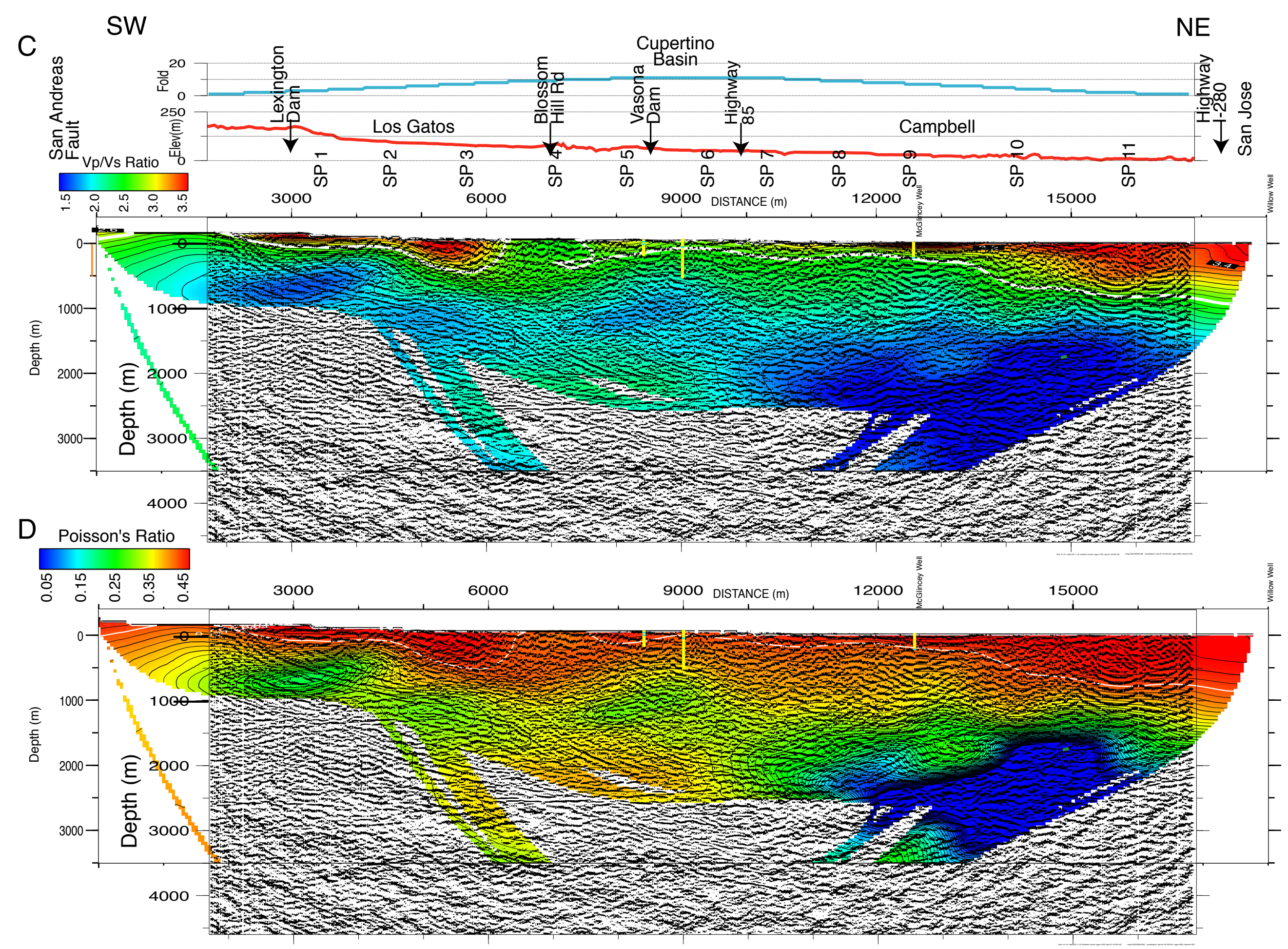

Fig. 8 


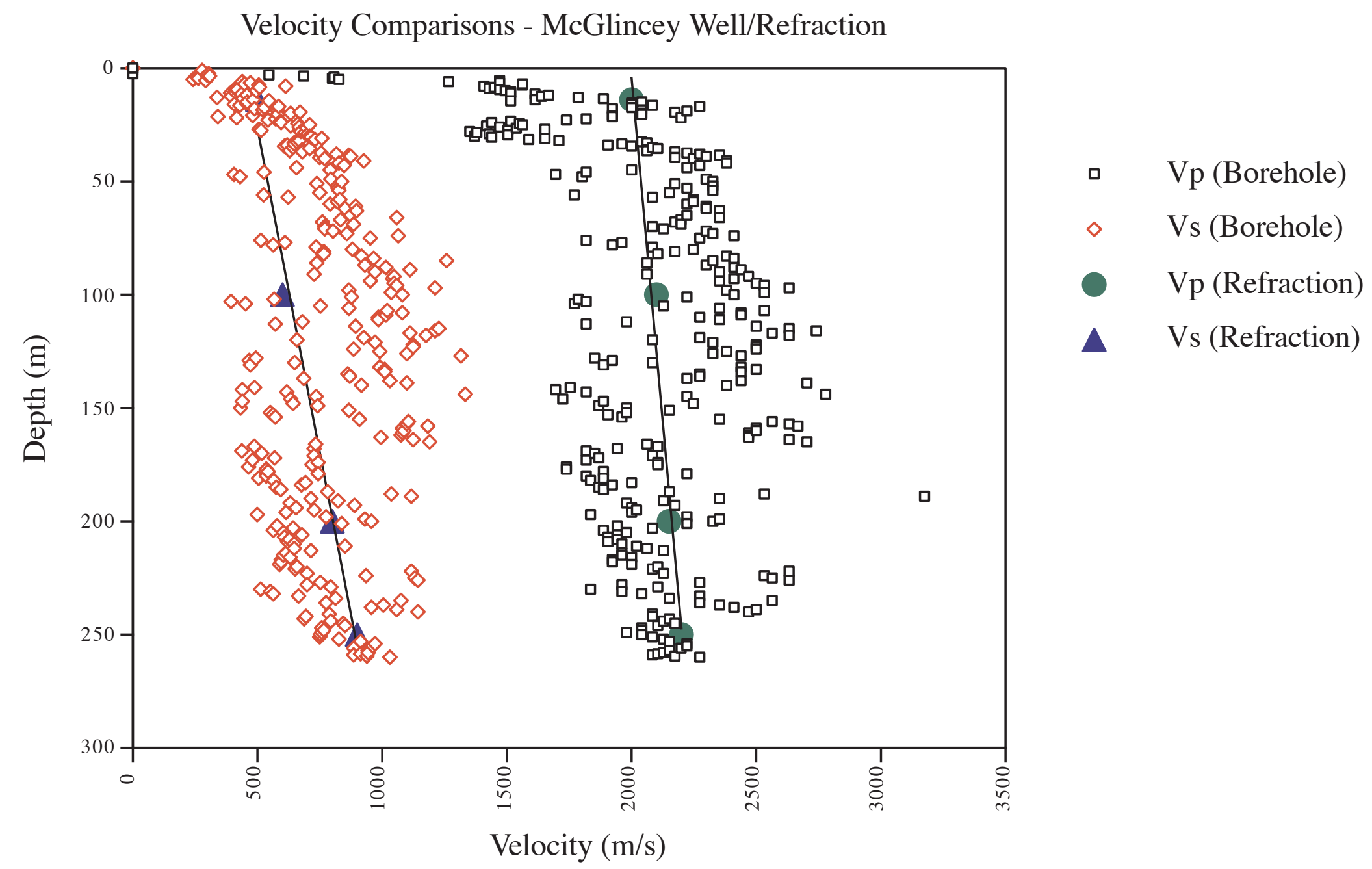

Fig. 9 

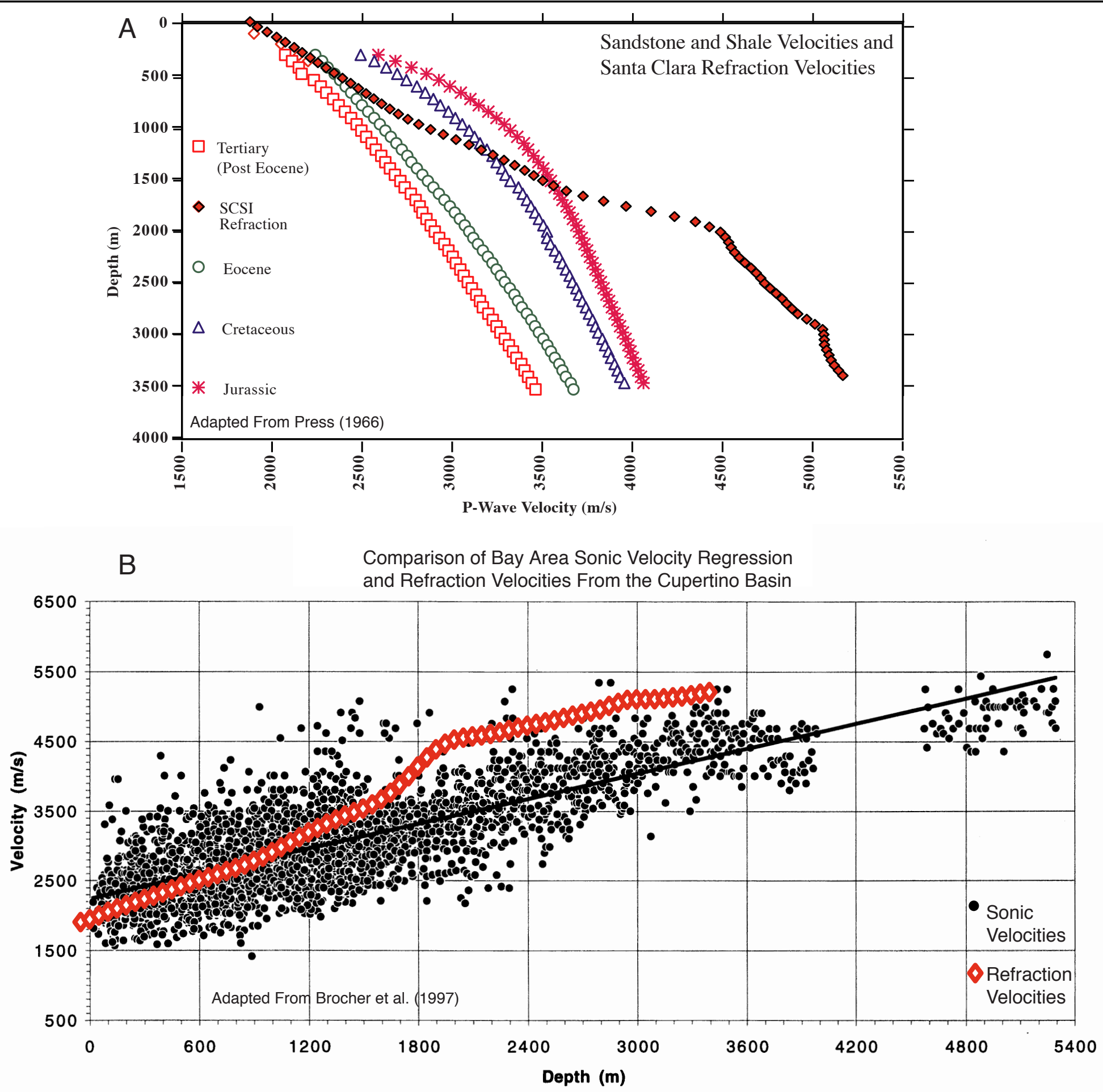

Fig. 10 


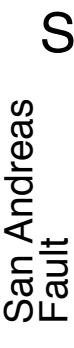

SW
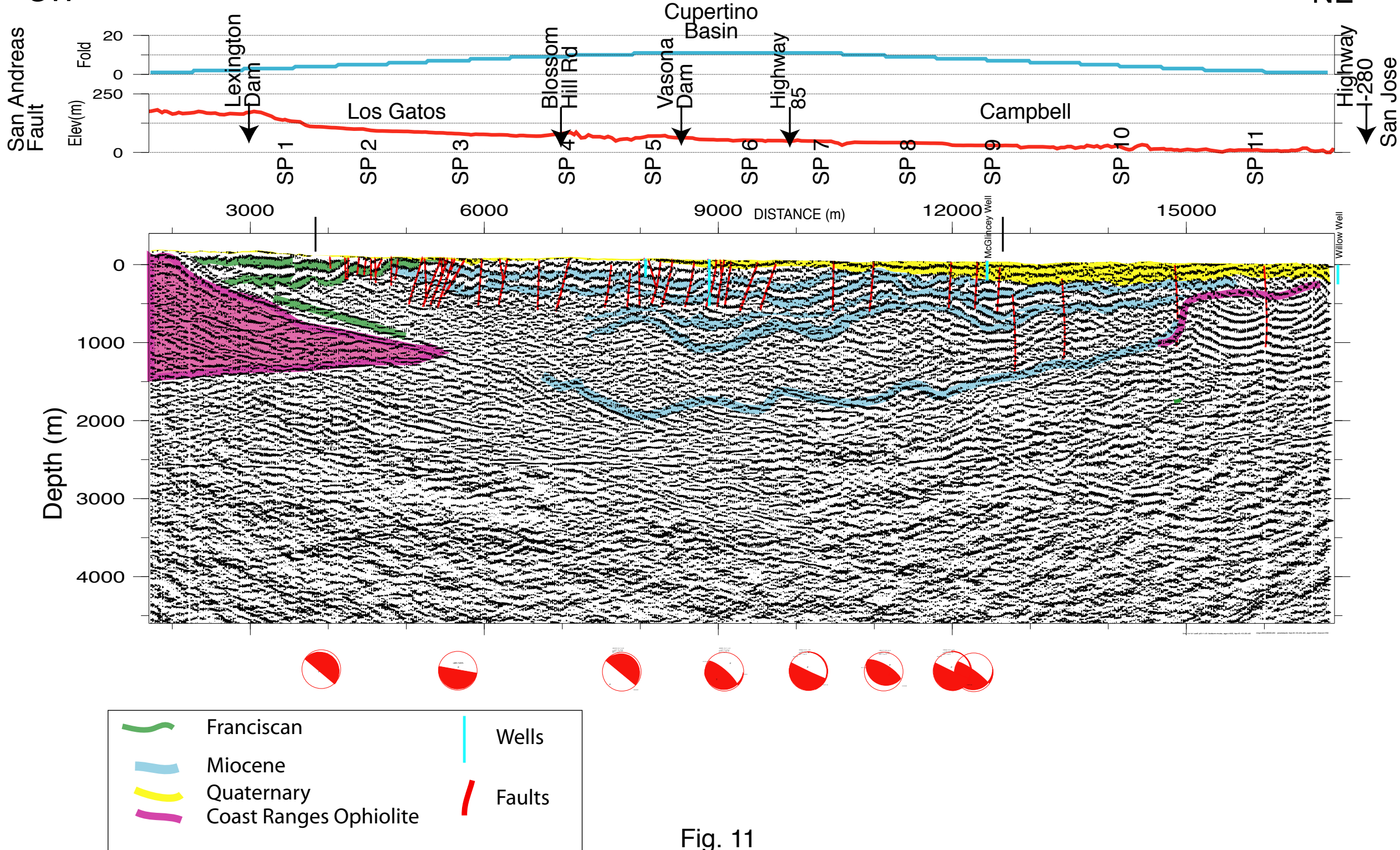

Fig. 11 


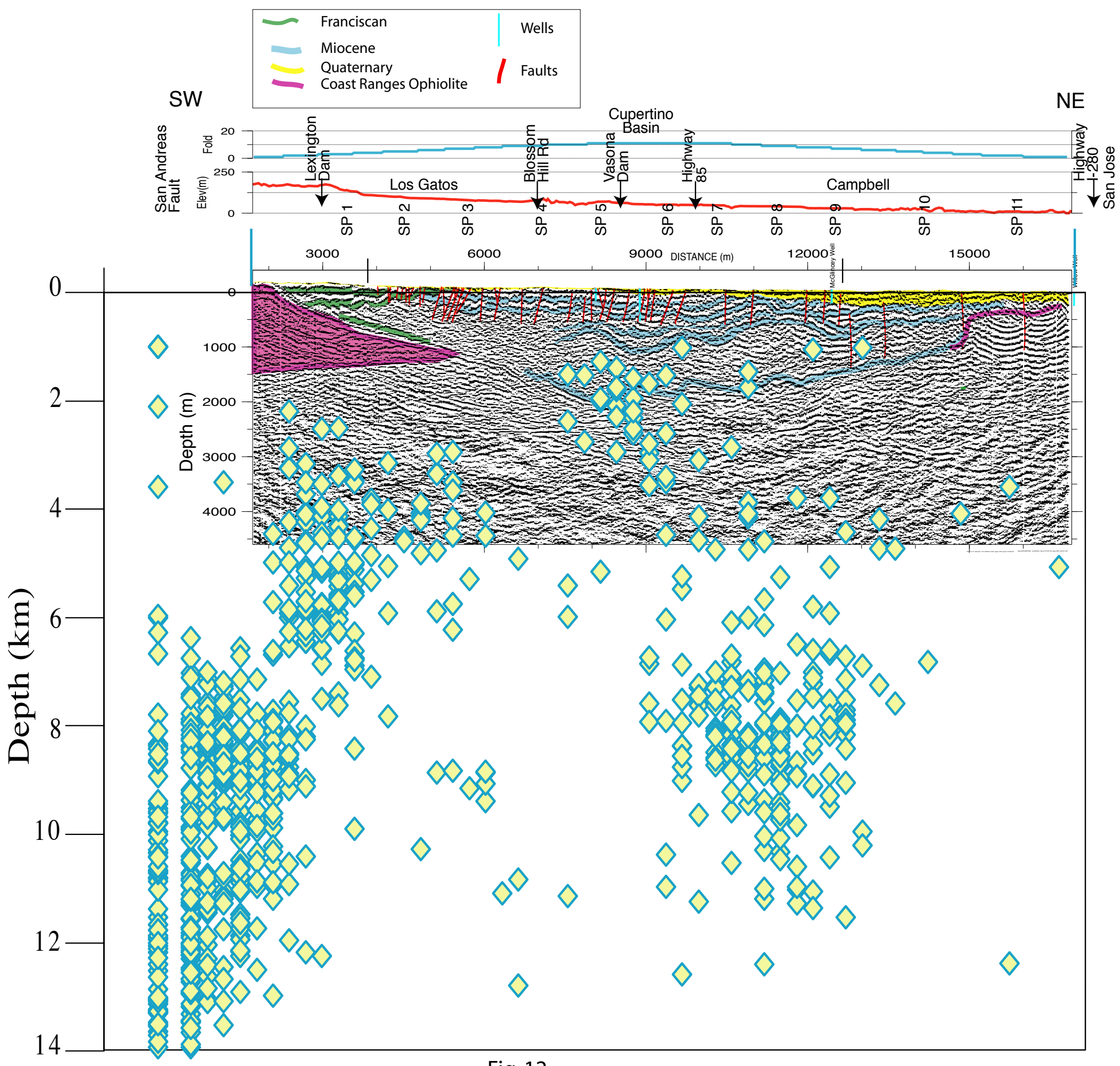

Fig. 12 


\section{Appendix 1 Shot Point Locations}

\begin{tabular}{rrrrrrr}
$\begin{array}{c}\text { Shot } \\
\text { Point } \\
\text { Number }\end{array}$ & $\begin{array}{r}\text { Nearest } \\
\text { Station }\end{array}$ & $\begin{array}{c}\text { Dist }(\mathrm{m}) \\
\text { Along } \\
\text { Profile }\end{array}$ & $\begin{array}{c}\text { Lateral Dist } \\
(\mathrm{m}) \text { From }\end{array}$ & $\begin{array}{c}\text { Elevation } \\
\text { Profile }\end{array}$ & $\begin{array}{c}\text { UTM } \\
\text { Northing }\end{array}$ & \multicolumn{1}{c}{$\begin{array}{c}\text { UTM } \\
\text { Easting }\end{array}$} \\
1001 & 99 & 3440.79 & 0 & 140.22 & 4118014.9 & 589542.1 \\
1002 & 127 & 4552.43 & -103.18 & 116 & 4119058 & 589940 \\
1003 & 158 & 5828.47 & -53.07 & 74 & 4120181 & 590548 \\
1004 & 182 & 7152.01 & 184.29 & 76 & 4121264 & 591345 \\
1005 & 205 & 8288.63 & -3.83 & 70.94 & 4122367 & 591677.7 \\
1006 & 233 & 9561.46 & -175.57 & 51.87 & 4123585 & 592085.2 \\
1007 & 257 & 10533.85 & 127.25 & 0.43 & 4124324 & 592786 \\
1008 & 279 & 11616.69 & -51.03 & 39.73 & 4125374.4 & 593103.8 \\
1009 & 302 & 12667.49 & 135.68 & 24 & 4126235 & 593735 \\
1010 & 342 & 14196.01 & 82.82 & 15 & 4127630 & 594362 \\
1011 & 379 & 15925.97 & 0 & 14 & 4129219 & 595051
\end{tabular}


Appendix 2 Seismograph Locations Along Profile

\begin{tabular}{|c|c|c|c|}
\hline Station \# & $\begin{array}{c}\text { Dist }(m) \text { Along } \\
\text { Profile }\end{array}$ & $\begin{array}{l}\text { Lateral Dist }(\mathrm{m}) \\
\text { From Profile }\end{array}$ & Elevation $(\mathrm{m})$ \\
\hline 1 & 0 & 2597.63 & 251 \\
\hline 2 & 24.47 & 2549.94 & 259 \\
\hline 3 & 44.44 & 2506.7 & 243 \\
\hline 4 & 80.04 & 2465.79 & 247 \\
\hline 5 & 106.63 & 2436 & 238 \\
\hline 6 & 146.2 & 2403.17 & 226 \\
\hline 7 & 166.02 & 2382.29 & 228 \\
\hline 8 & 186.29 & 2360.06 & 230 \\
\hline 9 & 192.39 & 2318.06 & 231 \\
\hline 10 & 162.75 & 2269.12 & 224 \\
\hline 11 & 225.21 & 2223.92 & 231 \\
\hline 12 & 258.55 & 2187.47 & 228 \\
\hline 13 & 283.45 & 2142.91 & 222 \\
\hline 14 & 282 & 2092.36 & 222 \\
\hline 15 & 285.88 & 2045.88 & 219 \\
\hline 16 & 316.13 & 2003.15 & 206 \\
\hline 17 & 296.7 & 1965.9 & 193 \\
\hline 18 & 319 & 1909.25 & 203 \\
\hline 19 & 365.5 & 1910.9 & 199 \\
\hline 20 & 408.56 & 1891.96 & 203 \\
\hline 21 & 444.1 & 1860 & 201 \\
\hline 22 & 489.79 & 1848.67 & 192 \\
\hline 23 & 539 & 1846.77 & 191 \\
\hline 24 & 559 & 1799.05 & 184 \\
\hline 25 & 583.42 & 1758.06 & 171 \\
\hline 26 & 602.96 & 1711.68 & 171 \\
\hline 27 & 650.12 & 1680.69 & 172 \\
\hline 28 & 684.29 & 1654.98 & 167 \\
\hline 29 & 727.39 & 1629.33 & 178 \\
\hline 30 & 761.65 & 1587.97 & 173 \\
\hline 31 & 781.62 & 1544.72 & 172 \\
\hline 32 & 808.25 & 1508.22 & 175 \\
\hline 33 & 839.85 & 1463.71 & 172 \\
\hline 34 & 882.09 & 1434.03 & 178 \\
\hline 35 & 926.02 & 1419.12 & 181 \\
\hline 36 & 977.52 & 1408.28 & 181 \\
\hline 37 & 1024.98 & 1400.55 & 180 \\
\hline 38 & 1070.29 & 1379.38 & 179 \\
\hline 39 & 1112.95 & 1352.84 & 186 \\
\hline 40 & 1153.84 & 1324.93 & 191 \\
\hline 41 & 1175.13 & 1284.38 & 189 \\
\hline 42 & 1213.36 & 1251.09 & 186 \\
\hline 43 & 1244.48 & 1212.39 & 173 \\
\hline 44 & 1283.54 & 1189.84 & 157 \\
\hline 45 & 1321.27 & 1164.6 & 169 \\
\hline 46 & 1358.99 & 1141.6 & 181 \\
\hline 47 & 1406.2 & 1103.9 & 190 \\
\hline
\end{tabular}




\begin{tabular}{|c|c|c|c|}
\hline 48 & 1430.6 & 1067.39 & 186 \\
\hline 49 & 1459.96 & 1022.86 & 177 \\
\hline 50 & 1491.07 & 986.4 & 179 \\
\hline 51 & 1531.95 & 958.5 & 179 \\
\hline 52 & 1582.57 & 945.87 & 172 \\
\hline 53 & 1632.23 & 942.62 & 179 \\
\hline 54 & 1680.27 & 915.66 & 175 \\
\hline 55 & 1727.31 & 902.56 & 176 \\
\hline 56 & 1770.84 & 880.04 & 180 \\
\hline 57 & 1810.42 & 847.21 & 182 \\
\hline 58 & 1836.25 & 795.5 & 172 \\
\hline 59 & 1868.25 & 758.6 & 170 \\
\hline 60 & 1898.5 & 715.86 & 176 \\
\hline 61 & 1930.47 & 683.43 & 175 \\
\hline 62 & 1961.18 & 639.36 & 167 \\
\hline 63 & 2002.52 & 610.12 & 164 \\
\hline 64 & 2044.71 & 587.15 & 166 \\
\hline 65 & 2082.98 & 549.39 & 171 \\
\hline 66 & 2106.22 & 483.35 & 171 \\
\hline 67 & 2132.15 & 418.23 & 166 \\
\hline 68 & 2164.24 & 367.91 & 170 \\
\hline 69 & 2219.89 & 338.32 & 168 \\
\hline 70 & 2278.21 & 311.87 & 170 \\
\hline 71 & 2336.42 & 301.08 & 175 \\
\hline 72 & 2385.81 & 272.34 & 173 \\
\hline 73 & 2440.85 & 266.45 & 168 \\
\hline 74 & 2494.18 & 250.26 & 167 \\
\hline 75 & 2549.75 & 234.08 & 168 \\
\hline 76 & 2608.46 & 215.24 & 162 \\
\hline 77 & 2665.82 & 198.18 & 161 \\
\hline 78 & 2738.37 & 182.56 & 166 \\
\hline 79 & 2859.87 & 271.03 & 164 \\
\hline 80 & 2913.63 & 257.97 & 164 \\
\hline 81 & 2950.48 & 230.94 & 170 \\
\hline 82 & 2974.46 & 189.06 & 175 \\
\hline 83 & 2993.19 & 129.7 & 171 \\
\hline 84 & 3046.87 & 127.83 & 175 \\
\hline 85 & 3087.3 & 101.26 & 173 \\
\hline 86 & 3137.45 & 92.21 & 171 \\
\hline 87 & 3184.91 & 84.47 & 165 \\
\hline 88 & 3233.76 & 68.25 & 157 \\
\hline 89 & 3274.17 & 43.92 & 154 \\
\hline 90 & 3319.12 & 10.68 & 145 \\
\hline 91 & 3371.06 & 0.74 & 141 \\
\hline 92 & 3398.74 & -18.89 & 138.44 \\
\hline 93 & 3409.76 & -21.18 & 138.12 \\
\hline 94 & 3417.07 & -23.55 & 138.05 \\
\hline 95 & 3420.43 & -24.87 & 138.19 \\
\hline 96 & 3431.72 & -28.19 & 138.27 \\
\hline 97 & 3443.42 & -32.94 & 137.86 \\
\hline 98 & 3455.57 & -36.57 & 137.47 \\
\hline 99 & 3443.66 & -0.96 & 140.26 \\
\hline
\end{tabular}




\begin{tabular}{|c|c|c|c|}
\hline 100 & 3465.58 & -42.05 & 137.02 \\
\hline 101 & 3479.12 & -47.37 & 135.9 \\
\hline 102 & 3488 & -51.52 & 135.33 \\
\hline 103 & 3496.89 & -55.66 & 135 \\
\hline 104 & 3479.4 & -35.92 & 136.48 \\
\hline 105 & 3523.75 & -59.96 & 133.48 \\
\hline 106 & 3580.65 & -56.18 & 131.82 \\
\hline 107 & 3636.01 & -7.51 & 130.45 \\
\hline 108 & 3710.88 & 11.95 & 116.04 \\
\hline 109 & 3763.66 & -16.45 & 111 \\
\hline 110 & 3822.76 & -33.36 & 110 \\
\hline 111 & 3877.37 & -46.73 & 109.78 \\
\hline 112 & 3925.8 & -65.86 & 108.96 \\
\hline 113 & 3961.13 & -99.84 & 107.86 \\
\hline 114 & 3998.17 & -134.43 & 106.86 \\
\hline 115 & 4040.94 & -170.28 & 105.91 \\
\hline 116 & 4086.23 & -194.66 & 105.47 \\
\hline 117 & 4133.59 & -208.03 & 104.55 \\
\hline 118 & 4188.66 & -204.58 & 103.28 \\
\hline 119 & 4236.84 & -180.02 & 101.43 \\
\hline 120 & 4278.69 & -152.01 & 100.56 \\
\hline 121 & 4329.12 & -148.72 & 99.56 \\
\hline 122 & 4397.93 & -145.89 & 100.1 \\
\hline 123 & 4445.95 & -163.82 & 99.95 \\
\hline 124 & 4495.41 & -171.31 & 96.96 \\
\hline 125 & 4544.55 & -195.81 & 93.98 \\
\hline 126 & 4526.01 & -97.99 & 119 \\
\hline 127 & 4552 & -106.31 & 114 \\
\hline 128 & 4599.09 & -126.12 & 114 \\
\hline 129 & 4651.05 & -138.3 & 120 \\
\hline 130 & 4697.18 & -148.73 & 111 \\
\hline 131 & 4582.15 & -228.11 & 92.37 \\
\hline 132 & 4620.1 & -259.03 & 92.01 \\
\hline 133 & 4656.03 & -295.42 & 91.65 \\
\hline 134 & 4691.64 & -330.42 & 91.51 \\
\hline 135 & 4730.04 & -361.12 & 91.32 \\
\hline 136 & 4774.96 & -383.54 & 91.26 \\
\hline 137 & 4822.71 & -394.98 & 90.41 \\
\hline 138 & 4873.37 & -393.48 & 90.12 \\
\hline 139 & 4969.34 & -373.25 & 89.55 \\
\hline 140 & 5018.49 & -359.86 & 89.41 \\
\hline 141 & 5065.36 & -339.33 & 88.5 \\
\hline 142 & 5106.31 & -310.66 & 87.65 \\
\hline 143 & 5149.54 & -287.79 & 87.4 \\
\hline 144 & 5201.87 & -267.94 & 86.67 \\
\hline 145 & 5245.76 & -244.39 & 87.05 \\
\hline 146 & 5290.57 & -210.37 & 85.36 \\
\hline 147 & 5335.78 & -190.26 & 84.59 \\
\hline 148 & 5380.57 & -167.15 & 83.73 \\
\hline 149 & 5428.33 & -153.19 & 83.63 \\
\hline 150 & 5474.99 & -134.9 & 83.32 \\
\hline 151 & 5525.35 & -114.31 & 81.7 \\
\hline
\end{tabular}




\begin{tabular}{|c|c|c|c|}
\hline 152 & 5577.28 & -95.71 & 81.18 \\
\hline 153 & 5627.61 & -78.79 & 80.06 \\
\hline 154 & 5675.07 & -59.11 & 79.69 \\
\hline 155 & 5717.56 & -33.42 & 78.93 \\
\hline 156 & 5761.09 & -8.35 & 77.88 \\
\hline 157 & 5804.66 & 16.8 & 76.83 \\
\hline 158 & 5828.47 & -53.07 & 75 \\
\hline 159 & 5848.27 & 41.83 & 75.78 \\
\hline 160 & 5889.16 & -66.76 & 77.89 \\
\hline 161 & 5902.52 & 61.73 & 75.67 \\
\hline 162 & 5936.62 & -67.91 & 76.96 \\
\hline 163 & 5957.03 & 76.5 & 75.18 \\
\hline 164 & 5986.57 & -67.63 & 77.13 \\
\hline 165 & 6010.86 & 99.17 & 74.33 \\
\hline 166 & 6041.6 & -64.04 & 76.36 \\
\hline 167 & 6091.68 & -63.03 & 74.83 \\
\hline 168 & 6141.32 & -62.25 & 75.16 \\
\hline 169 & 6191.84 & -60.13 & 75.2 \\
\hline 170 & 6240.69 & -55.06 & 75.16 \\
\hline 171 & 6298.79 & -49.08 & 74.2 \\
\hline 172 & 6334.66 & -2.65 & 72.1 \\
\hline 173 & 6370.84 & 43.75 & 70 \\
\hline 174 & 6411.03 & 73.58 & 70.15 \\
\hline 175 & 6453.47 & 100.07 & 72.12 \\
\hline 176 & 6498.7 & 118.17 & 72.17 \\
\hline 177 & 6547.71 & 118.36 & 70.92 \\
\hline 178 & 6606.62 & 111.02 & 70.23 \\
\hline 179 & 6665.52 & 103.67 & 69.54 \\
\hline 180 & 6724.57 & 107.74 & 69.86 \\
\hline 181 & 7104.38 & 150.88 & 85 \\
\hline 182 & 7152.04 & 179.82 & 76 \\
\hline 183 & 7178.2 & 146.9 & 86 \\
\hline 184 & 7242.31 & 55.2 & 62 \\
\hline 185 & 7291.11 & 47.92 & 64 \\
\hline 186 & 7335.87 & 41.51 & 75 \\
\hline 187 & 7390.92 & 35.62 & 67 \\
\hline 188 & 7438.41 & 23.41 & 67 \\
\hline 189 & 7483.2 & 12.53 & 67 \\
\hline 190 & 7540.18 & -14.37 & 62 \\
\hline 191 & 7585.7 & 1.14 & 68 \\
\hline 192 & 7635.28 & 9.07 & 62 \\
\hline 193 & 7685.33 & 15.67 & 49 \\
\hline 194 & 7734.52 & 16 & 55 \\
\hline 195 & 7784.19 & 12.75 & 57 \\
\hline 196 & 7833.85 & 9.5 & 58 \\
\hline 197 & 7883.89 & 16.1 & 53 \\
\hline 198 & 7938.98 & 17.54 & 62.06 \\
\hline 199 & 7993.89 & 19.52 & 62.2 \\
\hline 200 & 8043.38 & 0.97 & 64.83 \\
\hline 201 & 8100.31 & -12.2 & 69.85 \\
\hline 202 & 8147.19 & -6.16 & 69.8 \\
\hline 203 & 8205 & -3.49 & 69.99 \\
\hline
\end{tabular}




\begin{tabular}{|c|c|c|c|}
\hline 204 & 8257.87 & -5.2 & 70.3 \\
\hline 205 & 8284.14 & -1.62 & 70.94 \\
\hline 206 & 8316.65 & -0.56 & 72.01 \\
\hline 207 & 8356.5 & -8.12 & 66.32 \\
\hline 208 & 8396.71 & 17.91 & 64.68 \\
\hline 209 & 8436.97 & 44.03 & 63.04 \\
\hline 210 & 8486.97 & 83.18 & 62.48 \\
\hline 211 & 8528.66 & 115.62 & 62.28 \\
\hline 212 & 8576.47 & 142.59 & 62.66 \\
\hline 213 & 8632.2 & 128.34 & 61.57 \\
\hline 214 & 8668.88 & 87.12 & 61.6 \\
\hline 215 & 8706.64 & -23.04 & 57.92 \\
\hline 216 & 8757.77 & -98.33 & 55.4 \\
\hline 217 & 8801.23 & -123.26 & 55.19 \\
\hline 218 & 8845.99 & -155.74 & 55.02 \\
\hline 219 & 8892.6 & -184.68 & 54.57 \\
\hline 220 & 8937.75 & -215.24 & 54.44 \\
\hline 221 & 8982 & -244.24 & 53.23 \\
\hline 222 & 9031.46 & -263.76 & 53.52 \\
\hline 223 & 9080.24 & -276.05 & 53.54 \\
\hline 224 & 9125.47 & -291.04 & 53.58 \\
\hline 225 & 9188.47 & -296.39 & 49.68 \\
\hline 226 & 9230.33 & -282.87 & 50.55 \\
\hline 227 & 9272.06 & -269.4 & 51.43 \\
\hline 228 & 9317.94 & -254.96 & 52.54 \\
\hline 229 & 9365.69 & -240.11 & 52.02 \\
\hline 230 & 9413.71 & -224.72 & 51.89 \\
\hline 231 & 9461.42 & -210.63 & 51.67 \\
\hline 232 & 9509.31 & -195.28 & 51.83 \\
\hline 233 & 9562.78 & -173.54 & 51.49 \\
\hline 234 & 9603.85 & -202.21 & 47.74 \\
\hline 235 & 9632.09 & -258.55 & 50.54 \\
\hline 236 & 9683.11 & -276.95 & 50.49 \\
\hline 237 & 9734.12 & -295.34 & 50.43 \\
\hline 238 & 9781.12 & -314.22 & 50.23 \\
\hline 239 & 9827.13 & -333.5 & 50.16 \\
\hline 240 & 9875.64 & -344.31 & 47.4 \\
\hline 241 & 9923.61 & -355.75 & 47.34 \\
\hline 242 & 9967.88 & -361.36 & 49.21 \\
\hline 243 & 10017.05 & -357.45 & 52.32 \\
\hline 244 & 10065.97 & -349.52 & 49.2 \\
\hline 245 & 10113.16 & -337.18 & 49.13 \\
\hline 246 & 10154.88 & -309.66 & 48.59 \\
\hline 247 & 10195.96 & -280.5 & 48.49 \\
\hline 248 & 10232.19 & -247.39 & 47.92 \\
\hline 249 & 10270.12 & -214.89 & 47.85 \\
\hline 250 & 10311.81 & -188.81 & 47.54 \\
\hline 251 & 10359.52 & -175.38 & 47.14 \\
\hline 252 & 10403.42 & -152.06 & 47.19 \\
\hline 253 & 10445.21 & -133.94 & 47.4 \\
\hline 254 & 10402.85 & 53.48 & 46 \\
\hline 255 & 10466.55 & 92.37 & 44 \\
\hline
\end{tabular}




\begin{tabular}{|c|c|c|c|}
\hline 256 & 10496.82 & 113.14 & 42 \\
\hline 257 & 10533.86 & 125.02 & 40 \\
\hline 258 & 10586.84 & 94.51 & 31 \\
\hline 259 & 10649.11 & 78.38 & 39 \\
\hline 260 & 10747.89 & 52.65 & 43.27 \\
\hline 261 & 10787.57 & 85.3 & 43.03 \\
\hline 262 & 10827.94 & 114.59 & 42.74 \\
\hline 263 & 10870.24 & 141.71 & 42.49 \\
\hline 264 & 10920.18 & 156.71 & 42.38 \\
\hline 265 & 10973.96 & 160.47 & 42.46 \\
\hline 266 & 11019.1 & 157.77 & 42.33 \\
\hline 267 & 11067.33 & 154.78 & 42.18 \\
\hline 268 & 11117.22 & 151.54 & 41.9 \\
\hline 269 & 11166.8 & 147.89 & 41.91 \\
\hline 270 & 11217.86 & 142.06 & 42.16 \\
\hline 271 & 11265.58 & 135.76 & 41.94 \\
\hline 272 & 11314.2 & 115.2 & 41.97 \\
\hline 273 & 11360.11 & 97.3 & 41.67 \\
\hline 274 & 11405.77 & 77.97 & 41.82 \\
\hline 275 & 11452.31 & 60.22 & 41.59 \\
\hline 276 & 11499.27 & 39.47 & 41.7 \\
\hline 277 & 11545.71 & 24.21 & 40.23 \\
\hline 278 & 11589.91 & 0.58 & 39.78 \\
\hline 279 & 11620.31 & -50.24 & 39.75 \\
\hline 280 & 11674.46 & -28.73 & 39.47 \\
\hline 281 & 11721.32 & -47.42 & 39.26 \\
\hline 282 & 11768.33 & -62.4 & 39.12 \\
\hline 283 & 11821.63 & -68.22 & 38.92 \\
\hline 284 & 11870.58 & -64.32 & 38.45 \\
\hline 285 & 11942.36 & -78.33 & 35.55 \\
\hline 286 & 11998.54 & -73.08 & 30.96 \\
\hline 287 & 12045.47 & -81.22 & 30.17 \\
\hline 288 & 12093.89 & -93.33 & 30.05 \\
\hline 289 & 12142.22 & -104.95 & 29.97 \\
\hline 290 & 12189.7 & -122.16 & 30.25 \\
\hline 291 & 12236.74 & -134.59 & 30.05 \\
\hline 292 & 12287.8 & -145.88 & 30 \\
\hline 293 & 12336.27 & -157.9 & 30 \\
\hline 294 & 12384.74 & -169.92 & 30 \\
\hline 295 & 12433.21 & -181.94 & 29.99 \\
\hline 296 & 12478.36 & -192.1 & 29.84 \\
\hline 297 & 12529.78 & -204.68 & 29.99 \\
\hline 298 & 12578.26 & -211.47 & 29.73 \\
\hline 299 & 12630.04 & -216.31 & 29.32 \\
\hline 300 & 12645.62 & -4 & 34 \\
\hline 301 & 12600.73 & 88.27 & 33 \\
\hline 302 & 12670.17 & 136.59 & 24 \\
\hline 303 & 12729.11 & 84.21 & 31 \\
\hline 304 & 12788.03 & 34.07 & 31 \\
\hline 305 & 12852.65 & -65.68 & 28 \\
\hline 306 & 12679.3 & -219.7 & 29.82 \\
\hline 307 & 12729.43 & -219.27 & 29.37 \\
\hline
\end{tabular}




\begin{tabular}{|c|c|c|c|}
\hline 308 & 12781.11 & -216.83 & 29.3 \\
\hline 309 & 12829.74 & -211.76 & 29.44 \\
\hline 310 & 12877.65 & -193.86 & 20 \\
\hline 311 & 12925.9 & -186.39 & 22 \\
\hline 312 & 12975.89 & -170.85 & 24 \\
\hline 313 & 13023.19 & -156.22 & 23 \\
\hline 314 & 13069.61 & -141.15 & 24 \\
\hline 315 & 13115.09 & -121.17 & 24 \\
\hline 316 & 13160.13 & -102.09 & 24 \\
\hline 317 & 13206.98 & -86.12 & 23 \\
\hline 318 & 13252.94 & -69.72 & 22 \\
\hline 319 & 13294.92 & -61.39 & 23 \\
\hline 320 & 13343.95 & -36.46 & 16 \\
\hline 321 & 13390.82 & -22.73 & 21 \\
\hline 322 & 13437.68 & -9 & 21 \\
\hline 323 & 13476.46 & 10.93 & 25 \\
\hline 324 & 13523.33 & 24.66 & 25 \\
\hline 325 & 13577.42 & 28.16 & 18 \\
\hline 326 & 13637.95 & 71.94 & 18 \\
\hline 327 & 13650.92 & 71.13 & 23 \\
\hline 328 & 13690.36 & 58.43 & 22 \\
\hline 329 & 13726.17 & 54.19 & 30 \\
\hline 330 & 13817.48 & 42.73 & 24 \\
\hline 331 & 13855.49 & 42.98 & 28 \\
\hline 332 & 13900.67 & 41.94 & 20 \\
\hline 333 & 13949.86 & 42.27 & 27 \\
\hline 334 & 13992.36 & 40.32 & 30 \\
\hline 335 & 14039.84 & 28.11 & 23 \\
\hline 336 & 14077.59 & 0.64 & 38 \\
\hline 337 & 14110.62 & 11.14 & 28 \\
\hline 338 & 14138.63 & 36.37 & 26 \\
\hline 339 & 14170.38 & 103.22 & 23 \\
\hline 340 & 14178.83 & 110.21 & 23.5 \\
\hline 341 & 14187.28 & 117.2 & 24 \\
\hline 342 & 14223.5 & 118.33 & 15 \\
\hline 343 & 14266.38 & 126.22 & 11 \\
\hline 344 & 14307.86 & 142.6 & 14 \\
\hline 345 & 14340.99 & 137.45 & 22 \\
\hline 346 & 14379.46 & 136.37 & 28 \\
\hline 347 & 14432.67 & 138.07 & 33 \\
\hline 348 & 14463.53 & 137.38 & 15 \\
\hline 349 & 14495.28 & 138.48 & 30 \\
\hline 350 & 14541.73 & 146.84 & 13 \\
\hline 351 & 14581.54 & 146.22 & 14.5 \\
\hline 352 & 14616.05 & 134.82 & 16 \\
\hline 353 & 14647.05 & 114.01 & 15 \\
\hline 354 & 14679.89 & 85.6 & 15 \\
\hline 355 & 14712.27 & 58.54 & 16 \\
\hline 356 & 14738.39 & 30.09 & 12 \\
\hline 357 & 14764.02 & 9.69 & 15 \\
\hline 358 & 14807.07 & -7.02 & 13 \\
\hline 359 & 14844.7 & -16.61 & 10 \\
\hline
\end{tabular}




\begin{tabular}{|c|c|c|c|}
\hline 360 & 14883.59 & -14.56 & 11 \\
\hline 361 & 14919.29 & -3.14 & 8 \\
\hline 362 & 15014.11 & -2.95 & 13 \\
\hline 363 & 15124.96 & 4.94 & 9 \\
\hline 364 & 15156.18 & 18.57 & 10 \\
\hline 365 & 15203.94 & 31.85 & 12 \\
\hline 366 & 15252.18 & 41.57 & 14 \\
\hline 367 & 15308.02 & 50.89 & 9 \\
\hline 368 & 15353.49 & 73.1 & 7 \\
\hline 369 & 15411.14 & 79.3 & 4 \\
\hline 370 & 15462.45 & 97.53 & 2 \\
\hline 371 & 15513.83 & 104.58 & 7 \\
\hline 372 & 15559.82 & 116.52 & 10 \\
\hline 373 & 15615.7 & 119.13 & 8 \\
\hline 374 & 15668.83 & 132 & 10 \\
\hline 375 & 15714.33 & 149.75 & 10 \\
\hline 376 & 15763.44 & 163.49 & 10 \\
\hline 377 & 15812.54 & 177.24 & 10 \\
\hline 378 & 15898.01 & 101.78 & 14 \\
\hline 379 & 15912.58 & 63.42 & 10 \\
\hline 380 & 15919.72 & -1.38 & 19 \\
\hline 381 & 15861.19 & 192.32 & 10 \\
\hline 382 & 15910.3 & 203.83 & 11 \\
\hline 383 & 15962.1 & 216.25 & 8 \\
\hline 384 & 16012.55 & 228.22 & 7 \\
\hline 385 & 16063.91 & 239.74 & 7 \\
\hline 386 & 16113.01 & 253.48 & 7 \\
\hline 387 & 16163.45 & 267.68 & 8 \\
\hline 388 & 16213.92 & 277.41 & 5 \\
\hline 389 & 16264.37 & 291.61 & 6 \\
\hline 390 & 16312.6 & 301.33 & 6 \\
\hline 391 & 16347.85 & 314.08 & 9 \\
\hline 392 & 16396.51 & 326.93 & 8 \\
\hline 393 & 16446.96 & 338.89 & 11 \\
\hline 394 & 16493.39 & 351.73 & 18 \\
\hline 395 & 16544.29 & 364.59 & 18 \\
\hline 396 & 16593.38 & 380.57 & 8 \\
\hline 397 & 16647.85 & 393.9 & 5 \\
\hline 398 & 16699.64 & 406.32 & 6 \\
\hline 399 & 16751 & 417.85 & 9 \\
\hline 400 & 16796.98 & 429.78 & 0 \\
\hline 401 & 16844.73 & 445.31 & 0 \\
\hline 402 & 16876.02 & 447.75 & 12 \\
\hline 403 & 16930.48 & 463.32 & 7 \\
\hline 404 & 16983.17 & 475.3 & 3 \\
\hline 405 & 17032.27 & 489.04 & 1 \\
\hline 406 & 17081.37 & 502.79 & 2 \\
\hline 407 & 17133.6 & 518.34 & 5 \\
\hline 408 & 17188.02 & 538.38 & 3 \\
\hline 409 & 17234.07 & 541.37 & 2 \\
\hline 410 & 17324.67 & 569.26 & 8 \\
\hline 411 & 17373.34 & 579.87 & 5 \\
\hline
\end{tabular}


17423.83

17561.34

587.36

622.27

633.31

649.68

662.1

3

17606.89

17648.37

17700.16

4

6

5

416

6 


\section{Appendix 3 Seismograph UTM Locations}

PASSCAL Station \# UTM Northing UTM Easting Elevation (m) Geo. Freq.

Seismograph

Number

553

557

554

551

559

442

560

561

562

696

558

555

552

556

563

102

100

101

110

106

109

105

103

108

107

104

111

574

455

133

41

456

52

134

207

70

201

180

66

175

580

573

517

578

209

567

47

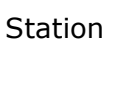

4

4113781
4113824
4113861
4113911

590355

590323

590293

590272

590257

590245

590235

590224

590189

590132

590119

590101

590072

590026

589986

589961

589919

589878

589900

589902

589889

589899

589919

589885

589859

589826

589819

589811

589807

589785

589755

589734

589708

589700

589706

589719

589733

589734

589729

589722

589695

589682

589661

589658

589652

589648

589635

\begin{tabular}{|c|c|}
\hline 281 & 4.5 \\
\hline 289 & 40 \\
\hline 273 & 4.5 \\
\hline 277 & 40 \\
\hline 268 & 4.5 \\
\hline 256 & 40 \\
\hline 258 & 4.5 \\
\hline 260 & 40 \\
\hline 261 & 4.5 \\
\hline 254 & 40 \\
\hline 261 & 4.5 \\
\hline 258 & 40 \\
\hline 252 & 4.5 \\
\hline 252 & 40 \\
\hline 249 & 4.5 \\
\hline 236 & 40 \\
\hline 223 & 4.5 \\
\hline 233 & 40 \\
\hline 229 & 4.5 \\
\hline 233 & 40 \\
\hline 231 & 4.5 \\
\hline 222 & 40 \\
\hline 221 & 4.5 \\
\hline 214 & 40 \\
\hline 201 & 4.5 \\
\hline 201 & 40 \\
\hline 202 & 4.5 \\
\hline 197 & 40 \\
\hline 208 & 4.5 \\
\hline 203 & 40 \\
\hline 202 & 4.5 \\
\hline 205 & 40 \\
\hline 202 & 4.5 \\
\hline 208 & 40 \\
\hline 211 & 4.5 \\
\hline 211 & 40 \\
\hline 210 & 4.5 \\
\hline 209 & 40 \\
\hline 216 & 4.5 \\
\hline 221 & 40 \\
\hline 219 & 4.5 \\
\hline 216 & 40 \\
\hline 203 & 4.5 \\
\hline 187 & 40 \\
\hline 199 & 4.5 \\
\hline 211 & 40 \\
\hline 220 & 4.5 \\
\hline
\end{tabular}




\begin{tabular}{|c|c|c|c|c|c|}
\hline 485 & 48 & 4115740 & 589613 & 216 & 40 \\
\hline 507 & 49 & 4115786 & 589586 & 207 & 4.5 \\
\hline 460 & 50 & 4115830 & 589567 & 209 & 40 \\
\hline 132 & 51 & 4115879 & 589560 & 209 & 4.5 \\
\hline 587 & 52 & 4115930 & 589571 & 202 & 40 \\
\hline 433 & 53 & 4115976 & 589590 & 209 & 4.5 \\
\hline 149 & 54 & 4116031 & 589587 & 205 & 40 \\
\hline 524 & 55 & 4116079 & 589596 & 206 & 4.5 \\
\hline 511 & 56 & 4116128 & 589595 & 210 & 40 \\
\hline 501 & 57 & 4116178 & 589583 & 212 & 4.5 \\
\hline 566 & 58 & 4116224 & 589548 & 202 & 40 \\
\hline 50 & 59 & 4116269 & 589529 & 200 & 4.5 \\
\hline 59 & 60 & 4116315 & 589504 & 206 & 40 \\
\hline 576 & 61 & 4116358 & 589489 & 205 & 4.5 \\
\hline 38 & 62 & 4116405 & 589463 & 197 & 40 \\
\hline 436 & 63 & 4116455 & 589455 & 194 & 4.5 \\
\hline 401 & 64 & 4116503 & 589453 & 196 & 40 \\
\hline 483 & 65 & 4116554 & 589436 & 201 & 4.5 \\
\hline 404 & 66 & 4116604 & 589387 & 201 & 40 \\
\hline 458 & 67 & 4116656 & 589340 & 196 & 4.5 \\
\hline 412 & 68 & 4116707 & 589309 & 200 & 40 \\
\hline 139 & 69 & 4116770 & 589307 & 198 & 4.5 \\
\hline 183 & 70 & 4116834 & 589309 & 200 & 40 \\
\hline 607 & 71 & 4116891 & 589325 & 205 & 4.5 \\
\hline 406 & 72 & 4116948 & 589321 & 203 & 40 \\
\hline 596 & 73 & 4117000 & 589340 & 198 & 4.5 \\
\hline 403 & 74 & 4117055 & 589349 & 197 & 40 \\
\hline 579 & 75 & 4117112 & 589359 & 198 & 4.5 \\
\hline 582 & 76 & 4117173 & 589368 & 192 & 40 \\
\hline 593 & 77 & 4117232 & 589378 & 191 & 4.5 \\
\hline 409 & 78 & 4117304 & 589396 & 196 & 40 \\
\hline 604 & 79 & 4117374 & 589529 & 194 & 4.5 \\
\hline 408 & 80 & 4117428 & 589541 & 194 & 40 \\
\hline 605 & 81 & 4117473 & 589533 & 200 & 4.5 \\
\hline 407 & 82 & 4117513 & 589506 & 205 & 40 \\
\hline 428 & 83 & 4117556 & 589461 & 201 & 4.5 \\
\hline 610 & 84 & 4117605 & 589483 & 205 & 40 \\
\hline 402 & 85 & 4117653 & 589477 & 203 & 4.5 \\
\hline 522 & 86 & 4117702 & 589491 & 201 & 40 \\
\hline 492 & 87 & 4117748 & 589505 & 195 & 4.5 \\
\hline 411 & 88 & 4117799 & 589512 & 187 & 40 \\
\hline 177 & 89 & 4117846 & 589508 & 184 & 4.5 \\
\hline 609 & 90 & 4117901 & 589498 & 175 & 40 \\
\hline 497 & 91 & 4117952 & 589512 & 171 & 4.5 \\
\hline 450 & 92 & 4118004 & 589510.5 & 168.05 & 40 \\
\hline 74 & 10001 & 4117985.5 & 589506.6 & 168.44 & 99 \\
\hline 431 & 10002 & 4117996.4 & 589509.4 & 168.12 & 99 \\
\hline 743 & 10003 & 4118007.6 & 589510.8 & 168.19 & 99 \\
\hline 116 & 10004 & 4118019.2 & 589512.8 & 168.27 & 99 \\
\hline 681 & 10005 & 4118031.8 & 589513.7 & 167.86 & 99 \\
\hline 130 & 10006 & 4118044.3 & 589515.8 & 167.47 & 99 \\
\hline 121 & 10007 & 4118055.7 & 589515.3 & 167.02 & 99 \\
\hline
\end{tabular}




\begin{tabular}{|c|c|c|c|c|c|}
\hline 529 & 10008 & 4118070.2 & 589516.5 & 165.9 & 99 \\
\hline 664 & 10009 & 4118080 & 589516.7 & 165.33 & 99 \\
\hline 750 & 10010 & 4118089.8 & 589516.9 & 165 & 99 \\
\hline 445 & 93 & 4118017.9 & 589542.5 & 170.26 & 40 \\
\hline 879 & 94 & 4118065.4 & 589526.9 & 166.48 & 4.5 \\
\hline 413 & 94.5 & 4118115.8 & 589524.9 & 163.48 & 40 \\
\hline 447 & 95 & 4118165.2 & 589553.4 & 161.82 & 4.5 \\
\hline 405 & 96 & 4118193.4 & 589621.5 & 160.45 & 40 \\
\hline 482 & 97 & 4118252 & 589672 & 146.04 & 4.5 \\
\hline 597 & 98 & 4118311.9 & 589669.8 & 141 & 40 \\
\hline 80 & 99 & 4118372.4 & 589680.7 & 140 & 4.5 \\
\hline 57 & 100 & 4118427.3 & 589692.8 & 139.78 & 40 \\
\hline 451 & 101 & 4118479.2 & 589697 & 138.96 & 4.5 \\
\hline 594 & 102 & 4118525.9 & 589682.1 & 137.86 & 40 \\
\hline 830 & 103 & 4118574.4 & 589667.4 & 136.86 & 4.5 \\
\hline 165 & 20001 & 4119032 & 589933 & 149 & 99 \\
\hline 464 & 20002 & 4119059 & 589937 & 144 & 99 \\
\hline 178 & 20003 & 4119110 & 589940 & 144 & 99 \\
\hline 486 & 20004 & 4119162 & 589952 & 150 & 99 \\
\hline 73 & 20005 & 4119208 & 589963 & 141 & 99 \\
\hline 844 & 104 & 4118628.6 & 589654.1 & 135.9199 & \\
\hline 136 & 105 & 4118680 & 589652.2 & 135.47 & 4.5 \\
\hline 417 & 106 & 4118728.4 & 589661.1 & 134.55 & 40 \\
\hline 81 & 107 & 4118776.3 & 589688.5 & 133.28 & 4.5 \\
\hline 46 & 108 & 4118808.7 & 589731.8 & 131.43 & 40 \\
\hline 86 & 109 & 4118833.9 & 589775.4 & 130.56 & 4.5 \\
\hline 508 & 110 & 4118877.7 & 589800.6 & 129.56 & 40 \\
\hline 79 & 111 & 4118938.2 & 589833.5 & 130.1 & 4.5 \\
\hline 55 & 112 & 4118989.2 & 589838.6 & 129.95 & 40 \\
\hline 85 & 113 & 4119036.9 & 589853.7 & 126.96 & 4.5 \\
\hline 512 & 114 & 4119091.8 & 589853.4 & 123.98 & 40 \\
\hline 82 & 115 & 4119139.8 & 589841 & 122.37 & 4.5 \\
\hline 506 & 116 & 4119187.5 & 589830 & 122.01 & 4.5 \\
\hline 78 & 117 & 4119235.8 & 589813.2 & 121.65 & 4.5 \\
\hline 49 & 118 & 4119283.2 & 589797.5 & 121.51 & 40 \\
\hline 75 & 119 & 4119331.2 & 589786.9 & 121.32 & 4.5 \\
\hline 441 & 120 & 4119381.4 & 589786.6 & 121.26 & 40 \\
\hline 84 & 121 & 4119429.3 & 589797.4 & 120.41 & 4.5 \\
\hline 425 & 122 & 4119474.1 & 589821.1 & 120.12 & 40 \\
\hline 514 & 124 & 4119551.3 & 589881.6 & 119.55 & 40 \\
\hline 45 & 125 & 4119589.5 & 589915.3 & 119.41 & 4.5 \\
\hline 840 & 126 & 4119622.5 & 589954.4 & 118.5 & 40 \\
\hline 40 & 127 & 4119646.6 & 589998.2 & 117.65 & 4.5 \\
\hline 503 & 128 & 4119675.3 & 590037.8 & 117.4 & 40 \\
\hline 523 & 129 & 4119713.5 & 590078.7 & 116.67 & 4.5 \\
\hline 414 & 130 & 4119742.5 & 590119.2 & 117.05 & 40 \\
\hline 148 & 131 & 4119767.7 & 590169.5 & 115.36 & 4.5 \\
\hline 418 & 132 & 4119799.4 & 590207.5 & 114.59 & 40 \\
\hline 513 & 133 & 4119829.4 & 590248 & 113.73 & 4.5 \\
\hline 500 & 134 & 4119866.1 & 590281.6 & 113.63 & 40 \\
\hline 77 & 135 & 4119899.9 & 590318.6 & 113.32 & 4.5 \\
\hline 518 & 136 & 4119936 & 590359.3 & 111.7 & 40 \\
\hline
\end{tabular}




\begin{tabular}{|c|c|c|c|c|c|}
\hline 25 & 137 & 4119974.4 & 590398.9 & 111.18 & 4.5 \\
\hline 419 & 138 & 4120012.1 & 590436.3 & 110.06 & 40 \\
\hline 30 & 139 & 4120046 & 590474.9 & 109.69 & 4.5 \\
\hline 581 & 140 & 4120072.8 & 590516.7 & 108.93 & 40 \\
\hline 83 & 141 & 4120100.8 & 590558.4 & 107.88 & 4.5 \\
\hline 420 & 142 & 4120128.8 & 590600.2 & 106.83 & 40 \\
\hline 843 & 143 & 4120156.9 & 590641.9 & 105.78 & 4.5 \\
\hline 424 & 144 & 4120196.8 & 590683.7 & 105.67 & 40 \\
\hline 841 & 145 & 4120239.2 & 590721 & 105.18 & 4.5 \\
\hline 422 & 146 & 4120277.5 & 590765.1 & 104.33 & 40 \\
\hline 505 & 147 & 4120181 & 590548 & 115 & 4.5 \\
\hline 504 & 148 & 4120241.5 & 590562.5 & 107.89 & 40 \\
\hline 89 & 149 & 4120284.6 & 590582.4 & 106.96 & 4.5 \\
\hline 87 & 150 & 4120329.3 & 590604.7 & 107.13 & 40 \\
\hline 93 & 151 & 4120377.1 & 590632.2 & 106.36 & 4.5 \\
\hline 416 & 152 & 4120421.6 & 590655.2 & 104.83 & 40 \\
\hline 143 & 153 & 4120465.8 & 590677.8 & 105.16 & 4.5 \\
\hline 421 & 154 & 4120510.2 & 590702 & 105.2 & 40 \\
\hline 544 & 155 & 4120551.8 & 590728.1 & 105.16 & 4.5 \\
\hline 415 & 156 & 4120601.3 & 590759.1 & 104.2 & 40 \\
\hline 141 & 157 & 4120613 & 590816.6 & 102.1 & 4.5 \\
\hline 172 & 158 & 4120625 & 590874.2 & 100 & 40 \\
\hline 546 & 159 & 4120647.9 & 590918.7 & 100.15 & 4.5 \\
\hline 577 & 160 & 4120674.3 & 590961.2 & 102.12 & 40 \\
\hline 488 & 161 & 4120706.9 & 590997.4 & 102.17 & 4.5 \\
\hline 34 & 162 & 4120750.8 & 591019.2 & 100.92 & 40 \\
\hline 27 & 163 & 4120806.9 & 591038.6 & 100.23 & 4.5 \\
\hline 590 & 164 & 4120863 & 591058 & 99.54 & 40 \\
\hline 547 & 165 & 4120914.2 & 591087.7 & 99.86 & 4.5 \\
\hline 832 & 40001 & 4121236 & 591294 & 115 & 99 \\
\hline 612 & 40002 & 4121266 & 591341 & 106 & 99 \\
\hline 757 & 40003 & 4121304 & 591323 & 116 & 99 \\
\hline 90 & 401 & 4121402 & 591269 & 92 & 4.5 \\
\hline 474 & 402 & 4121449 & 591284 & 94 & 40 \\
\hline 88 & 403 & 4121492 & 591298 & 105 & 4.5 \\
\hline 469 & 404 & 4121544 & 591317 & 97 & 40 \\
\hline 154 & 405 & 4121592 & 591327 & 97 & 4.5 \\
\hline 95 & 406 & 4121637 & 591337 & 97 & 40 \\
\hline 542 & 407 & 4121700 & 591338 & 92 & 4.5 \\
\hline 33 & 408 & 4121734 & 591372 & 98 & 40 \\
\hline 203 & 409 & 4121775 & 591401 & 92 & 4.5 \\
\hline 569 & 410 & 4121817 & 591429 & 79 & 40 \\
\hline 435 & 411 & 4121861 & 591451 & 85 & 4.5 \\
\hline 570 & 412 & 4121907 & 591470 & 87 & 40 \\
\hline 540 & 413 & 4121953 & 591489 & 88 & 4.5 \\
\hline 568 & 414 & 4121995 & 591517 & 83 & 40 \\
\hline 69 & 415 & 4122043.8 & 591542.6 & 92.06 & 4.5 \\
\hline 36 & 416 & 4122092.2 & 591568.6 & 92.2 & 40 \\
\hline 541 & 417 & 4122144.8 & 591573.8 & 94.83 & 4.5 \\
\hline 571 & 418 & 4122201.7 & 591587.1 & 99.85 & 40 \\
\hline 545 & 419 & 4122241.1 & 591613.2 & 99.8 & 4.5 \\
\hline 589 & 420 & 4122291.8 & 591641.1 & 99.99 & 40 \\
\hline
\end{tabular}




\begin{tabular}{|c|c|c|c|c|c|}
\hline 29 & 421 & 4122340 & 591662.9 & 100.3 & 4.5 \\
\hline 31 & 422 & 4122362 & 591677.7 & 100.94 & 40 \\
\hline 510 & 423 & 4122390.7 & 591693 & 102.01 & 4.5 \\
\hline 881 & 424 & 4122429.8 & 591703.8 & 96.32 & 40 \\
\hline 548 & 425 & 4122454.4 & 591744.9 & 94.68 & 4.5 \\
\hline 525 & 426 & 4122479 & 591786.1 & 93.04 & 40 \\
\hline 868 & 427 & 4122506.6 & 591843.3 & 92.48 & 4.5 \\
\hline 480 & 428 & 4122529.7 & 591890.8 & 92.28 & 40 \\
\hline 127 & 429 & 4122560.7 & 591936.1 & 92.66 & 4.5 \\
\hline 871 & 430 & 4122617 & 591947.9 & 91.57 & 40 \\
\hline 400 & 431 & 4122668.1 & 591927.1 & 91.6 & 4.5 \\
\hline 391 & 432 & 4122750.6 & 591844.9 & 87.92 & 40 \\
\hline 54 & 433 & 4122829.7 & 591799.9 & 85.4 & 4.5 \\
\hline 394 & 434 & 4122879.7 & 591796.7 & 85.19 & 40 \\
\hline 867 & 435 & 4122934.2 & 591787.3 & 85.02 & 4.5 \\
\hline 393 & 436 & 4122988.8 & 591781.9 & 84.57 & 40 \\
\hline 125 & 437 & 4123042.8 & 591774.4 & 84.44 & 4.5 \\
\hline 392 & 438 & 4123095.3 & 591767.9 & 83.23 & 40 \\
\hline 481 & 439 & 4123148.3 & 591772.2 & 83.52 & 4.5 \\
\hline 60 & 440 & 4123197.5 & 591782.7 & 83.54 & 40 \\
\hline 861 & 441 & 4123244.7 & 591789.2 & 83.58 & 4.5 \\
\hline 874 & 442 & 4123303.6 & 591812.2 & 79.68 & 40 \\
\hline 863 & 443 & 4123335.2 & 591842.8 & 80.55 & 4.5 \\
\hline 839 & 444 & 4123366.7 & 591873.3 & 81.43 & 40 \\
\hline 876 & 445 & 4123401.5 & 591906.5 & 82.54 & 4.5 \\
\hline 140 & 446 & 4123437.8 & 591940.9 & 82.02 & 40 \\
\hline 72 & 447 & 4123474.1 & 591975.9 & 81.89 & 4.5 \\
\hline 397 & 448 & 4123510.7 & 592009.6 & 81.67 & 40 \\
\hline 146 & 449 & 4123546.9 & 592044.5 & 81.83 & 4.5 \\
\hline 198 & 601 & 4123585.3 & 592087.6 & 81.49 & 40 \\
\hline 550 & 602 & 4123634.8 & 592080 & 77.74 & 4.5 \\
\hline 509 & 604 & 4123685 & 592041.9 & 80.54 & 4.5 \\
\hline 176 & 605 & 4123738.9 & 592047.9 & 80.49 & 40 \\
\hline 443 & 606 & 4123792.8 & 592053.9 & 80.43 & 4.5 \\
\hline 444 & 607 & 4123843.3 & 592057.7 & 80.23 & 40 \\
\hline 187 & 608 & 4123893.1 & 592060.7 & 80.16 & 4.5 \\
\hline 196 & 609 & 4123941.4 & 592072.4 & 77.4 & 40 \\
\hline 195 & 610 & 4123989.5 & 592083.3 & 77.34 & 4.5 \\
\hline 193 & 611 & 4124031.7 & 592097.8 & 79.21 & 40 \\
\hline 189 & 612 & 4124074.1 & 592123 & 82.32 & 4.5 \\
\hline 197 & 613 & 4124114.5 & 592151.7 & 79.2 & 40 \\
\hline 199 & 614 & 4124151.4 & 592183.6 & 79.13 & 4.5 \\
\hline 191 & 615 & 4124176.7 & 592226.7 & 78.59 & 40 \\
\hline 188 & 616 & 4124200.7 & 592271 & 78.49 & 4.5 \\
\hline 99 & 617 & 4124218.6 & 592316.7 & 77.92 & 40 \\
\hline 96 & 618 & 4124238.3 & 592362.6 & 77.85 & 4.5 \\
\hline 465 & 619 & 4124264.2 & 592404.4 & 77.54 & 40 \\
\hline 475 & 620 & 4124301.1 & 592437.5 & 77.14 & 4.5 \\
\hline 466 & 621 & 4124330.2 & 592477.8 & 77.19 & 40 \\
\hline 92 & 622 & 4124359.7 & 592512.5 & 77.4 & 4.5 \\
\hline 94 & 623 & 4124239 & 592662 & 76 & 40 \\
\hline 498 & 625 & 4124279 & 592725 & 74 & 40 \\
\hline
\end{tabular}




\begin{tabular}{|c|c|c|c|c|c|}
\hline 97 & 626 & 4124297 & 592757 & 72 & 4.5 \\
\hline 399 & 701 & 4124325 & 592784 & 70 & 40 \\
\hline 208 & 702 & 4124386 & 592780 & 61 & 4.5 \\
\hline 206 & 703 & 4124449 & 592793 & 69 & 40 \\
\hline 76 & 704 & 4124549 & 592813.5 & 73.27 & 4.5 \\
\hline 179 & 705 & 4124570.2 & 592860.3 & 73.03 & 40 \\
\hline 26 & 706 & 4124593.5 & 592904.4 & 72.74 & 4.5 \\
\hline 734 & 707 & 4124619.5 & 592947.4 & 72.49 & 40 \\
\hline 543 & 708 & 4124657.7 & 592982.9 & 72.38 & 4.5 \\
\hline 423 & 709 & 4124704.3 & 593010 & 72.46 & 40 \\
\hline 128 & 710 & 4124746 & 593027.5 & 72.33 & 4.5 \\
\hline 585 & 711 & 4124790.6 & 593046.1 & 72.18 & 40 \\
\hline 539 & 712 & 4124836.8 & 593065.2 & 71.9 & 4.5 \\
\hline 866 & 713 & 4124882.9 & 593083.8 & 71.91 & 40 \\
\hline 865 & 714 & 4124931.3 & 593101.1 & 72.16 & 4.5 \\
\hline 438 & 715 & 4124976.9 & 593116.5 & 71.94 & 40 \\
\hline 549 & 716 & 4125029.6 & 593119.5 & 71.97 & 4.5 \\
\hline 205 & 717 & 4125078.7 & 593123.7 & 71.67 & 40 \\
\hline 389 & 718 & 4125128.2 & 593126.5 & 71.82 & 4.5 \\
\hline 395 & 719 & 4125177.8 & 593131.1 & 71.59 & 40 \\
\hline 862 & 720 & 4125229.1 & 593133.2 & 71.7 & 4.5 \\
\hline 71 & 721 & 4125277.5 & 593140 & 70.23 & 40 \\
\hline 864 & 722 & 4125327.6 & 593138.3 & 69.78 & 4.5 \\
\hline 463 & 801 & 4125377.3 & 593106.1 & 69.75 & 40 \\
\hline 35 & 802 & 4125416.4 & 593149.3 & 69.47 & 4.5 \\
\hline 32 & 803 & 4125466.7 & 593153.2 & 69.26 & 40 \\
\hline 390 & 804 & 4125515.5 & 593160.5 & 69.12 & 4.5 \\
\hline 755 & 805 & 4125565.9 & 593178.8 & 68.92 & 40 \\
\hline 598 & 806 & 4125608.1 & 593203.9 & 68.45 & 40 \\
\hline 833 & 807 & 4125678.7 & 593223 & 65.55 & 4.5 \\
\hline 741 & 808 & 4125726.8 & 593252.5 & 60.96 & 40 \\
\hline 502 & 809 & 4125772.5 & 593265.9 & 60.17 & 40 \\
\hline 221 & 810 & 4125821.3 & 593276.4 & 60.05 & 4.5 \\
\hline 212 & 811 & 4125869.8 & 593287.3 & 59.97 & 40 \\
\hline 487 & 812 & 4125920 & 593292.8 & 60.25 & 40 \\
\hline 124 & 813 & 4125967.7 & 593302.4 & 60.05 & 4.5 \\
\hline 211 & 814 & 4126018.5 & 593314.8 & 60 & 40 \\
\hline 532 & 815 & 4126067.3 & 593325.4 & 60 & 40 \\
\hline 224 & 816 & 4126116.1 & 593336 & 60 & 4.5 \\
\hline 530 & 817 & 4126164.9 & 593346.6 & 59.99 & 40 \\
\hline 168 & 818 & 4126209.9 & 593357.4 & 59.84 & 40 \\
\hline 113 & 819 & 4126261.6 & 593368.8 & 59.99 & 4.5 \\
\hline 526 & 820 & 4126308.1 & 593384.1 & 59.73 & 40 \\
\hline 223 & 821 & 4126356.7 & 593402.6 & 59.32 & 40 \\
\hline 214 & 822 & 4126402.4 & 593421.3 & 59.82 & 4.5 \\
\hline 158 & 823 & 4126447.2 & 593443.8 & 59.37 & 40 \\
\hline 760 & 824 & 4126492.5 & 593468.8 & 59.3 & 40 \\
\hline 837 & 825 & 4126533.9 & 593494.8 & 59.44 & 4.5 \\
\hline 150 & 826 & 4126569 & 593532 & 50 & 40 \\
\hline 534 & 827 & 4126609 & 593560 & 52 & 40 \\
\hline 490 & 90001 & 4126277 & 593600 & 64 & 99 \\
\hline 753 & 90002 & 4126196 & 593663 & 63 & 99 \\
\hline
\end{tabular}




\begin{tabular}{|c|c|c|c|c|c|}
\hline 135 & 90003 & 4126237 & 593737 & 54 & 99 \\
\hline 754 & 90004 & 4126313 & 593716 & 61 & 99 \\
\hline 43 & 90005 & 4126388 & 593697 & 61 & 99 \\
\hline 166 & 90006 & 4126490 & 593636 & 58 & 99 \\
\hline 120 & 828 & 4126647 & 593596 & 54 & 4.5 \\
\hline 521 & 829 & 4126683 & 593630 & 53 & 40 \\
\hline 672 & 830 & 4126718 & 593664 & 54 & 40 \\
\hline 117 & 831 & 4126750 & 593702 & 54 & 4.5 \\
\hline 592 & 832 & 4126782 & 593739 & 54 & 40 \\
\hline 623 & 833 & 4126817 & 593774 & 53 & 40 \\
\hline 126 & 834 & 4126851 & 593809 & 52 & 4.5 \\
\hline 742 & 835 & 4126885 & 593835 & 53 & 40 \\
\hline 531 & 836 & 4126918 & 593879 & 46 & 40 \\
\hline 123 & 837 & 4126954 & 593912 & 51 & 4.5 \\
\hline 457 & 838 & 4126990 & 593945 & 51 & 40 \\
\hline 586 & 839 & 4127016 & 593980 & 55 & 40 \\
\hline 216 & 840 & 4127052 & 594013 & 55 & 4.5 \\
\hline 156 & 841 & 4127099 & 594040 & 48 & 40 \\
\hline 479 & 842 & 4127134 & 594106 & 48 & 40 \\
\hline 440 & 843 & 4127146 & 594111 & 53 & 4.5 \\
\hline 144 & 844 & 4127187 & 594117 & 52 & 40 \\
\hline 614 & 845 & 4127221 & 594129 & 60 & 40 \\
\hline 119 & 846 & 4127308 & 594159 & 54 & 4.5 \\
\hline 519 & 847 & 4127342 & 594176 & 58 & 40 \\
\hline 44 & 848 & 4127383 & 594195 & 50 & 40 \\
\hline 477 & 849 & 4127427 & 594217 & 57 & 4.5 \\
\hline 468 & 850 & 4127466 & 594234 & 60 & 40 \\
\hline 528 & 851 & 4127514 & 594244 & 53 & 40 \\
\hline 679 & 852 & 4127560 & 594236 & 68 & 40 \\
\hline 219 & 853 & 4127585 & 594260 & 58 & 4.5 \\
\hline 112 & 854 & 4127599 & 594295 & 56 & 40 \\
\hline 747 & 10101 & 4127598 & 594369 & 53 & 99 \\
\hline 744 & 10102 & 4127602.5 & 594379 & 53.5 & 99 \\
\hline 138 & 10103 & 4127607 & 594389 & 54 & 99 \\
\hline 740 & 2074 & 4127639 & 594406 & 45 & 40 \\
\hline 159 & 2073 & 4127674 & 594432 & 41 & 40 \\
\hline 155 & 2072 & 4127704 & 594465 & 44 & 4.5 \\
\hline 432 & 2071 & 4127736 & 594475 & 52 & 40 \\
\hline 439 & 2070 & 4127771 & 594491 & 58 & 40 \\
\hline 875 & 2069 & 4127818 & 594516 & 63 & 4.5 \\
\hline 153 & 2068 & 4127846 & 594529 & 45 & 40 \\
\hline 583 & 2067 & 4127874 & 594544 & 60 & 40 \\
\hline 202 & 2066 & 4127912 & 594572 & 43 & 4.5 \\
\hline 495 & 2065 & 4127948 & 594589 & 4.5 & 40 \\
\hline 186 & 2064 & 4127984 & 594594 & 46 & 40 \\
\hline 68 & 2063 & 4128021 & 594589 & 45 & 4.5 \\
\hline 484 & 2062 & 4128063 & 594578 & 45 & 40 \\
\hline 62 & 2061 & 4128104 & 594568 & 46 & 40 \\
\hline 204 & 2060 & 4128140 & 594554 & 42 & 4.5 \\
\hline 494 & 2059 & 4128172 & 594547 & 45 & 40 \\
\hline 473 & 2058 & 4128218 & 594551 & 43 & 40 \\
\hline 538 & 2057 & 4128256 & 594559 & 40 & 4.5 \\
\hline
\end{tabular}




\begin{tabular}{|c|c|c|c|c|c|}
\hline 137 & 2056 & 4128290 & 594578 & 41 & 40 \\
\hline 732 & 2055 & 4128317 & 594604 & 38 & 40 \\
\hline 67 & 2054 & 4128402 & 594646 & 43 & 4.5 \\
\hline 662 & 2053 & 4128498 & 594702 & 39 & 40 \\
\hline 665 & 2052 & 4128520 & 594728 & 40 & 40 \\
\hline 145 & 2051 & 4128557 & 594761 & 42 & 4.5 \\
\hline 619 & 2050 & 4128596 & 594791 & 44 & 40 \\
\hline 210 & 2049 & 4128642 & 594824 & 39 & 40 \\
\hline 878 & 2048 & 4128673 & 594864 & 37 & 4.5 \\
\hline 611 & 2047 & 4128722 & 594895 & 34 & 40 \\
\hline 736 & 2046 & 4128760 & 594934 & 32 & 40 \\
\hline 448 & 2045 & 4128803 & 594963 & 37 & 4.5 \\
\hline 410 & 2044 & 4128839 & 594994 & 40 & 40 \\
\hline 157 & 2043 & 4128888 & 595021 & 38 & 40 \\
\hline 185 & 2042 & 4128930 & 595056 & 40 & 4.5 \\
\hline 427 & 2041 & 4128963 & 595092 & 40 & 40 \\
\hline 745 & 2040 & 4129001 & 595126 & 40 & 40 \\
\hline 618 & 2039 & 4129039 & 595160 & 40 & 40 \\
\hline 761 & 2038 & 4129076 & 595195 & 40 & 4.5 \\
\hline 751 & 2037 & 4129115 & 595227 & 41 & 40 \\
\hline 462 & 2036 & 4129156 & 595261 & 38 & 4.5 \\
\hline 620 & 11001 & 4129149 & 595130 & 44 & 99 \\
\hline 452 & 11002 & 4129179 & 595102 & 40 & 99 \\
\hline 173 & 11003 & 4129214 & 595047 & 49 & 99 \\
\hline 151 & 2035 & 4129196 & 595294 & 37 & 4.5 \\
\hline 515 & 2034 & 4129237 & 595327 & 37 & 40 \\
\hline 613 & 2033 & 4129275 & 595361 & 37 & 40 \\
\hline 835 & 2032 & 4129314 & 595396 & 38 & 4.5 \\
\hline 472 & 2031 & 4129355 & 595427 & 35 & 40 \\
\hline 446 & 2030 & 4129394 & 595462 & 36 & 40 \\
\hline 615 & 2029 & 4129433 & 595492 & 36 & 40 \\
\hline 192 & 2028 & 4129459 & 595519 & 39 & 4.5 \\
\hline 668 & 2027 & 4129497 & 595552 & 38 & 40 \\
\hline 42 & 2026 & 4129537 & 595585 & 41 & 40 \\
\hline 453 & 2025 & 4129573 & 595617 & 48 & 40 \\
\hline 220 & 2024 & 4129613 & 595651 & 48 & 4.5 \\
\hline 164 & 2023 & 4129650 & 595687 & 38 & 40 \\
\hline 735 & 2022 & 4129693 & 595723 & 35 & 40 \\
\hline 181 & 2021 & 4129734 & 595757 & 36 & 40 \\
\hline 430 & 2020 & 4129775 & 595790 & 39 & 4.5 \\
\hline 667 & 2019 & 4129811 & 595821 & 30 & 40 \\
\hline 115 & 2018 & 4129847 & 595856 & 30 & 40 \\
\hline 114 & 2017 & 4129874 & 595872 & 42 & 40 \\
\hline 520 & 2016 & 4129916 & 595910 & 37 & 4.5 \\
\hline 48 & 2015 & 4129958 & 595944 & 33 & 40 \\
\hline 56 & 2014 & 4129996 & 595978 & 31 & 40 \\
\hline 142 & 2013 & 4130034 & 596012 & 32 & 40 \\
\hline 595 & 2012 & 4130074 & 596049 & 35 & 4.5 \\
\hline 622 & 2011 & 4130114 & 596091 & 33 & 40 \\
\hline 152 & 2010 & 4130154 & 596114 & 32 & 40 \\
\hline 122 & 2009 & 4130223 & 596179 & 38 & 40 \\
\hline 91 & 2008 & 4130262 & 596210 & 35 & 4.5 \\
\hline
\end{tabular}




$\begin{array}{llllll}459 & 2007 & 4130304 & 596239 & 33 & 4.5 \\ 222 & 2004 & 4130412 & 596331 & 34 & 4.5 \\ 215 & 2003 & 4130448 & 596361 & 36 & 4.5 \\ 535 & 2002 & 4130478 & 596394 & 35 & 4.5 \\ 845 & 2001 & 4130519 & 596428 & 36 & 4.5\end{array}$

